\title{
International Labour Migration, Remittances and Remittances-based Spending: Quantitative Study of Decision-making in the Kyrgyz Republic
}

by

\section{Christopher Ostropolski}

A thesis submitted to the Faculty of Graduate and Postdoctoral Affairs in partial fulfillment of the requirements for the degree of

Doctor of Philosophy

in

International Affairs

Carleton University

Ottawa, Ontario 


\begin{abstract}
The following $\mathrm{PhD}$ dissertation is a quantitative study of individual as well as household decision-making in three linked processes: international labour migration, remittances and remittances-based spending. Three sets of questions are posed in three separate chapters. First, in regards to migration: why do some individuals intend to migrate whereas others do not; and does the intention to migrate affect actual migration behaviour? Second, in regards to remitting: which migrants are more likely to remit; and which migrants remit more? Third, in regards to spending: is it migrants themselves who decide how their remittances are spent; and to what extent do remittances offset the monetary cost of hosting festivities regarded as "customs and traditions"? In search of answers, the dissertation resorts to a statistical analysis of national household survey data from the Kyrgyz Republic. The choice of the methodology is due to the availability of a robust dataset that is suitable for empirical methods, and to the fact that the country is highly dependent on migration and remittances.
\end{abstract}

Several key empirical findings emerge. First, the intention to migrate is correlated with travel experience, ethnicity, access to a family network abroad and regional unemployment; also, an intention does have a strong positive impact on actual migration behaviour. Second, the incidence of remitting is increased consistently in the case of men and older migrants, whereas the amount of remittances per remitter is higher when sent by household heads or highly educated migrants, especially to urban or post-shock households. Third, remitters often do not decide how their remittances are used, and remittances-receiving households spend on average more on some types of festivities, but not on all; despite the high average expenditures on festivities, gifts received by households substantially offset the total cost, thus reducing the financial burden of hosting such events. Policy-relevant implications of the findings as well as suggestions for further research are discussed. 


\section{Acknowledgements}

This research project would not be possible without the patient guidance of my supervisors, Dr. Dane Rowlands and Dr. Jeff Sahadeo, and the encouragement of the many friends at Carleton University, especially P.

Although the research is primarily quantitative, the hospitality and kind words of the people in the Kyrgyz Republic have given it a human face.

For my parents,

Dziękuję Wam za wsparcie i cierpliwość, i za to że pozwoliliście mi zrobić to co uważam jest stuszne. 


\section{Table of Contents}

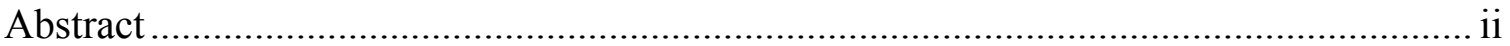

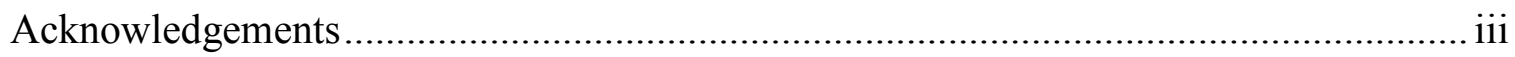

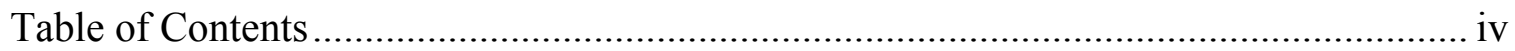

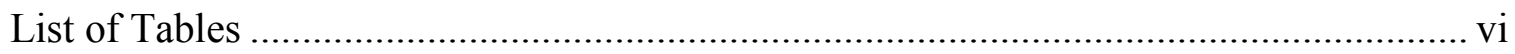

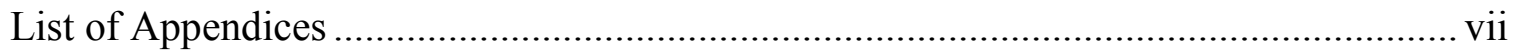

Chapter 1: Introduction ...................................................................................... 1

Chapter 2: Labour Migration Decision-Making: Intentions versus Reality

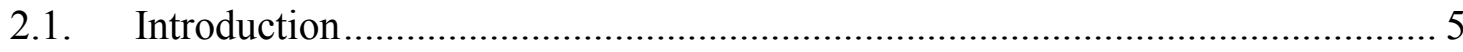

2.2. Literature Review and Hypotheses ......................................................... 8

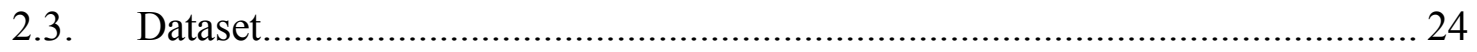

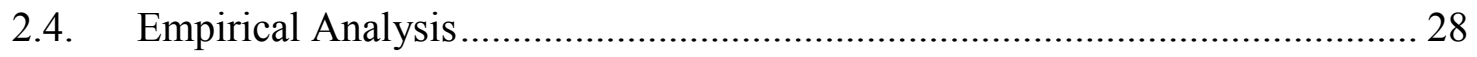

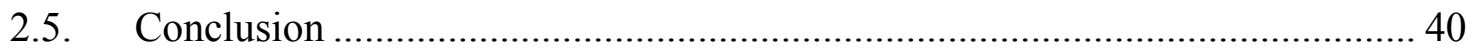

Chapter 3: Remittances Decision-Making: to remit or not to remit, and how much?

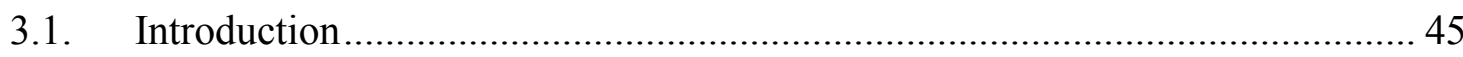

3.2. Literature Review and Hypotheses ......................................................... 47

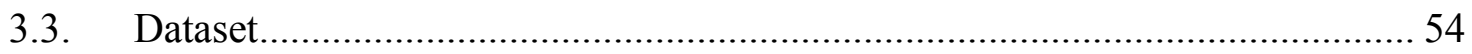

3.4. Empirical Analysis ............................................................................... 58

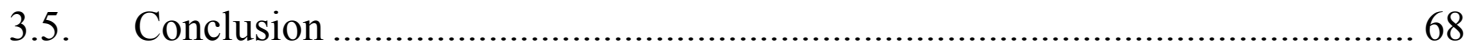

Chapter 4: Spending Decision-Makers and the Cost of "customs and traditions"

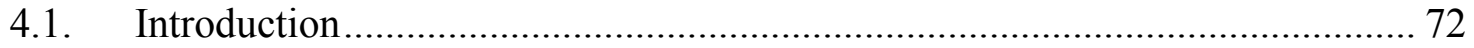

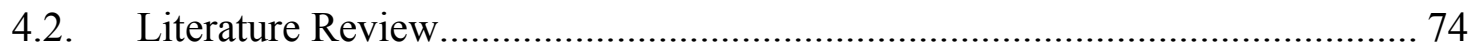

4.3. Research Questions and Hypotheses .................................................... 81

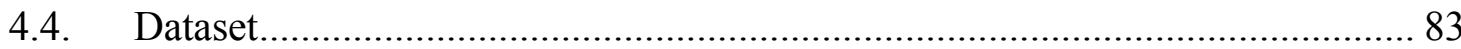


4.5. Spending Decision-Makers .............................................................. 84

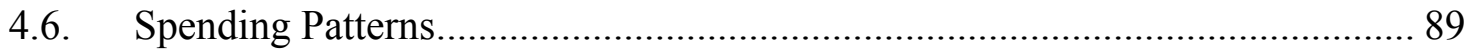

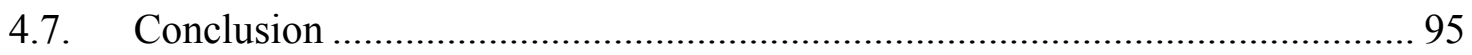

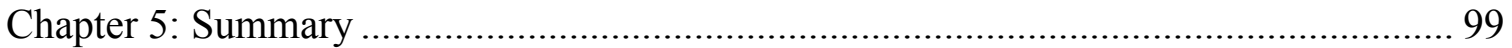

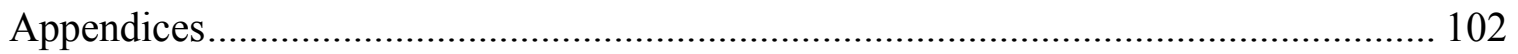

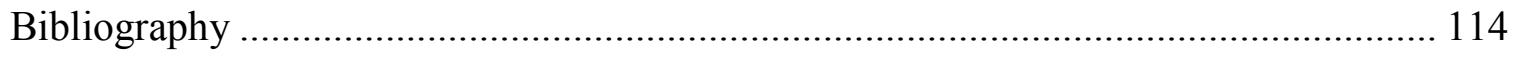




\section{List of Tables}

Table 1. Chapter 2: Migration intentions: fulfilled vs. non-fulfilled. ........................... 28

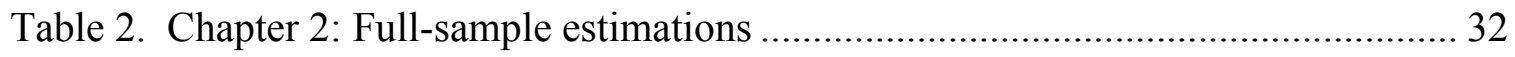

Table 3. Chapter 2: Sub-sample estimations: intending vs. non-intending migrants ...... 39

Table 4. Chapter 3: Household members abroad..................................................... 56

Table 5. Chapter 3: Model 1 full-sample estimation results (incidence of remitting)..... 61

Table 6. Chapter 3: Model 2 estimation results (remittances per remitter) .................... 66

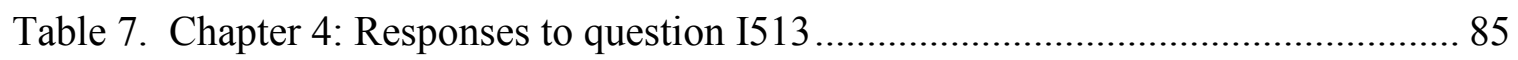

Table 8. Chapter 4: Estimation results (independent decision-making) ......................... 88

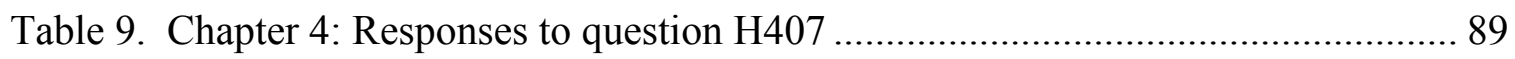

Table 10. Chapter 4: Spending on "customs and traditions"..................................... 90

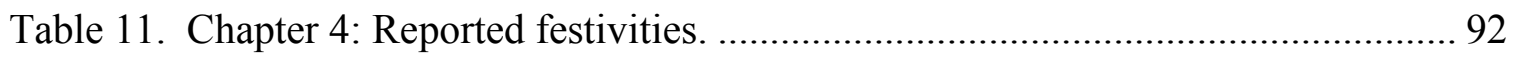

Table 12. Chapter 4: Spending on "customs and traditions".................................... 93

Table 13. Chapter 4: Responses to questions H431 \#1-5 ......................................... 96

Table 14. Chapter 4: Responses to questions H432 \#1-3 ........................................ 97 


\section{List of Appendices}

Appendix A: Chapter 2

A.1. Data Overview: Community Characteristics ………………………...... 102

A.2. Data Overview: Intending Migrants' Characteristics ............................ 103

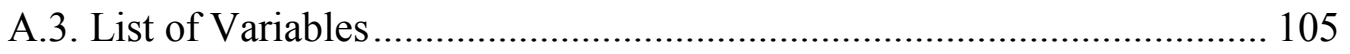

Appendix B: Chapter 3

B.1. Data Overview: Migrants' Characteristics …………................................ 106

B.2. Data Overview: Confirmed Remitters' Characteristics ........................... 108

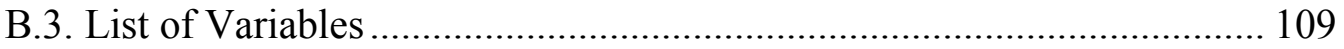

B.4. Test for Multicollinearity ................................................................... 110

Appendix C: Chapter 4

C.1. LIK 2011 Survey Questionnaire (I513) ................................................. 111

C.2. LIK 2011 Survey Question (Section 4C) ............................................... 112

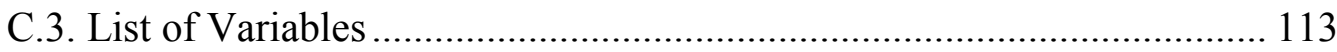




\section{Chapter 1: Introduction}

As the first words of this $\mathrm{PhD}$ dissertation are being written, the international media are dominated by headlines covering the most recent capsizing of a ship in the Mediterranean Sea - a ship carrying over 700 people from Libya to Italy. The latest update informs that only 28 people have been rescued so far, which "would make it by far the worst maritime disaster in the Mediterranean since the second world war" (Economist 2015). These people - women and men, young and old, Muslims and Christians - had departed on their uncertain voyage in order to get to Europe, where they could start a new life, work and perhaps one day be reunited with their families. These people are migrants. Although their tragic story is a drastic case, it is only one of millions of migrations that take place around the world every year. Every story exemplifies the reality that migration is a complex, omnipresent and serious matter.

There are many types of migrants. Those fleeing war are often referred to as refugees, as exemplified above, and they rightly occupy the public's attention during times of crisis. This thesis, by contrast, focuses on a labour migration - people who move primarily in search of work - a much less dramatic and visible form of migration, but one that involves far more people. Interest in international labour migration increased substantially during past two decades. Global projects have been launched in support of migration research, and migration-led development has become a central theme of the Post-2015 Agenda. ${ }^{1}$ This heightened interest is attributed to the recognition that

\footnotetext{
${ }^{1}$ The Post-2015 Agenda refers to the efforts of the international community - led by the United Nations - to make developmental plans and goals after the passing of the deadline (2015) of the prior Millennium Development Goals (MDG's). The Agenda incorporates many new items, including migration, than did the MGD's (http://www.un.org/en/ecosoc/about/mdg.shtml).
} 
migration can have positive effects for developing countries, including jobs for the unemployed, brain gain through education and experience, and inflow of remittances. The migration mantra has gained popularity despite critics who warn of potential drawbacks of migration, including a decrease in domestic production and tax revenues, outflow of workers, corruption, remittances-dependence, and remittances-sponsored terrorism.

These macro-level considerations, however, often do not take into account microlevel concerns such as the selectively of migration or the hardships that migrants endure during the migration process. The need to conduct more micro-level research, in terms of data collection as well as theory-building, is echoed repeatedly in migration literature. The need is so evident that it has even been noted by the United Nation in its agenda for “making migration work" for development (UN 2013).

From the micro-level perspective, a migration begins with a person who chooses or is coerced - to leave his or her place of origin in order to go elsewhere. Each migration is a complicated and risky affair, and may be a decision made by an individual or by an entire household. Taken together, the migration phenomenon represents not only the movement of people, but also social change, economic development and political controversy. Its policy relevance is undeniable, yet its large-scale developmental potential is still questionable. Despite the fact that many policy papers, academic books and doctoral dissertations have already been dedicated to the subject of migration, there nevertheless remain many unaddressed issues and unresolved puzzles. For example, it is yet to be determined why migrants from different countries have different profiles; why migrants from Central Asia are typically low-skilled young males, whereas from the 
Philippines they are young or middle-aged female trained nurses? A related issue is whether migration is a net brain drain or gain. Will the Central Asian migrants contribute their skills learned abroad to home countries' economies, and will the Filipino nurses' remittances offset the cost of their initial training?

The purpose of this dissertation is to conduct a micro-level study of international labour migration in the context of one highly remittances-dependent country. The project scope encompasses three related processes: migration, remittances and remittancesfunded expenditures. The ultimate goal of the study is not to measure the impact of migration or remittances, but instead to explain the decision-making process involved in each of the processes. The country under investigation is the Kyrgyz Republic (KR). The motivation for the choice of the country is twofold. First, the KR may be considered a "critical case" because a large portion of its labour force works abroad and the country ranks second in the world in terms of remittances as percentage of GDP. Second, migrants from KR are typically involved in regional (international) and temporary or circular migration, a relatively understudied phenomenon. The overarching research puzzle is the existence of variation among individuals and households in migrating, remitting and spending behaviour patterns in the $\mathrm{KR}$ in particular, and in migrantsending countries in general.

To solve this puzzle, the study starts by empirically analyzing migrant and household profiles to determine which variables are correlated with, and potentially causal to, each behaviour pattern. The profiles come from a survey dataset recently made available by the German Institute for Economic Research. The Life in Kyrgyzstan (LIK) panel survey had encompassed nearly 3,000 households, including 8,000 individuals, 
annually over a three-year period 2010-2012. The LIK dataset contains diverse information covering topics such as education, income, migration history and perceptions of well-being.

The final research product is divided into three journal-style articles, each of which focuses on one specific process. Each article asks a separate set of questions, including: 1) who intends to migrate and who actually does so; 2) who remits, why, to whom and how much; and 3) on what are remittances ultimately spent? Questions are linked directly to relevant data points in the LIK survey. To answer these questions, each study takes into consideration variables at the individual, household and community levels; in so doing, it follows the advice from Massey (1990) to incorporate multiple levels of analysis, rather than only a single one, in migration research.

In sum, this dissertation addresses international migration, which is one of the most pressing issues facing the international community today. The research combines the most current data with a mixed-methods approach to provide an analysis to a level of detail that is yet to appear in the literature. The research conclusions are informative for policy initiatives focusing on migration management, poverty reduction and economic development both in migrant-sending as well as migrant-receiving countries.

In the coming years, the number of legal and illegal migrants will inevitably increase, be they North Africans in Italy or Central Asians in Russia. In all such cases, more appropriate government policies and higher public awareness are needed to prevent humanitarian disasters, economic exploitation and social discrimination. If migration is to be the central pillar for development in the coming future, then this dissertation hopes to add a stone to this pillar. 


\section{Chapter 2: Labour Migration Decision-Making: Intentions versus Reality}

\subsection{Introduction}

Interest in international labour migration increased in the past two decades both in academic as well as policy circles. ${ }^{2}$ The research focus in the migration literature has broadened to include migrant flows between developing countries, as it has become evident that this type of migration not only surpasses, but also differs from the traditional South-North route. ${ }^{3}$ In particular, regional migration corridors between countries of the former Soviet Union (e.g. from Ukraine or Kazakhstan to Russia) are receiving more attention in the literature. ${ }^{4}$

So far, analytical studies of migration have often focused on the national or global level. However, macro-level analysis rarely takes into account sub-national factors (e.g. regional poverty within countries), or the selectivity of migration based on individuals' characteristics (e.g. gender, ethnicity) and subjective factors (e.g. personal preferences). The need to conduct more micro-level research, in terms of data collection as well as analysis, is echoed repeatedly in the literature and is noted in the international community's making migration work discourse. ${ }^{5}$

Consequently, the current study addresses two identified gaps in the literature. First, there remains a gap in our understanding of the micro-level decision-making process involved in international labour migration. For example, while most existing

\footnotetext{
2 Borjas 1999; Adam 2003; Adams \& Page 2003; Bhagwati 2003; Rosenzweig 2005; IOM 2006; OECD 2006; Özden \& Schiff 2006; Bilsborrow 2007; de Haas 2007; Winters 2007; USAID 2009; Dumont et al. 2010; IOM 2013

${ }^{3}$ Rowlands 2004; Tamas 2004; Andreopoulos et al. 2005; Ratha 2005; Ratha \& Shaw 2006; Hujo \& Piper 2007; De Haan \& Yaqub 2008; Gindling 2008; Bakewell 2009; Campillo-Carrete 2013; Laczko \& Brian 2013; UN 2014; World Bank 2015

${ }^{4}$ The International Organization for Migration officially considers migration between post-Soviet countries (UkraineRussia, Russia-Ukraine, Kazakhstan-Russia) as South-South (IOM 2013:62). Each of the corridors involves over 2.5 million people.

${ }^{5}$ German Development Institute 2013; ILO 2013; UN 2013
} 
research does analyze migrants' profiles, few studies focus on individuals' intention to migrate and the realization of this intention. This study contributes to the ongoing attempt to solve one specific puzzle: the existence of variation among individuals in their intention and in their actual behaviour. In other words, while some people express an intention to migrate, most do not. In the near future, some of those who had expressed the intention do in fact migrate, whereas others do not. Just as importantly, many individuals who had not initially expressed an intention do actually go abroad.

Second, we also know little about migration phenomena in Central Asia, one the world's most migration-prone regions. Not only does the region offer unique geographical and cultural perspectives, it also provides an evidence base for a relatively recent form of international migration, since large-scale population movements started only after the fall of the Soviet Union. ${ }^{6}$ This study makes a contribution by focusing on a country that has received only limited research attention to date - the Kyrgyz Republic (KR) - which not only experiences a substantial outflow of its labour force abroad, but also ranks second in the world in terms of remittances received as percentage of GDP; migration outflow is making the KR dependent on remittance income inflow. ${ }^{7}$

This study asks two questions regarding international labour migration: 1) why do certain individuals intend to migrate whereas others do not; and 2) does the intention to

\footnotetext{
${ }^{6}$ For a thorough account of migration in Central Asia during and immediately after the Soviet Union, see Tishkov et al. (2005) and Buckley et al. (2008).

7 500,000 to 1 million Kyrgyz citizens work abroad, primarily in Russia (IOM 2012). While the outflow of labour migrants from the KR is not as large in absolute numbers as Kazakhstan's, it is greater in terms of percentage of the total population and labour force (Abazov 1999; Tishkov et al. 2005; Laruelle 2007 \& 2013; Rubinov 2010; IOM 2012). Remittances account for $31 \%$ of the KR's GDP (WB 2014, 2013 data). Tajikistan ranks first with 52\%. The numbers are under-represented, given that a large portion of remittances is transferred through informal channels, thus escapes official records.
} 
migrate affect actual migrating behaviour? ${ }^{8}$ Two sets of hypotheses are proposed in relation to seventeen characteristics measured at the individual, household and community levels. The first set relates to the intention to migrate, whereas the second set relates to the realization (or not) of this intention. The hypotheses stem from theories in the fields of economics and social psychology, and from evidence from past studies. Both sets of hypotheses are tested empirically using national panel survey data. Given the data and estimation methods employed, the empirical results should be interpreted as correlational rather than causal.

The study's findings contribute to literature devoted to migration decisionmaking, particularly in regards to the impact of subjective factors (e.g. satisfaction), and to literature focusing on Central Asia. The findings may be deemed informative for policy initiatives focusing on migration management, migration-based economic development, and the improvement of migrants' well-being.

The rest of the chapter unfolds accordingly: section II offers a review of the literature, including theory and relevant studies, and states the hypotheses; section III describes the dataset and explains the data merging process conducted prior to the quantitative analysis; section IV presents and discusses the formal empirical results; and section V concludes.

\footnotetext{
${ }^{8}$ The study does not distinguish between permanent and seasonal migration, although it must acknowledged that the two types do differ in motivations and "selectivity". For example, Atamanov \& van den Berg (2012) find that the type of migration interacted with education in the KR: higher educated individuals are likely to resort to permanent migration, whereas less educated individuals are more likely to resort to seasonal migration. Furthermore, ethnicity may also be a factor, since minorities may consider migration as an "exit strategy." However, there are two reasons for the lack of distinction in the current study. First, the dataset used does not provide information on whether a person's intention was to migrate permanently or seasonally. Second, an intention may change during the migration process, as some seasonal migrants may decide to remain for a longer period (e.g. to maintain a secure job), whereas permanent migrants may return after only a short stay abroad (e.g. due to lack of success in finding unemployment).
} 


\subsection{Literature Review and Hypotheses}

Labour migration is broadly defined as the "movement of persons from one State to another, or within their own country of residence, for the purpose of employment" (IOM 2016). Although there is no universal definition of a labour migrant, there exist elaborate classifications based on destination (international vs. domestic), legal status (documented vs. irregular), skill level (skilled, semi-skilled, unskilled), or duration of stay (e.g. permanent vs. temporary or seasonal). The multitude of sub-topics has resulted in a broad yet specialized scope of migration literature. While the present study focuses on international labour migration at the micro-level, it is also situated in the emerging literatures dedicated to the measurement of well-being, subjective perceptions and migration decision-making in general.

\subsubsection{Theory}

The Harris-Todaro model remains the theoretical foundation of international labour migration at the micro-level, even though it was first introduced to explain ruralurban migration within a single developing country (Harris \& Todaro 1970). Based on neoclassical economic theory, this cost-benefit model stipulates that an individual makes a decision to migrate according to a rational calculation of anticipated income to be earned at home and abroad; if the income abroad is higher, minus the cost of migration (e.g. travel costs), then the individual migrates. However, the model does not explicitly take into account diversity in migrants' characteristics (e.g. gender) and it assumes a perfect market and complete information. Critics of the model indicate that not only is migration a selective process, but also many other factors (e.g. education, initial wealth) play a role in migrants' decision-making (Massey 1990; Taylor 1999). 
Given the limitations of the Harris-Todaro model, the migration literature turned its attention to the household-level. The new economics of labour migration (NELM) theory places the migrant in the context of a household with whom he or she shares economic risks and responsibilities of mutual dependence (Stark 1978 \& 1991; Schiff 1994; Taylor 1996a, 1996b, 1999). Such communal decision-making serves two purposes: income maximization and risk minimization. However, just because a household decides to resort to migration, it does not mean that the household does so eagerly. In addition to the economic cost of migration, the household also considers social and human costs (e.g. family separation, hardship of living in a foreign country). In the KR, despite the benefits such as remittances, the migration phenomenon as a whole is often viewed negatively, since it is considered "wrong" that people cannot find employment in their home country (Bichsel et al. 2007:39).

Furthermore, from a theoretical perspective, rational decision-making is more likely to take place if a household is situated in a peaceful environment rather than in a conflict area (Lindley 2007 \& 2009); in the latter case, household member(s) may still go abroad to work despite the fact the primary reason for departure is survival. For example, in the aftermath of the ethnic-based Osh Conflict in southern KR in 2010, the Uzbek minority adopted a "post-traumatic strategy" (Ismailbekova 2013:117) of migration with two objectives: 1) to generate income, given that many Uzbek businesses had been destroyed and unemployment was high, and 2) to keep the men safe, since young Uzbek males were becoming involved in conflict situations (often in response to agitation from the Kyrgyz) and they were routinely targeted by the state police. 
Two additional limitations of the NELM theory require attention. First, just as with migrants, households also differ in their characteristics (e.g. size, composition, ethnicity). In addition to such differences, households are embedded into a specific economic, political and social context. Consequently, households from different communities or countries may view and use migration differently (e.g. analysis of costs vs. benefits of household members' absence; choice of household member for migration). Bichsel et al. (2007) demonstrate large differences in attitudes towards migration among rural migrant-sending households in the KR, India and Mexico.

Second, a migrant's behaviour depends on subjective, non-material factors such as social norms or personal preferences (de Jong 2000; Heering et al. 2004; Reeves 2012). The recognition that a migrant is more than just homo economicus has led to the incorporation of sociological and psychological theories into the study of migration, including the theory of reasoned action, and its successor, the theory of planned behaviour (Fishbein \& Ajzen 1975; Ajzen 1985; Ajzen 1991; Hale et al. 2002). Both theories stipulate that one intends determines what one does, and one's intentions are influenced by the social environment, including general culture as well as immediate family norms and pressures. ${ }^{9}$ Furthermore, if a behaviour is judged socially acceptable (e.g. young adults should go abroad) and one possesses facilitating characteristics (e.g. access to a network), then one's intentions will be strengthened and more likely realized. One of the peculiarities of the social context in the KR is that men are motivated to go

\footnotetext{
${ }^{9}$ Building upon the theory of planned behaviour, Coulter et al. (2011) differentiate between two types of "pre-move thoughts" - desire and expectation - which constitute the intention to move, but which may not necessarily be held simultaneously. Desire refers to a "subjective evaluation" of one's environment and it does not depend on feasibility, whereas expectation is an objective evaluation of one's capacity and it is often a reaction to unexpected events (Coulter et al. 2011:2). These two types allow four distinct combinations of attitudes towards moving, including expecting an undesired move and not expecting yet desiring a move.
} 
abroad not only to earn money, but also to prove themselves as mature adults and capable breadwinners (Reeves 2012). If they succeed abroad (e.g. send back remittances), then their own as well as their family's social status increases; such a motivation was also observed in India, but not (at least explicitly) in Mexico (Bichsel et al. 2007).

\subsubsection{Empirical Literature}

Most of the studies consulted in preparation for this study are quantitative, as they conduct large-n statistical analysis using a variation of probit, logit or OLS estimation technique. ${ }^{10}$ The data are cross-sectional or longitudinal, and come from household and/or individual surveys at the regional or national level. The dependent variable is typically in binary or ordinal format, and it represents either a measure of satisfaction or an intention to migrate. This study is similar to the past studies in four ways, since it: 1) considers both the intention to migrate as well as realization of this intention in one dual research design (most studies focus on only one aspect); 2) uses national household survey data; 3) includes various typical independent variables (e.g. gender, age); and 4) employs a binary dependent variable, thus resorts to a probit estimation technique.

However, this study differs from past studies in four ways, since it: 1) applies the dual design not only to full-sample estimations, but also to sub-samples; 2) applies the research design to the case of the KR; 3) includes numerous novel or rarely used independent variables (e.g. number of siblings, worries, attitudes to risk-taking, shocks, and various interactive terms); 4) examines the real significance of the statistically

\footnotetext{
10 Quantitative studies: Rodriguez (1996); Namazie \& Sanfey (1998); Lu (1999); Yang (1999); de Jong (2000); Rodriguez \& Tiongson (2001); Heering et al (2004); Hadler (2006); Agadjanian, Nedoluzhko \& Kumskov (2008); Kalyuzhnova \& Kambhampati (2008); Van Dalen \& Henkens (2008); Gubhaju \& de Jong (2009); Becerra (2010); Wood et al (2010). One of the exceptions is Reeves (2012), who resorts to ethnographic interviews and descriptive analysis of 225 household surveys.
} 
significant variables by focusing on the marginal effects of the explanatory variables.

Thanks to the growing availability of panel data, some past studies attempted to verify if intentions do in fact result in moving behaviour. Lu (1999) analyzes the discrepancies between the intention to change one's residence and actual behaviour in the United States. ${ }^{11}$ Results confirm that 1) certain individual characteristics (e.g. young age, single status, no children, prior moving experience) increase the intention, and 2) the intention increases the likelihood of moving. Also in the realm of residential moving, Coulter et al. (2011) find that variables often have different impacts on desire/expectation thoughts (e.g. education has $+/+$ effect, age $+/-$, children -/-). Although the likelihood of moving is highest among individuals who express both a desire as well as an expectation to move, the study highlights the fact that almost half of such individuals do not actually move, perhaps due to factors beyond their control.

Turning to international migration, in a study of a high-income country - the Netherlands - Van Dalen \& Henkens (2008:19) find that 1) the intention is increased by individual characteristics (e.g. young age, good health, higher income, access to networks, risk-taking and dissatisfaction with current location), and 2) "intentions are good predictors of future emigration"; however, gender and education have no effect. Agadjanian, Nedoluzhko \& Kumskov (2008) conduct a study of the intention to migrate in the KR, but only among youth ranging from 18 to 29 years of age. The study focuses on four key variables: ethnicity, gender, marital status and type of migration. Hypotheses stipulate that 1) Europeans intend to migrate more than Asians, 2) men intend more than

\footnotetext{
${ }^{11}$ Changing one's living location incorporates a decision-making process and variables that are theoretically similar to labour migration.
} 
women, but only case of individual and temporary migration, 3) married individuals (with or without children) intend less, and 4) migration networks increase intention, but "non-migration social capital" decreases it. Multinomial logit results using crosssectional data from three northern regions of the KR indicate the salience of ethnic differences, but not of gender.

Gender is one of the most reoccurring micro-level variables in migration analyses, albeit with mixed results. Heering et al. (2004:325) explore gender-specific factors in migration intentions in Morocco and find that intentions of both for men and women are increased by an access to family networks abroad as well as a presence of "culture of migration" in the region; however, networks have a stronger impact on women, whereas the culture has a stronger one on men. In addition, women with higher levels of education and emancipation are more likely to migrate. Gubhaju \& de Jong (2009) address the intention to migrate within South Africa, with special focus on gender and marital status. Results show that self-interest decision-making applies to unmarried individuals and to married men in their short-term plans; in contrast, household-interest applies to most married individuals and to women in general.

Macro-level variables are becoming more commonly included. Hadler (2006) compares the intention to migrate in fifteen European Union countries and concludes that 1) economically disadvantaged places experience more migration, 2) macro-level factors (e.g. unemployment rate) interact with micro-level factors, 3) regions with existing migration flows experience more migration; overall, the results indicate that micro-level factors have a larger impact than macro-level ones. Wood et al. (2010) focus on Mexico plus sixteen Central/Latin American countries. Results reveal the positive impact of 
macro-level factors such as crime, national score on the Human Development Index, and closer distance to the United States; micro-level factors also matter, including gender (male), younger age, high education and high income. Docquier et al. (2014) explore migration among 138 countries and find that access to a network and the GDP per capita in the destination country have a positive impact on intention. Although difference in the education level has no impact on people's intention, highly educated individuals are more likely to realize their intention.

Subjective factors are being incorporated into migration studies, either as single independent variables or as the focus of inquiry. De Jong (2000) confirms the importance of social norms in rural Thailand. A "two-step model" hypothesizes that 1) expectations interact with norms to form intention, and 2) intention influences actual behaviour. Binomial logistic results using longitudinal panel data confirm the importance of norms, since men intend more than women, as well as one's perceptions, since positive expectations in destination area increase the intention.. Otrachshenko \& Popova (2014) determine that low life-satisfaction increases the intention in Europe. Ivlevs (2015:3) confirms the impact of satisfaction on emigration intentions in post-Soviet countries, but finds the impact to be U-shaped: the least- and the most-happy individuals are more likely to intend; the outflow of the happiest people constitutes a "happiness drain."

\subsubsection{Emerging Hypotheses}

This study presents 21 hypotheses - divided into two parts - that are based on 21 independent variables (17 single and 4 interactive) from the LIK survey. The first part of each hypothesis pertains to the intention to migrate, whereas the second part pertains to actual migration behaviour. Each hypothesis is referenced to existing empirical literature, 
especially to research - if available - on the KR. Although the hypotheses assume that every independent variable has the same impact on the intention as on the behaviour, this may not necessarily be the case. Given the complexity of the migration phenomenon, it is possible that a variable has a positive impact on the intention, but a negative one on the behaviour, or vice-versa. Furthermore, certain variables may prohibit migration even if there is an intention, whereas others may be conducive to migration even in the absence of an intention. All such considerations are addressed in the empirical analysis.

\subsubsection{Gender}

Hypothesis 1: if an individual is female, then she is less likely to intend to migrate or to actually migrate.

Gender is one of the most important themes in migration research, albeit with mixed conclusions due to influence of additional factors, especially social norms. Given that most migrant-sending countries are located in the global South, where gender norms remain more traditional, men are more likely to be expected and allowed migrate (de Jong 2000; Heering et al. 2004; Rowlands 2004; Hadler 2006; Gubhaju \& de Jong 2009; Becerra 2010; Wood et al. 2010). In some cases, however, no gender differences are observed (Yang 2000; Van Dalen \& Henkens 2008).

Therefore, although the effect of gender on the intention is ambiguous, men may face fewer barriers to migration, thus men are more likely to actually go abroad. ${ }^{12}$ In a multi-country study of mostly post-Soviet states, including the KR, Ivlevs (2015) finds a negative correlation between being female and intention to emigrate. In the case of the KR specifically, no differences between women and men were observed in their

\footnotetext{
${ }^{12}$ A notable exception is the Philippines, where despite traditional norms, females - as nurses or housemaids - make up the majority of labour migrants (Rodriguez 1996; Rodriguez \& Tiongson 2001; Burgess \& Vikram 2005; de Haas 2007).
} 
perceptions of well-being (Namazie \& Sanfey 1998), nor in the intention to migrate among youth (Agadjanian et al. 2008). However, when it comes to actually going abroad, most migrants from rural communities are male (Bichsel et al. 2007:26), and in general, "migration is still predominantly a male affair" (Reeves 2012:119); especially in areas of ethnic tensions, where men are more likely to be targeted (Ismailbekova 2013). Males are prevalent both in permanent and seasonal migration (Atamanov \& van den Berg 2012). In addition to differences between genders, differences within gender groups can exist based on key factors such as education, marital status or ethnicity. ${ }^{13}$

\subsubsection{Age}

Hypothesis 2: if an individual is of young age (18-30), then he or she is more likely to intend or to migrate; as the age increases, the intention and the likelihood of migration decrease.

Youth is associated with higher mobility, risk-taking and perceived necessity to migrate (Yang 2000; de Haas 2005; Hadler 2006; Wood et al. 2010; Coulter et al. 2011; Otrachshenko \& Popova 2014; Ivlevs 2015). In the KR, even though being younger is associated with higher life satisfaction (Namazie \& Sanfey 1998), young males are particularly prone to going abroad given social pressure on men to provide for the household. Male migrants tend to be young or middle-aged (Bichsel et al. 2007).

\subsubsection{Marital status}

Hypothesis 3: if an individual is single, then he or she is more likely to intend or to migrate.

Being single is typically associated with higher mobility (Yang 1999; Gubhaju \& de Jong 2009; Ivlevs 2015). Non-single status - be it married, divorced, widowed or other - is

\footnotetext{
${ }^{13}$ See Hypotheses 18-20.
} 
more complex since migration is subject to opposing forces. On the one hand, individuals are less willing to go abroad if it entails being separated from family (de Jong 2000). On the other hand, the need to provide financial support (e.g. children) may compel even unwilling individuals to go abroad. In the KR, married individuals, with or without children, are less likely to intend to migrate (Agadjanian et al. 2008; Reeves 2012).

\subsubsection{Children}

Hypothesis 4: if an individual has no children, then he or she is more likely to intend or to migrate.

Similarly to the argument in the case of married individuals, the presence of children has a complex effect on migration. Individuals without children may be more mobile to go abroad for extended periods of time (Yang 1999; Coulter et al. 2011). In the KR, those with children often consider it as necessary to go abroad - despite reluctance to be away from the children - to earn an income sufficient for sustaining a large family; children are usually left with grandparents (Isabaeva 2011).

\subsubsection{Siblings}

Hypothesis 5: if an individual has siblings, then he or she is more likely to intend or to a migrate.

Siblings have not yet been explored extensively as a variable in migration research. However, the argument may be opposite to that in the case of children. Individuals without siblings may be more inclined to remain close to home to provide immediate care for other household members (e.g. aging parents). Individuals with siblings may not only be able to count on others to take care of household responsibilities, but also see the need to earn an income for the larger household. Also, as per NELM theory, having multiple siblings also provides greater opportunities for income diversification and risk reduction. 


\subsubsection{Ethnicity}

Hypothesis 6: if an individual is not from the major ethnic group (e.g. not Kyrgyz, but rather Russian or Uzbek), then he or she is more likely to intend or to migrate.

Ethnicity does not refer to the racial or cultural predisposition of a particular group, but rather the group's relation towards its country of residence. Individuals from a group that is an ethnic minority, especially if the group considers itself marginalized or persecuted, are more likely to intend to go abroad, since migration may be seen as a way to escape discrimination (Ivlevs 2015). In the case of the KR, Europeans - Russians or non-Russian Europeans - are found to intend to migrate more than Asians; this behaviour may be explained in part by their perceived sense of lower status and alienation in the post-Soviet reality (Agadjanian et al. 2008). Although the Uzbek minority is larger than the Russian in the KR, most studies focus on the differences between Europeans and Asians due to the larger cultural, linguistic and historical cleavages between Europeans and Kyrgyz/Uzbek/others. The author of this study acknowledges these cleavages, as well as the differences in migration motivations between Kyrgyz and non-Kyrgyz, especially among the Uzbek minority after the Osh conflict in 2010 (Ismailbekova 2013).

\subsubsection{Place of birth}

Hypothesis 7: if an individual was not born in the community where he or she resides, then he or she is more likely to intend or to migrate.

Even if a member of the majority ethnic group, an individual who was not born in a community where he or she resides may consider himself or herself to have less roots in the community, or to be facing alienation or discrimination, thus be more willing to go elsewhere (Yang 1999). In addition, such individuals may have already demonstrated a behavioural propensity to move. 


\subsubsection{Experience abroad}

Hypothesis 8: if an individual has been abroad, then he or she is more likely to intend or to migrate.

Prior experience abroad not only accustoms an individual to living abroad, but also allows him or her to gather information as well as foster connections that can reduce the social, psychological and economic costs of migration in the future (de Jong 2000; de Haas 2005; Otrachshenko \& Popova 2014). Having been exposed to a different culture and lifestyle - potentially better than in the home country - and being more certain for finding work upon arrival may motivate the migrant to go abroad again. In contrast, an individual without prior experience faces higher costs and uncertainty.

\subsubsection{Education}

Hypothesis 9: if an individual possesses a high level of education, then he or she is more likely to intend or to migrate; the higher the level, the stronger the intention and the likelihood of migration.

Individuals with higher human capital may expect to gain more from going abroad, especially if their skills are not adequately used or rewarded in the home country. Furthermore, they may possess skills (e.g. language, professional) that would make the transition to a different country less difficult or that are explicitly demanded by the host country (Massey 1990; Borjas 1999; Adams 2003; Wood et al. 2010; Coulter et al. 2011; Javid et al. 2012; Docquier et al. 2014). In the KR, education was found to be the key factor in determining the propensity for labourers to leave farming activities for nonfarming or migration: higher-educated individuals were more likely to resort to nonfarming or permanent migration, whereas lower-educated individuals either remained in farming or opted for seasonal migration (Atamanov \& van den Berg 2012). 


\subsubsection{Worries}

Hypothesis 10: if an individual is worried about his or her economic situation and/or personal security, then he or she is more likely to intend or to migrate.

Worries are another variable that has not been explored extensively in migration research, and they may have opposing effects. On the one hand, an individual who is worried about his or her status in the home country may be more willing to go abroad, if he or she expects own position to improve there. For example, a high crime rate in the neighbourhood or country in general may make individual more worried about personal safety, thus more willing to go abroad (Wood et al. 2010). On the other hand, an individual who considers himself or herself to be more vulnerable to financial exploitation or personal harm in a foreign environment may avoid going abroad.

\subsubsection{Risk-taking}

Hypothesis 11: if an individual considers him-/herself a risk taker, then he or she is more likely to intend or to migrate.

By definition, a individual more willing to take risks will be more willing to face the uncertainty of going abroad, whereas a risk-averse individual will be more likely remain in their current location (Van Dalen \& Henkens 2008 \& 2013).

\subsubsection{Interest in politics}

Hypothesis 12: if an individual takes interest in politics, then he or she is more likely to intend or to actually migrate.

A potential migrant's interest in politics has not yet been explored in migration research, and the effect may well be ambiguous. For example, it is possible that higher awareness of the political and economic trends in the home country relative to other locations, especially in time of domestic political or economic turmoil, may motivate an individual to seek better fortune abroad. Conversely, if an interest in politics is associated with a 
strong attachment to one's country - be it for patriotic or practical reasons - then its presence may motivate an individual to remain at home, even in times of turmoil.

\subsubsection{Satisfaction with household well-being}

Hypothesis 13: if an individual is not satisfied with the level of his or her household income, then he or she is more likely to intend or to migrate.

Similarly to worries, perceptions of current and future household income influence the cost-benefit analysis of migration. An individual is more likely to migrate if he or she considers objectively (e.g. income differential) or subjectively (e.g. relative deprivation) the household's economic status to be unsatisfactory (de Jong 2000; Van Dalen \& Henkens 2008 \& 2013).

\subsubsection{Network}

Hypothesis 14: if an individual has access to family/friends abroad, then he or she is more likely to intend or to migrate.

Access to networks has long been regarded in the migration literature as a key factor facilitating migration by providing information and support, which lower the cost and uncertainty of going abroad ((Yang 1999; Heering et al. 2004; Özden \& Schiff 2006; Ratha \& Shaw 2006; Agadjanian et al. 2008; Van Dalen \& Henkens 2008 \& 2013; Docquier et al. 2014; Ivlevs 2015). In the KR, access to family or friends abroad is seen as a fundamental motivator and enabler (Reeves 2012).

\subsubsection{Shock}

Hypothesis 15: if an individual's household has experienced any type of shock, then he or she is more likely to intend or to actually migrate.

Three types of shocks are considered in the current study: natural, social and household. In each case, an individual's household may face unexpected financial or physical hardship, which will motivate him or her to go abroad to gain additional resources to help 
to overcome the effects of the shock. Past research has shown that any type of shock may trigger migration, even if only temporary, for income-generating purposes (Clarke \& Wallsten 2003; Fagen 2006; Lueth \& Ruiz-Arranz 2007; Lindely 2007 \& 2009; Yang \& Choi 2007; Nielsen et al 2011).

\subsubsection{Community type}

Hypothesis 16: if an individual lives in a rural area, then he or she is more likely to intend or to actually migrate.

In most countries, rural regions are generally less developed and offer fewer economic opportunities and poorer public service provision than urban regions. Consequently, inhabitants of rural communities may consider migration as the preferable, if not the only, way to escape poverty (Yang 1999; de Haas 2005). In the KR, the individuals from rural areas who do not own land are the most likely to migrate (Atamanov \& van den Berg 2012); being landless may be due to poverty or to the inheritance structure whereby land often is given to the eldest child, typically a son.

\subsubsection{Community unemployment}

Hypothesis 17: if an individual lives an area with a high unemployment rate, then he or she is more likely to intend or to actually migrate.

High unemployment rate in a community motivates, or rather forces, individuals to go elsewhere in search of work (Hadler 2006; Becerra 2010). In the KR, the disintegration of the centrally planned economy after the fall of the Soviet Union, which resulted in widespread unemployment, is considered as the main reason for the present-day labour migration abroad (Reeves 2012).

\subsubsection{Educated female}

Hypothesis 18: if a woman has high education, then she is more likely to intend or to migrate. 
Educated women differ from less- or uneducated women in their perceptions of self and of their role within family or society. They are more aware of professional opportunities and lifestyle choices abroad, of which they may be financially or socially deprived in their home countries. Thus, they are more willing to migrate in search of better pay, and more liberal social norms or personal autonomy (Gubhaju \& de Jong 2009).

\subsubsection{Single female}

Hypothesis 19: if a woman is single, then she is more likely to intend or to migrate.

Single women may be more prone to migration than non-single women not only due to the greater physical mobility afforded by single status, but also thanks to the prospect of greater social mobility abroad (e.g better career or marriage choices). In the KR, many men go abroad in order to save money for a wedding, since they wish to, or are expected to, marry a woman who lives in their community (Reeves 2012). Although women may have similar wishes, or be faced with the same expectations, they - more so than men may view migration as a means to escape poverty and restrictive gender norms, or to find better marriage opportunities. Within the KR, single women have a higher propensity for internal migration; in the case of pregnant women, migration is seen as part of a "familyformation" process, whereby a woman either moves to join a future husband or her own family members (e.g. parents) (Nedoluzhko \& Agadjanian 2010:section 4.1).

\subsubsection{Russian female}

Hypothesis 20: if a woman is Russian, then she is more likely to intend or to migrate.

Russian women in particular are prone to migration because they not only may feel alienated in the post-Soviet Kyrgyz society, but also they may not be able to find a 
suitable spouse in the KR. Given the traditional gender norms, even within the Russian community, and the high unemployment in the KR - for both Russian women and their potential (Russian) husbands - Russian women may view migration as the best means for professional and personal fulfillment.

\subsubsection{Russian in social shock}

Hypothesis 21: if a Russian lives in a household that has experienced a social shock, then he or she is more likely to intend or to migrate.

In the KR, Russians already express a sense of alienation or even discrimination in the post-society society (Tishkov et al. 2005; Laruelle 2007; Buckley et al. 2008; Rubinov 2010). If that sensation is exacerbated by a social shock (i.e. political riot with ethnic undertones), then they may consider migration as a means to cope with the shock.

\subsection{Dataset}

Despite the importance of migration in Central Asia, the region remains severely "understudied" (Brück et al. 2012:2). Of all the surveys conducted in Central Asia in the past 25 years, the Life in Kyrgyzstan (LIK) is the only micro-level national panel survey; other surveys were more limited in scope (e.g. some were only regional; all were only cross-sectional) and a few were conducted by the Kyrgyz authorities. ${ }^{14}$ The LIK survey was conducted annually over a three-year period (2010-2012). ${ }^{15}$ The survey dataset is

\footnotetext{
14 Only 14 micro-level surveys have been conducted in the KR since 1989 (Brück et al. 2012). Based on these surveys, 29 academic papers have been published, which gives a "papers per survey" rate of 2.1. The record of other countries in Central Asia is even less impressive: Uzbekistan $(20 / 10=2.0)$, Kazakhstan $(21 / 11=1.9)$, Tajikistan $(21 / 11=1.9)$, and Turkmenistan (none).

${ }^{15}$ The LIK survey was designed by the German Institute for Economic Research (DIW), located in Berlin. The survey was conducted as part of the "Economic Transformation, Household Behaviour and Well-Being in Central Asia: The Case of Kyrgyzstan" research project, which was funded the Volkswagen Foundation. The goal of the survey was "to (1) to collect nationally representative panel survey data in Kyrgyzstan, (2) to investigate well-being and behaviour of individuals and households in this country, and (3) to improve research capacity within the Central Asian region." The final data includes information on "demographics, assets, expenditure, migration, employment, agricultural markets, shocks, social networks, and subjective well-being." The DIW encourages the use of the survey findings to generate
} 
ideal for quantitative analysis for five reasons: 1) information is of exceptionally high reliability $^{16}$; 2) data have been collected at multiple levels of analysis; 3 ) survey questions address a wide range of topics relevant to migration; 4) survey answers can be coded as variables for large sample empirical analysis; and 5) the panel format allows us to verify migrants' behaviour in subsequent years.

The LIK survey divides the KR into 120 communities (see Appendix A.1. for community characteristics). In 2010, 3,000 households were surveyed, which encompassed 13,739 people including children and absent adults. By design, data have been collected at three levels of analysis: community, household, individual. ${ }^{17}$ In total, 8,160 adults filled out the individual survey, of whom half (53\%) were female and a majority (67\%) were ethnic Kyrgyz. ${ }^{18}$ The current study is based on 2010 and 2011 data only. ${ }^{19}$ The dataset has thus far not been used to study the migration phenomena identified in this paper. ${ }^{20}$

\footnotetext{
"knowledge spillovers to the wider academic." However, the dataset is not available openly to the public, but rather it is distributed to researchers upon signing of a contractual data-privacy agreement.

16 The DIW is an independent, non-profit research institution founded it 1925. It has an outstanding experience in research and publication. Data obtained under its supervision may be judged reliable and impartial, especially in comparison with government-funded projects in the region. See Brück et al. (2012) for explanation of the scarcity of data in Central Asia, which may be attributed to lack of funding, expertise and political freedom - in some countries more than others - to conduct research.

17 At the community-level, a "community representative" filled out one questionnaire with covering topics related not only to community characteristics (e.g. urban/rural), but also to employment and migration status of the population; not all questions were answered by every respondent. At the household-level, the household head filled out a questionnaire that included detailed information about all household members, as well as questions covering topics such as assets, income sources, expenditures and migrants. At the individual-level, each adult in the household present at the type of survey filled out a questionnaire covering multiple measures of well-being, satisfaction, subjective characteristics, and future plans. Samples of all the questionnaires can be found on the DIW website (http://www.diw.de/en/diw_01.c.412482.en/research_advice/macroeconomics_and_financial_markets/development_an d_security/questionnaires_and_manuals_kyrgyzstan.h.tml).

${ }^{1 \overline{8}}$ The ethnic composition represents the current ethnic makeup of the KR: Kyrgyz (72.6\%), Uzbek (14.4\%), Russian (6.4\%), Dungan (1.1\%), and other (5.5\%) (National Statistical Committee of the Kyrgyz Republic 2014).

19 The 2012 data have not yet been made available in spring of 2015, when research for this study began.

${ }^{20}$ The DIW lists publications and work-in-progress that utilize the LIK survey. The list is based on the topics declared by researchers in their application to obtain the dataset. Therefore, even if not complete, the list is indicative. According to the list, no research similar to mine has or is being conducted. List accessed May 4, 2015. (http://www.diw.de/de/diw_01.c.100313.en/forschung_beratung/projekte/projekte.html?id=diw_01.c.345525.en)
} 
According to the LIK survey, a typical migrant is a Kyrgyz male under 30 yearsof-age from a rural community, who is already married and has at least one child; he has a secondary education and has already been abroad (to Russia); he probably has a job, but is only moderately satisfied with his income; finally, he considers himself a risk-taker and takes interest in politics. In terms of ethnicity, stark differences are observed between Russians and non-Russians. ${ }^{21}$ A typical Russian migrant is a female over 30, married or with children; she is highly educated, but although she may be satisfied with her job, she is worried about her economic and social well-being, and wants to move to Russia.

To investigate migration intentions, the key question in the LIK individual questionnaire is I413: "Are you planning to move abroad within the following 12 months for more than 1 month (excluding vacation, family visits, business trips)?" The response is in binary format and it relates explicitly to labour migration. In 2010, 358 adults (4.4\%) responded in the affirmative (see Appendix A.2. for intending migrants' characteristics).

The merging of data from surveys at the three levels of analysis was done by the author of this study for two reasons. First, 2010 data from all questionnaires were merged to obtain a complete set of cross-sectional variables. Certain variables were obtained from the community questionnaire (e.g. unemployment rate), whereas others came from the household (e.g. household size) or the individual (e.g. intention to migrate). Entries with incomplete data were dropped from the dataset, thus retaining 8,156 individuals. Second, 2010 and 2011 data were merged to obtain panel information about the 2010 intending migrants' behaviour over the course of the following year in order to determine if the migrants' intention had been realized. Of the 8,066 respondents to the individual

\footnotetext{
${ }^{21}$ This profile is similar to those presented analysis in past studies (Bichsel et al. 2007; Reeves 2012).
} 
survey in 2011, 7,324 (91\%) re-appeared from the previous year.

Verifying the realization of intentions proved challenging for two reasons. First, no single question in the 2011 survey could account for all intending migrants from 2010. Second, many of the respondents in 2011 did not participate in the 2010 survey. In the 2011 individual questionnaire, only 553 (7\%) respondents answered the "During the last 12 months, have you been abroad for more than one month (excluding vacation, visiting, business trips)?" Of these 553, only 149 (27\%) replied in the affirmative, of whom 26 had intended to migrate in 2010, 57 had not intended, and 66 had not appeared in the previous year's survey. The only other relevant question in the 2011 household questionnaire asked, "Did [household member] stay in the household in the last week?" 727 individuals (5.3\%) were reported to have stayed abroad, of whom only 284 took part in the 2010 individual survey. Nevertheless, it was at least possible to determine that of the 284, $51(22 \%)$ had intended to go abroad and $233(78 \%)$ did not.

Consequently, in regards to labour migrants, it is possible to ascertain that 77 (26 + 51) migrants fulfilled their intention to migrate, and that $290(57+233)$ migrants went without a previous intention. Therefore, the total number of migrants who had gone abroad over the course of 2011 is at least 367 (see Table 1). However, it is still left to be determined how many individuals did not migrate despite their intentions. To do so, 2011 data from the two mentioned questions were combined with 2010 data on intentions. The total number of merged individuals was 7,615 , including the 367 confirmed labour migrants. Of the remaining 7,248 who did not migrate over the course of 2011, 243 had expressed an intention to migrate in 2010 and 7,005 did not. 
Table 1. Migration intentions: fulfilled vs. non-fulfilled.

\begin{tabular}{|l|r|r|r|}
\hline & Migrated in 2011 & Did not migrate in 2011 & Total \\
\hline Intended to migrate in 2010 & $\mathbf{7 7}$ & $\mathbf{2 4 3}$ & 320 \\
\hline Did not intend in 2010 & $\mathbf{2 9 0}$ & $\mathbf{7 0 0 5}$ & 7295 \\
\hline Total & 367 & 7248 & $\mathbf{7 6 1 5}$ \\
\hline
\end{tabular}

Three results stand out. First, more non-intending migrants (290) than intending migrants (77) had actually gone abroad; thus, labour migration appears to be a predominantly unplanned phenomenon. Second, more intending migrants (243) did not migrate than those (77) who successfully did so; thus, most migration intentions are unfulfilled. Third, most (7005) individuals can be regarded as "stayers" (Van Dalen \& Henkens 2008:13), since they neither intended to migrate nor did so. However, these absolute numbers must be considered by taking into account the fact that proportionally, more people realized their intention (77 out of 243 is $32 \%$ ) than went without an intention (290 out of 7295 is $4 \%$ ).

\subsection{Empirical Analysis}

\subsubsection{Methodology}

Given the quantitative methods employed in past research as well as the proposed hypotheses presented in section II, the current study conducts an empirical analysis of two separate econometric models. Using full-sample as well as sub-sample data, each model is tested using the probit estimation technique; the models were also tested using two alternative techniques - logit and OLS - and the results were similar. To obtain the 
marginal effects, rather than just the parameter estimates, the dprobit statistical command is used, and only these marginal effects are reported in the tables. ${ }^{22}$ Given the methodology, the results should be interpreted as correlational rather than causal.

The explanatory variables represent the concepts discussed in the 21 Hypotheses, including three separate shocks as well as two separate worries. Variables can be classified according to three level of analysis. Of the 14 variables at the individual, five are binary (female gender; single status; Russian ethnicity; born in community; and travel experience), three are interval-ratio (age; number of children; number of siblings), and six are ordinal (education level; worry about personal security; worry about economic status; risk-taking, interest in politics; and satisfaction with household income). Of the four variables at the household level, all are binary (access to network; three types of shocks). Of the two variables at the community level, both are binary (urban; unemployment among males). In addition, of the four interactive terms, three are binary (single female; Russian female; Russian under social shock) and one is ordinal (educated female) (see Appendix A.3. for the list of variables). ${ }^{23}$

Model 1 tests the impact of 24 independent variables (20 single variables and 4 interactive terms) on an individual's intention to migrate in 2010:

$$
\begin{gathered}
\text { (1) } I^{*}={ }_{1} a+{ }_{l} b_{1}\left(x_{1}\right)+{ }_{l} b_{2}\left(x_{2}\right)+\ldots{ }_{1} b_{j}\left(x_{j}\right)+{ }_{l} e \\
\text { (1.1) } I=1 \text { if } I^{*}>0 \text { and } 0 \text { otherwise }
\end{gathered}
$$

Where $I^{*}$ is a latent variable measuring a respondent's propensity to intend to migrate, $I$ is

\footnotetext{
${ }^{22}$ Logit, OLS and probit results are available upon request. Calculations were carried out using the STATA (v14.0).

${ }^{23}$ Initial estimations included two quadratic terms (of age and education) as well as more interactive terms. However, inclusion of quadratics and multiple interactive terms diminished the statistical significance of many variables (especially of age and education). Consequently, the quadratics and most interactive terms were excluded from the final estimations.
} 
the respondent's expressed intention to migrate $(I=1)$ or not $(I=0)$ in the 2010 survey, ${ }_{1} a$ is the constant term, $x_{j}$ are explanatory variables $(j=1, \ldots, 24),{ }_{1} b_{j}$ are the parameter coefficients to be estimated from equation 1 , and ${ }_{1} e$ is the error term having a normal distribution with mean 0 and standard deviation 1.

Model 2 tests the impact of 25 independent variables (the 24 already mentioned explanatory variables, plus the previous year's intention) on migrating behaviour. Two versions of Model 2 are considered: with the intention variable as an explanatory variable (2a) and without (2b); the two separate versions allow to isolate for the impact of intention on other variables. For example, for model 2a:

$$
\begin{aligned}
& \text { (2a) } M^{*}={ }_{2} a+{ }_{2} b_{1}\left(x_{1}\right)+{ }_{2} b_{2}\left(x_{2}\right)+\ldots{ }_{2} b_{j}\left(x_{j}\right)+{ }_{2} e \\
& \text { (2a.1) } M=1 \text { if } M^{*}>0 \text { and } 0 \text { otherwise }
\end{aligned}
$$

Where $M^{*}$ is a latent variable measuring a respondent's propensity to migrate, $M$ indicates whether the respondent has actually migrated $(M=1)$ or not $(M=0)$ in the 2011 survey, ${ }_{2} a$ is the constant term, $x_{j}$ are explanatory variables $(j=1, \ldots, 24),{ }_{2} b_{j}$ are the parameter coefficients to be estimated, and ${ }_{2} e$ is the error term having a normal distribution with mean 0 and standard deviation 1 . Ten additional estimations are conducted for Model 1 and Model 2a each to account in population subgroups: 1) gender: male vs. female; 2) ethnic groups: Russian vs. non-Russian; 3) age: under 30 vs. over 30; 4) marital status: single vs. non-single; and 5) community type: urban vs. rural. ${ }^{24}$

Two econometric concerns require attention. First, endogeneity constitutes a potential, albeit limited, concern in the estimations. Neither the innate individual characteristics (e.g. gender) nor the clearly exogenous factors (e.g. shocks, regional

\footnotetext{
${ }^{24}$ Results from additional estimations are available from the author upon request.
} 
unemployment) constitute such a concern. Other explanatory variables were specifically chosen to limit endogeneity. For example, instead of employing a general life-satisfaction explanatory variable as in previous studies (Otrachshenko \& Popova 2014; Ivlevs 2015), the current study employs the satisfaction with household income variable, which is less likely to be influenced by the thought of going abroad. ${ }^{25}$ All estimations were conducted using the typical robustness tests and only the robust estimators are reported.

Second, coefficients of interactive terms in non-linear models cannot be taken at face value (see Ali \& Norton 2003 for discussion). Although the coefficients obtained for the four interactive terms in this study are interpreted as computed, their exact value may be different. Two of the interactive terms have the hypothesized effect; thus the confidence in their correctness is high. Of the remaining two terms, one is not found to be statistically significant and the other has an unexpected negative effect; thus caution should be used in the interpretation. Nevertheless, given the low number of interactive terms used and their limited statistical significant (i.e. only significant in full-sample estimation of Model 1), their inclusion into the models can be deemed as informative.

\subsubsection{Results and Discussion}

\subsubsection{Intentions to Migrate}

In the full sample estimation of Model 1 (see Table 2), most of the variables have a statistically significant impact on the intention, and most have the expected sign. Among the individual-level variables, as expected, the intention is lower for women,

\footnotetext{
25 See Ivlevs (2015) for a thorough discussion of concerns over endogeneity in similar estimation models. After correcting for endogeneity, the final results resembled the initial ones. Note that the general solution to endogeneity from omitted variables is to partition the variance by including an instrument for the missing variable, in this case most likely household income. The "satisfaction with household income" can be seen as the best available instrument given the limitations of the survey questions.
} 
Table 2. Full-sample estimations: Model 1 (intention to migrate), Model $2 a \& 2 b$ (migrating behaviour)

\begin{tabular}{|c|c|c|c|c|c|c|c|}
\hline & $\begin{array}{c}\text { Hypothesized } \\
\text { Effect }\end{array}$ & $\begin{array}{c}\text { Model 1 } \\
\text { (marginal } \\
\text { effect) }\end{array}$ & Z score & $\begin{array}{l}\text { Model 2a } \\
\text { (marginal } \\
\text { effect) }\end{array}$ & Z score & $\begin{array}{c}\text { Model } 2 \mathrm{~b} \\
\text { (marginal } \\
\text { effect) }\end{array}$ & Z score \\
\hline \multicolumn{8}{|l|}{ Variable (LEVEL) } \\
\hline \multicolumn{8}{|l|}{ INDIVIDUAL } \\
\hline Intention to migrate & + & - & - & $0.051 * * *$ & 6.07 & - & - \\
\hline Female & - & $-0.042 * * *$ & -2.89 & -0.005 & -0.42 & -0.007 & -0.65 \\
\hline Age & - & $-0.001 * * *$ & -3.59 & $-0.001 * * *$ & -4.63 & $-0.001 * * *$ & -4.67 \\
\hline Single status & + & 0.006 & 0.92 & 0.008 & 1.42 & 0.009 & 1.59 \\
\hline \# of children & - & $-0.003 * *$ & -2.02 & $-0.006 * * *$ & -4.42 & $0.007 * * *$ & -4.63 \\
\hline \# of siblings & + & -0.001 & -0.64 & 0.001 & 1.06 & 0.001 & 0.98 \\
\hline Russian ethnicity & + & $0.091 * * *$ & 3.60 & $-0.051 * * *$ & -16.07 & $-0.050 * * *$ & -14.97 \\
\hline Born in community & - & $0.010^{* *}$ & 1.99 & $0.013 * * *$ & 3.29 & $0.014^{* * *}$ & 3.47 \\
\hline Has been abroad & + & $0.171 * * *$ & 13.94 & $0.050 * * *$ & 6.37 & $0.078 * * *$ & 8.64 \\
\hline Education & + & $-0.004 * *$ & -1.97 & -0.001 & -0.92 & -0.002 & -1.21 \\
\hline Worried-economy & + & $0.002 * * *$ & 2.71 & -0.001 & -1.08 & -0.001 & -0.60 \\
\hline Worried - security & + & $-0.002 * * *$ & -2.61 & $-0.001 *$ & -1.76 & $-0.001^{*}$ & -2.29 \\
\hline Risk-taker & + & $0.002^{* * *}$ & 3.84 & -0.001 & -1.69 & -0.001 & -1.14 \\
\hline Interest in politics & + & $-0.009 * * *$ & -4.30 & $-0.005^{* * *}$ & -3.38 & $-0.006^{* * *}$ & -3.75 \\
\hline \multicolumn{8}{|l|}{ HOUSEHOLD } \\
\hline Satisfaction - HH income & - & $-0.002 * *$ & -2.54 & -0.001 & -0.81 & -0.001 & -0.95 \\
\hline Network abroad & + & $0.027^{* * *}$ & $4 . .52$ & $0.045^{* * *}$ & 8.13 & $0.050 * * *$ & 8.73 \\
\hline Shock - natural & + & $-0.007^{*}$ & -1.81 & 0.004 & 1.23 & 0.003 & 1.15 \\
\hline Shock - social & + & $0.007^{*}$ & 1.75 & -0.006 & -1.80 & -0.005 & -1.45 \\
\hline Shock-household & + & -0.002 & -0.48 & 0.003 & 0.99 & 0.003 & 0.75 \\
\hline \multicolumn{8}{|l|}{ COMMUNITY } \\
\hline Urban area & - & -0.001 & -0.34 & -0.001 & -0.08 & -0.001 & -0.16 \\
\hline Regional unemployment & + & $0.020 * * *$ & 4.66 & -0.005 & -1.33 & -0.003 & -0.78 \\
\hline \multicolumn{8}{|l|}{ INTERACTIVE TERMS } \\
\hline Educated female & + & $0.007^{* *}$ & 2.49 & -0.0001 & -0.06 & 0.001 & 0.19 \\
\hline Single female & + & 0.009 & 0.94 & -0.003 & -0.44 & -0.003 & -0.44 \\
\hline Russian female & + & $0.0322 *$ & 1.77 & 0.047 & 1.17 & 0.054 & 1.27 \\
\hline Russian - social shock & + & $-0.023 * * *$ & -3.19 & - & - & - & - \\
\hline Observations & & 6,366 & & 6,366 & & 6,366 & \\
\hline Pseudo $\mathrm{R}^{2}$ & & 0.195 & & 0.215 & & 0.202 & \\
\hline Mean of dependent $\mathrm{v}$. & & 0.049 & & 0.054 & & 0.054 & \\
\hline$*=<0.1, * *=<0.05, * * *=<0.01$ & & & & & & & \\
\hline
\end{tabular}


older individuals, and those with more children. Also as expected are the positive relationships between intending and being Russian or having prior experience abroad.

Contrary to expectations, being born in one's community of residence increases the intention, whereas higher education decreases it. Although it may be presumed that the sense of belonging to a community heightens one's well-being - thus decreases the intention to go elsewhere - no difference in the satisfaction with household income was found between those born in or outside the community. ${ }^{26}$ Although it may be expected that higher education influences perception of higher earning abroad, many highlyqualified individuals might avoid migration since they expect to often be constrained to unskilled, physical work in a foreign country (Brzozowski 2007).

Furthermore, as expected, worries about one's economic situation increase the intention to go abroad. However, contrary to expectations, worries about one's personal security decrease the probability of intention. Although this may at first glance be attributed to gender - women being typically more vulnerable - almost no difference was found between the genders. ${ }^{27}$ Consequently, a greater sense of personal insecurity may simply make one anticipate even greater insecurity in a foreign environment, thus discouraging an intention to migrate; insecurity is higher among the risk-averse than among risk-takers. The results indicate that risk-takers are significantly more likely to indicate an intention to migrate. ${ }^{28}$ In the KR, the general attitude is that women are

\footnotetext{
${ }^{26}$ The average "satisfaction with household income" among respondents born in the community was 5.4 out of 10 , which is comparable to 5.3 among respondents born outside of community (Appendix G, Table 1).

${ }^{27}$ The average level of worry about personal security among women was 6.5 out of 10 , which does not differ much from 6.3 among men (Appendix G, Table 2).

${ }^{28}$ Individuals who consider themselves risk-averse ( 5 or less out of 10$)$ have an average worry about personal security of 6.5, whereas those who consider themselves risk-takers (more than 5 out of 10) indicate an average level of worry of
} 
subject to more risks and insecurity abroad than men (Reeves 2012).

Of the three types of shocks, a social shock has the expected positive impact, whereas a natural shock has an unexpected negative impact, which may be influenced by other factors, including the exact type of a natural shock, family size or type of community. Certain types of shocks (e.g. flooding) may necessitate a person to remain at home to deal with the impact of the shock (e.g. rebuild a house), whereas others (e.g. drought) may not require one's presence, but instead create an incentive to seek an alternative income abroad to deal with loss of livelihood (e.g. destroyed crops). In terms of family size, a person with many siblings may count on others to remain at home to deal with the shock, while he or she goes abroad to work. In terms of community size, individuals from rural areas are more prone to natural shocks, since their livelihoods are more exposed to natural forces.

Among the community-level variables, regional unemployment has the expected positive impact. Among the four interactive terms, three - educated women, Russian women, Russians who had experienced a social shock - are found to be significant. The first two have the expected positive impact, but the social shock has an unexpected negative one. Although a social shock may be especially perceived as disturbing by the already status-anxious Russian minority - thus make some Russians want to leave - the pessimistic impact may in fact lead many to entrench at home, since prospects of a better life in Russia - especially after the 2008 financial crisis - would not appear as a better 
alternative. ${ }^{29}$ Only the single female variable does not have a significant effect, probably due to the continued reluctance in the Kyrgyz society to send single women abroad alone.

The marginal effects allow us to compare the relative strength of each of the independent variables, of which the ones with the strongest positive impact (in descending order) are travel experience abroad, Russian ethnicity, access to family network abroad, and regional unemployment. In contrast, the variables with the strongest negative impact are being female, interest in politics, natural shock and education. It seems that in a more traditional society such as the KR, women do not wish to migrate or are discouraged from doing so, and that people interested in politics are either more attached to their home country or are more aware of the challenges they would face abroad. A natural shock may discourage migration because an individual perceives a need to remain at home in order to address the shock. The negative impact of education may require a theoretical rethinking of the willingness of people with high human capital to go abroad where they may expect to perform menial tasks unsuitable for their qualifications.

In addition to comparing the raw size of the marginal effect, one must also interpret the real significance by referring to what the variables represent. ${ }^{30}$ Among the binary variables with a positive impact, the ones with the strongest significance are prior experience abroad (having such experience increases the estimated probability of intending to migrate by $17 \%$ over that of the base comparator case), Russian ethnicity (a 9.1\% effect), and access to a network abroad (2.7\%); among the non-binary variables, the

\footnotetext{
${ }^{29}$ As discussed in Section 1.4-a, the unexpected sign of the interactive term may be due to methodological concerns.

${ }^{30}$ Many of the variables are binary, thus the marginal effect represents the exact change in the probability of intention to migrate.
} 
estimated probability of intending to migrate is increased by $0.2 \%$ by each level (ordinal rank from 1 to 10 ) of worries about the economy, and $0.2 \%$ by each level of risk-taking.

Among the binary variables with a negative impact, the ones with the strongest significance are being female (a $4.2 \%$ decline in the predicted intention to migrate) and to a much lesser extent a natural shock (-0.07\%); among the non-binary variables, the chance decreases $0.9 \%$ by each level of interest in politics, and $0.4 \%$ by each category (not year) of education. Consequently, variables with the strongest real significance are binary (prior experience abroad, ethnicity, network and gender), whereas the age, number of children, level of worries, and most other non-binary variables have small real impacts; for example, a person who is extremely worried about the economy (10 out 10) would only have a $2 \%$ higher probability of intending to migrate than a person who is not worried at all.

Sub-sample estimations generally mirror the results from the full-sample. In the sample of women only, single status is found to be statistically significant, but not risktaking. In the sample of men only, the case is reversed. In the sample of Russians only, children are found to have a positive impact on the intention to migrate and all types of shocks are significant; however both natural and social shocks have a negative impact. In comparison, in the sample of non-Russians, most variables are found to be significant except for natural and household shock. It seems that non-Russians' decision-making process is more complex, whereas Russians respond significantly to shocks.

In the sample of youth under the age of 30 , children have a positive impact on migration intentions, and the impact of prior experience abroad is very high. Also, young Russian females have a higher probability of intention. In the sample of those over the 
age of 30, the strength of the Russian ethnicity variable drops immensely, indicating the propensity of older individuals - regardless of background - to have a lower intention to migrate. In the sample of single individuals only, both Russian ethnicity and experience abroad have overwhelming impacts. In the sample of non-singles, impacts of both variables drop drastically, and the educated female variable is significant.

\subsubsection{Realization of Intentions}

In the full sample estimation of Model 2a, a third of the independent variables is found to be statistically significant, of which most have the expected signs. As expected, intending to migrate raises the probability of actually going in the next year by over $5 \%$; in some ways, this result understates the importance of intentions on migration behaviour since current intentions may also affect migration choices in subsequent years (i.e. a stated intention does not necessarily mean in the immediate future). Moreover, actual migration rates are only $5 \%$ in the sample, so the effect of intending to migrate is very large. Actual migration also increases with experience abroad and access to a family network. As expected, the probability is decreased by age and number of children.

Contrary to expectations, the probability is increased by being born in the community. Also unlike expected, it is decreased by interest in politics, most likely due to patriotic reasons or better awareness of challenges abroad. The negative impact of a social shock may be attributed to the country-wide civil unrest in 2010, which had resulted in tighter border controls, thus effectively preventing people from leaving the KR. Surprisingly, Russian ethnicity decreases migrating behaviour. Although results from Model 1 indicate that Russians are especially keen to migrate, it seems that they are less likely to actually do so. Considering the theoretically distinction between the desire 
and expectation to move (Coulter et al. 2011), the expression of intention may simply be a way to state their wish to migrate due to dissatisfaction with status quo, but in reality, Russians may not actually expect to migrate due to limited capacity to do so or due to a realization that their situation abroad would not be better.

Once again, the marginal effects indicate that the independent variables with the strongest positive impact (and their real significance) are intention (5.1\% higher probability), experience abroad (5.0\%) and network (4.5\%). Consequently, it is evident that subjective factors do indeed have a strong impact. The variables with the strongest negative impact are Russian ethnicity $(-5.1 \%)$, and much weaker children (-0.6\% per child) and interest in politics (-0.5\% per category). Just like in Model 1, the full-sample estimation results for Model 2a generally confirmed by estimations from sub-samples.

The full-sample estimation of Model $2 \mathrm{~b}$ confirms the results from the estimation of Model 2a. Most of the same variables are found to be significant - except of risktaking and social shock - at the same significance levels. The variables in Model 2b tend to have only a slightly higher marginal effects, thus indicating only a minimal distortion caused by the inclusion of the intention variable into the equation.

Two additional sub-sample estimations of Model 2 can be deemed informative: intending vs. non-intending migrants. Given that most of the intending migrants in 2010 did not realize their intention and that many of the non-intending migrants did in fact go abroad, it is important to ask two questions. On the one hand, which factors facilitate the realization of intention? On the other hand, which factors over-power the lack of intention? Two sets of results emerge (see Table 3). First, despite the fact that only three variables are found to be statistically significant in the sub-sample of intending migrants, 
Table 3. Sub-sample estimations: intending vs. non-intending migrants (intention to migrate)

\begin{tabular}{|c|c|c|c|c|c|}
\hline Variable (LEVEL) & $\begin{array}{c}\text { Hypothesized } \\
\text { Effect }\end{array}$ & $\begin{array}{l}\text { Intended } \\
\text { to migrate } \\
\text { (marginal } \\
\text { effect) }\end{array}$ & Z score & $\begin{array}{l}\text { Did not } \\
\text { intend } \\
\text { to migrate } \\
\text { (marginal } \\
\text { effect) }\end{array}$ & Z score \\
\hline \multicolumn{6}{|l|}{ INDIVIDUAL } \\
\hline Female & - & -0.008 & -0.03 & -0.006 & -0.560 \\
\hline Age & - & 0.006 & 1.80 & $-0.001 * * *$ & -5.430 \\
\hline Single status & + & 0.593 & 0.66 & 0.007 & 1.300 \\
\hline \# of children & - & $-0.098^{* *}$ & -3.00 & $-0.005^{* * *}$ & -3.29 \\
\hline \# of siblings & + & 0.011 & 0.71 & 0.001 & 1.290 \\
\hline Russian ethnicity & + & - & - & $-0.040 * * *$ & -14.62 \\
\hline Born in community & - & 0.037 & 0.41 & $0.012 * * *$ & 3.270 \\
\hline Has been abroad & + & $0.336 * * *$ & 5.16 & $0.031 * * *$ & 3.82 \\
\hline Education & + & -0.042 & -1.11 & -0.001 & -0.810 \\
\hline Worried - economy & + & $0.040 *$ & 2.53 & -0.001 & -1.92 \\
\hline Worried - security & + & -0.014 & -1.61 & -0.001 & -1.340 \\
\hline Risk-taker & + & -0.010 & -1.12 & -0.001 & -1.460 \\
\hline Interest in politics & + & 0.012 & 0.34 & $-0.005^{* * *}$ & -3.610 \\
\hline \multicolumn{6}{|l|}{ HOUSEHOLD } \\
\hline Satisfaction - HH income & - & 0.007 & 0.56 & -0.001 & -1.430 \\
\hline Network abroad & + & 0.085 & 1.24 & $0.046 * * *$ & 8.440 \\
\hline Shock - natural & + & 0.066 & 1.16 & 0.002 & 0.910 \\
\hline Shock - social & + & 0.049 & 0.75 & $-0.007^{*}$ & -2.430 \\
\hline Shock-household & + & 0.086 & 1.26 & 0.002 & 0.780 \\
\hline \multicolumn{6}{|l|}{ COMMUNITY } \\
\hline Urban area & - & -0.095 & -1.32 & 0.001 & 0.09 \\
\hline Regional unemployment & + & -0.157 & -1.46 & -0.004 & -1.110 \\
\hline \multicolumn{6}{|l|}{ INTERACTIVE TERMS } \\
\hline Educated female & + & 0.011 & 0.22 & -0.001 & -0.070 \\
\hline Single female & + & -0.047 & -0.40 & -0.001 & -0.060 \\
\hline Russian female & + & - & - & 0.06 & 1.46 \\
\hline Russian - social shock & + & - & - & - & - \\
\hline Observations & & 272 & & 6,056 & \\
\hline Pseudo $R^{2}$ & & 0.194 & & 0.183 & \\
\hline Mean of dependent $v$. & & 0.276 & & 0.045 & \\
\hline$*=<0.1, * *=<0.05, * * *=<0.01$ & & & & & \\
\hline
\end{tabular}


the results underline the importance - as hypothesized - of experience abroad, economic worries and presence of children. Individuals who have already been abroad are 34\% more likely to go again, presumably due to the information and connections that they have already obtained first-hand. Also, worries about the economy motivate individuals (4\% per level) to realize their intention, probably due to a higher perception of financial need; a person who is extremely worried (10 out of 10 ) is thus $40 \%$ more likely to go than a person who is not worried at all. Children, however, are a strong constraining factor $(-10 \%$ per child), undoubtedly due to a large extent to the unwillingness of parents to be separated from their children for an extended time.

Second, in the sub-sample of non-intending migrants, not only are more (8) variables found to be statistically significant, but there are also large differences in the magnitude of the marginal effects of certain variables. Non-intending migrants respond much less to prior experience abroad (only 3.1\%) and are much less constrained by children (-0.5\% per child). Furthermore, they are less likely to migrate due to age, interest in politics and social shock; Russian ethnicity constrains migration by $4.0 \%$. Nevertheless, non-intending migrants appear to be opportunistic, since access to a network abroad increases the likelihood of going by $4.6 \%$.

\subsubsection{Intentions versus Reality}

The differences in results between Model 1 and Model 2 indicate that many variables have a dissimilar impact on intention than on behaviour. Some variables increase intention but constrain behaviour (or have no impact on behaviour): Russian ethnicity, worries about the economy, risk-taking, social shock, regional unemployment, and being a Russian female. Other variables decrease intention but facilitate behaviour 
(or have no impact): female gender, satisfaction with household income, natural shock and being a Russian undergoing a social shock. Furthermore, two variables maintain the same (positive) sign, but the strength of the impact varies substantially: experience abroad and access to a network. These discrepancies put into question the sociopsychological theories that stipulate that intentions determine behaviour. Qualitative research would help to determine whether the discrepancies are due to cultural factors (e.g. gender roles), structural constraints (e.g. border closings in time of a shock), or cognitive dissonance (e.g. expressing an intention as a means to signal frustration, but without true desire to leave).

\subsection{Conclusion}

This chapter addressed two gaps in the migration literature: the decision-making process involved in people's intention to migrate and knowledge about labour migration from Central Asia. The study asked two questions: 1) why do certain individuals intend to migrate whereas others do not; and 2) does the intention to migrate affect the actual migrating behaviour? Similarly to de Jong (2000), this study uses panel data from a developing country to confirm the importance of social norms and differences among genders. Similarly to Agadjanian, Nedoluzhko \& Kumskov (2008), this study conducts a multinomial regression of survey data from the KR; however, it takes into account all age groups and all regions of the country, and it does find differences among genders.

Empirical analysis supports almost all of the proposed hypotheses, including that an intention to migrate has a positive impact on behaviour. Empirical results from Model 1 indicate that the three variables that have the strongest positive impact on the intention are prior travel experience abroad, access to a network, and Russian ethnicity; in contrast, 
the three variables with the strongest negative impact are being female, having an interest in politics, and exposure to a natural shock. Results from Model 2 indicate that the three variables that have the strongest positive impact on actually migrating are intention, travel experience and networks; actual migration is constrained by the presence of children and a social shock. Finally, although many of the intending individuals do not migrate, some of the non-intending individuals actually do; the former are often constrained by reluctance to leave their family, whereas the latter respond opportunistically to access to a network abroad.

The theoretical relevance of the results pertains to the complexity of the intention to migrate. It is evident that economic models are insufficient to provide a complete explanation, since social and psychological aspects (e.g. ethnicity, social turmoil, personal preferences) play a fundamental role. The fact that many intentions are unfilled and many moves are unintended points to the complex - often contradictory - nature of migration. Unfilled intentions may in most cases be attributed to constraining factors (e.g. high cost of travel, unwillingness to leave family behind). In other cases, particularly among ethnic minorities, the intention may be simply an expression of dissatisfaction rather than a serious plan; a person may choose not to migrate even if it is possible. Unplanned migration may be attributed to opportunism, since an unexpected opportunity to go abroad may be difficult turn down; a person may have genuinely had no intention, or preferred not to express it in order to avoid disappointment. However, some people may be forced into migration due to unexpected expenses or due to family pressures (e.g. being chosen to work abroad). Consequently, especially in the more patriarchal and 
culturally-conscious context of Central Asia, the complexity of the intention points to the need to expand the theoretical frame by which migration is explained.

The policy relevance of the results is multifold. As findings of this study indicate, measures aiming to curb migration (e.g. tighter border security) will prove ineffective if they do not address micro-level concerns (e.g. perceptions of economic well-being). If migration is to be managed, either in the home or host country, then the root causes of migration need to be addressed. These are both economic in terms of poverty or wage differentials, as well as psychological and social in term of people's dissatisfaction with their current situation or the culture of migration in which they find themselves.

The most important policy recommendation for migrant-sending countries is to formulate a coherent pro-migration government strategy, which would not only facilitate the migration process, but also allow to reap greater economic benefits. Sending countries must not remain in denial about the outflow of their labour force abroad nor about the benefits of migration. ${ }^{31}$ A basic yet fundamental policy would be to simplify the procedures for obtaining a passport or other travel documents (e.g. establish visa-regimes with priority destination countries) for their citizens. The often lengthy and expensive procedures particularly disadvantage the poor and rural aspiring migrants, who may lack resources to pay for documents or who live too far from a government office (Laruelle

\footnotetext{
${ }^{31}$ The KR is yet to embrace the developmental potential of migration. According to the International Organization for Migration, the KR "practically does not have a formulated policy in the area of immigration of population" (IOM 2012:15). It appears that the Kyrgyz government's strategy towards migration is "control and accounting" rather than development. In the government's National Strategy of Sustainable Development for the Kyrgyz Republic 2013-2017, there are no references made to remittances, and migration is mentioned only nine times, often in a critical tone (National Council 2012). The Strategy lists migration as the cause of, rather than a symptom or solution to, economic problems: "reduction of real value of wages and social benefits, growing unemployment and lack of experience of living in a market economy led to increasing poverty and inequality, which was a consequence of outward migration" (National Council 2012:53). Furthermore, the Strategy also considers migration to have negative social impacts: "Over the past years, due to of increased internal and external migration, the traditional family ties have dramatically weakened" National Council 2012:42).
} 
2007:114). Given the importance of education, government-sponsored training programs aiming to develop desirable skills in host countries (e.g. engineering, nursing) prior to migration would improve migrants' chances of finding employment as well as increase their earning potential. An essential long-term policy is to reduce domestic poverty and unemployment, which would allow individuals who do not wish to migrate to remain at home; in this sense, migration would no longer be a necessary survival strategy.

On the other side of the fence, migrant-receiving countries need to begin by revising any overtly restrictive and cumbersome entry policies, be it labour visa or asylum regime (Economist 2016). Putting up physical or bureaucratic barriers does not stop migrants from entering a country, but rather forces them to seek illegal and dangerous means of entry. Illegal migration not only has the obvious financial and human costs, but it also leads to resentment and isolation - potentially to hostility and lack of integration - among migrant communities. The next step for host countries is to ensure a social environment in which migrants do not fall victim to discrimination and exploitation. To do so, policy recommendations include launching anti-discrimination campaigns for the public, establishing better awareness training for local lawenforcement, and strengthening anti-trafficking and anti-exploitive-labour initiatives.

Future research should continue to test the impact of subjective factors on the migrants' decision-making process; such micro-level factors should be accompanied by novel macro-level factors. Studies in other countries, especially in the under-researched Central Asian region, would provide a complimentary perspective. Last but not least, it is critical for future research to explore the effect of the recent economic slowdown in Russia on labour migration from the KR and other Central Asia countries. 


\section{Chapter 3: Remittances Decision-Making: to remit or not to remit, and how much?}

\subsection{Introduction}

The rising inflows of remittances to developing countries continue to gain attention in research and policy circles. This attention is due both to the recognition that the volume of inflows has increased dramatically in recent years, as well as to the enthusiasm about remittances' ability to spur economic growth. The official recorded inflows to developing countries equaled US $\$ 404$ billion in 2013 , which surpassed the value of aid or foreign investment in many countries. ${ }^{32}$ Most studies in the remittances literature focus on the impact of the inflows on macro-level indicators (e.g. GDP growth); so far, most conclusions regarding growth have been cautiously optimistic. ${ }^{33}$ Consequently, the current policy "development mantra" calls for a "big push" of remittances by encouraging flows, facilitating the transfer process, and ensuring a more effective use of the funds in a "better policy environment." 34

Yet, despite the focus on the impacts of remittances, it still remains a puzzle why some countries receive more remittances than others. While this question has been addressed at the macro-level, there remains a research gap concerning the impact of micro-level factors (e.g. gender, education), which shed light on people's remitting behaviour. In response to this gap, the current study analyzes remitting patterns of international labour migrants. The study considers variables from three levels of analysis - individual, household, community - to determine who the senders of remittances are.

\footnotetext{
${ }^{32}$ Recorded flows are usually grossly underestimated. It is common knowledge that a large proportion of remittances is transferred by unofficial channels (de Haas 2005; Ratha 2005; Pieke et al. 2007). Furthermore, although remittances are usually associated with cash or bank transfers, they may also be material goods (e.g. clothing, electronics).

33 Adams \& Page 2003; Ratha \& Mohapatra 2007; Chami et al. 2008; Özden \& Schiff 2008; Combes \& Ebeke 2010; Combes al. 2012; Das \& Serieux 2010; Ukueva 2010; Das \& Chowdhury 2011; Javid et al. 2012; Salahuddin 2013

${ }^{34}$ OECD 2006; Ratha \& Mohapatra 2007; Brinkerhoff 2009; Brücker 2013; GDI 2013; ILO 2013; UN 2013
} 
The study poses two research questions: 1) which migrants are more likely to remit; and 2) which migrants remit more? In search of answers, the study resorts to empirical analysis of national household survey data from a highly remittances-dependent country: the Kyrgyz Republic (KR). ${ }^{35}$ The data have been collected by the German Institute for Economic Research as part of the Life in Kyrgyzstan (LIK) survey project, which encompassed nearly 3,000 households annually over a three-year period (20102012) ${ }^{36}$ The variables obtained from the LIK survey are recoded and then employed in statistical estimations that correspond to the research hypotheses. Empirical results allow to ascertain which migrant characteristics are correlated with 1) incidence of remittancessending, and 2) magnitude of the remittances per remitter (RPR).

The results are informative for academic research and policy initiatives focusing on migration management, facilitation of remittances transfers, and remittances-led growth. The study contributes to the remittances literature by providing an in-depth analysis of high-quality, yet under-utilized, data using novel variables and statistical methods not employed in past studies. ${ }^{37}$ Given the current migration crisis in Europe and other regions, the study hopes to contribute especially to the policy debate surrounding the treatment of migrants by highlighting not only the economic importance that they

\footnotetext{
${ }^{35}$ In terms of remittances as percentage of GDP, the KR ranks second in the world with $31 \%$. Tajikistan ranks first with 52\%. Data for 2013 (WB 2014).

${ }^{36}$ The LIK survey contains diverse information on households' and household members' characteristics, including the members' migration and remitting history. See website:

http://www.diw.de/de/diw_01.c.100313.en/forschung_beratung/projekte/projekte.html?id=diw_01.c.345525.en. Accessed Dec. 10, 2015.

${ }^{37}$ The LIK dataset may be considered "under-utilized" because it is not available openly to the general public; instead, it is distributed to researchers only upon signing of a contractual data-privacy agreement. The number of publications based on the dataset is limited, and the dataset has not been utilized for the type of research identified in the current study. The German Institute for Economic Research lists publications and work-in-progress that are based on the LIK survey. According the, no research similar to the one in the current study has been, or is being, conducted (http://www.diw.de/de/diw_01.c.100313.en/forschung_beratung/projekte/projekte.html?id=diw_01.c.345525.en). Accessed October 27, 2015.
} 
have for their households as well as home countries, but also by bringing attention to the diversity among the migrants in their characteristics and needs.

The chapter unfolds as follows: section II reviews theory and states the research hypotheses with the aid of relevant literature; section III introduces the data and summarizes descriptive statistics; section IV outlines the methodology and presents empirical results; section $\mathrm{V}$ concludes.

\subsection{Literature Review and Hypotheses}

\subsubsection{Theory}

Remittances may be defined as "monies earned or acquired by non-nationals that are transferred back to their country of origin" (IOM 2016). ${ }^{38}$ An important aspect of remitting behaviour is understanding why people actually send money home. Motivations to remit may be classified into three categories: pure altruism, pure self-interest, and household motives (Lucas \& Stark 1985; Taylor 1999; Clarke \& Wallsten 2003; Goldring 2004; Das 2012). First, pure altruism supposes that migrants remit out of sincere, nonreciprocal care for those who they have left behind (e.g. support for elderly parents). Second, pure self-interest supposes that migrants remit to seek a benefit (e.g. pay for care of their children left behind). Also, migrants may remit to signal success abroad, which would increase their prestige at home (Naiditch \& Vranceanu 2011; Reeves 2012).

Third, household motives suppose that migrants respond to agreed-upon responsibilities towards their family. The third category stems from the new economics of labour migration (NELM) theory, which considers a migrant to be part of a household

\footnotetext{
${ }^{38}$ More exhaustive definitions distinguish among "personal remittances", "personal remittances", "disposal income from abroad" and "total remittances"; different definitions take into account various financial payments, including capital transfers or social contributions (Alfieri \& Havinga 2006; Chami et al. 2008; IMF 2011).
} 
with whom he or she makes communal decisions and shares economic risks (Stark 1978 \& 1991; Lucas \& Stark 1985; Schiff 1994; Taylor 1999). Since household income is considered to be pooled, the migrant is expected to contribute to it. Furthermore, if other household members assist the migrant with going abroad (e.g. provide funds for travel expenses), then the obligation to remit is heightened. ${ }^{39}$ Since more than one motivation may be involved at the same time, it is often difficult to determine the principal one. The motivations may overlap (e.g. gaining prestige for altruistic donations) and individualistic decision-making may be contrary to household decision-making (e.g. migrant may be unwilling to go abroad, but chooses to do so as a sacrifice for the household well-being).

In determining the principal motivation, it is helpful to consider the migrant's perception of "relative deprivation" (Massey 1990:18). In some cases, migrants may remit more just because other migrants remit more; for example, if households of successful migrants use remittances to build elaborate houses, than other households may feel more deprived and thus request more remittances to also improve their own housing. Furthermore, Brown (2010:10) assesses remittance patterns based on a migrant's "subjective income gap", which is the perceived level of income required to just get by.

\subsubsection{Emerging Hypotheses and Empirical Literature}

Based on the prevalent theory and findings from past research, this study proposes 13 hypotheses - each divided into two parts - which incorporate variables from the LIK dataset. The first part of each hypothesis pertains to the incidence of remitting, while the

\footnotetext{
${ }^{39}$ However, it is becoming acknowledged in the literate that household motives apply to impoverished, yet nevertheless stable countries, but not necessarily to conflict areas; migrants from such areas may still remit despite the fact the primary reason for departure was survival, rather than household planning (Ratha \& Shaw 2006; Lindley 2007 \& 2009).
} 
second to the magnitude of the RPR. Every hypothesis is supported by references to past empirical research, especially to existing studies in the KR.

From a methodological perspective, a seminal work in the literature is Rodriguez (1996), who employs a national survey dataset to empirically test the impact of migrant characteristics on 1) the incidence of remitting, and 2) the value of amount sent. Results from the Philippines indicate that remitters are usually older, educated household heads, who go abroad on contracts; although they send more money the longer they stay abroad, the marginal effect decreases over time; on the receiving end, higher amounts are sent to younger and educated household members, especially in urban regions and regions with high unemployment. Another example is Houle \& Schellenberg (2008), who analyze a longitudinal survey of migrants in Canada to determine the incidence and value of remittances. Empirical results indicate that two factors - "financial and family characteristics" - have a consistent effect on remitting among migrants from all countries.

\subsubsection{Gender}

\section{Hypothesis 1: if a migrant is male, then he is more likely to remit or to remit more.}

Gender has a complex impact on remitting-behaviour due to the influence of factors (e.g. cultural background). Given the more traditional culture of migrant-sending countries in the global South, there is a higher expectation on men - as the traditional breadwinners to remit. However, men remit typically only to their own household (i.e. wives), whereas women often remit to their parents and other family members (IOM 2013). The effect of gender remains contested in the literature. On the one hand, women often remit as much as (or even more than) men because they send a higher proportion of their income; in contrast to men, women tend to remit smaller amounts, but more frequently (IOM Ibid). 
On the other hand, research indicates either that women remit less (Lindley 2007) due to their lower earning potential, or that there is no consistent difference between genders (Houle \& Schellenberg 2008). In the KR, where the household encompasses all extended family living under one roof, men tend to remit more not only to provide for the large household, but also to prove themselves as breadwinners (Reeves 2012).

\subsubsection{Age}

H-2: if a migrant is older, then he or she is more likely to remit or to remit more; the marginal effect decreases with age in both instances.

Older migrants are more likely to remit because they usually have more obligations (e.g. children) in the home country. Furthermore, they may have a higher income thanks to their experience and skills, thus they may afford to remit more (Rodriguez 1996; Dustmann \& Mestres 2010). However, over time, aging migrants may divert a portion of their income to their own needs (e.g. medication), and thus remit less. In the KR, older individuals remit regularly to their households, whereas younger ones - especially men often save their income and bring it back for a large expense (e.g. house, wedding) for their future household (i.e. after marriage) (Reeves 2012).

\subsubsection{Marital status}

\section{H-3: if a migrant is married, then he or she is more likely to remit or to remit more.}

Married migrants are more likely to remit in order to provide funds to their spouse and children; the larger the family, the more a migrant will remit (Lindley 2007). However, if a household is planning family unification abroad, then the amount remitted will decrease as family members migrate (Houle \& Schellenberg 2008; Unheim \& Rowlands 2012). Single migrants, especially without children, are more likely to keep income to themselves for their own needs. 


\subsubsection{Household role}

H-4: if a migrant is the household head, then he or she is more likely to remit or to remit more.

A household head has a higher sense of obligation to provide for his or her household (Rodriguez 1996). In the KR, although other household members (e.g. son or daughter) also remit, they may save a proportion of their income for their own households, existing or future (Reeves 2012).

\subsubsection{Ethnicity ${ }^{40}$}

H-5: if a migrant is from the major ethnic group, then he or she is more likely to remit or to remit more.

Reference to ethnicity does not imply an inherent cultural trait of a specific group, but rather the group's association with its home country. Migrants stemming from the major ethnic group are more likely to feel attached to the country and wish to return there. Therefore, they are more like to remit funds to maintain family relations and financial assets. Migrants stemming from minority groups are more likely to feel detached or even alienated from the home country, thus spend less on maintaining relations or assets; instead of remitting, they may intentionally devote income to establishing a new life abroad, including to support family unification. In the KR, ethnic minorities, especially Russians, tend to express dissatisfaction with their social status after the breakup of the

\footnotetext{
${ }^{40}$ Ethnic division in this chapter (major ethnic group vs. minor groups) differs from the division in Chapter II (Russians vs. non-Russians). Based on theory and evidence from the literature, various divisions based on ethnicity are possible in the KR. The approach taken in this study is to differentiate between Russians and non-Russians in regards to migration, since Russians have better options for moving to Russia, where they can expect more opportunities to find work and to integrate more easily than non-Russians. In regards to remitting behaviour, the Kyrgyz - being the majority group - send money "home", whereas Russians and other non-Kyrgyz (e.g. Uzbeks) may feel equally not at home in the KR, thus behave similarly.
} 
Soviet Union (Agadjanian et al. 2008); consequently, they are more likely to devote income earned abroad to establishing a new life there.

\subsubsection{Education}

H-6: if a migrant possesses a higher level of education, then he or she is less likely to remit, but is likely to remit a greater amount; in the first instance, the marginal negative effect increases with education level, but in the second instance, the positive effect increases with level.

Educated migrants typically earn a higher income abroad thanks to their higher human capital, thus they can afford to remit more (Dustmann \& Mestres 2010). However, given the better opportunities available to them abroad, they may be less willing to return to the home country, thus be less willing to maintain family or financial ties there. Consequently, they may intend less to remit and the intention will dwindle over time as the migrants establish a life in the new country, especially with family unification. The opposing forces of earning power and intentions can lead to inconclusive (Houle \& Schellenberg 2008) or even negative (Unheim \& Rowlands 2012) interpretations of education's role. In addition, Rodriguez (1996) notes that the role of education is unclear, since it is not possible to determine if the amount sent is influenced by the higher income of more educated workers, or by the more educated household members, who may request higher remittances.

\subsubsection{Job type}

H-7: if a migrant has a high-skilled job, then then he or she is more likely to remit or to remit more.

Although a high-skilled job may imply that a migrant have a high education, and thus acts in accordance to Hypothesis 6, less educated migrants may also obtain a high-skilled 
job thanks to experience or seniority. Since a high-skilled job usually provides a higher income, the migrant will be able to remit more (Dustmann \& Mestres 2010).

\subsubsection{Network}

H-8: if a migrant obtained information about opportunities abroad from household members, then he or she is more likely to remit or to remit more.

Given that access to a network facilitates migration, ${ }^{41}$ migrants who have been able to go abroad thanks to information obtained from their households members may want - or be expected - to repay for the help by sending money. Consequently, they will intend more to remit and remit more than migrants who have gone abroad without any help.

\subsubsection{Loan}

H-9: if a migrant obtained funding to go abroad from household members, then he or she is more likely to remit or to remit more.

Similarly to Hypothesis 8 , migrants who have been able to go abroad thanks to financial help from their households members may want - or be expected - to repay for the help by remitting. Consequently, they will intend more to remit and remit more than migrants who have gone abroad without any funding from the household. Bichsel et al. (2007) find that in the case of Indian migrants who receive financial assisant from family and friends abroad, they repay the loan first and only then send remaining income as remittances.

\subsubsection{Contact}

H-10: if a migrant maintains regular contact with the household, then he or she is more likely to remit or to remit more.

Migrants who maintain regular contact (e.g. via telephone, email, text messages) with their families not only receive more information about household needs, but also retain

\footnotetext{
${ }^{41}$ Yang 1999; Heering et al. 2004; Özden \& Schiff 2006; Ratha \& Shaw 2006; Agadjanian et al. 2008; Van Dalen \& Henkens 2008 \& 2013
} 
closer personal bonds with household members. Consequently, they may have a higher sense of obligation and thus be more willing to be financially involved. In the KR, the recent expansion in telecommunications has allowed households in even remote villages to have mobile services, thus improving contact with migrants (Isabaeva 2011).

\subsubsection{Shock}

H-11: if a migrant's household experienced a shock, then he or she is more likely to remit or to remit more.

This study differentiates among natural, social and household shocks. The central debate in the literature is whether remittances are pro- or counter-cyclical. Although most authors favour the latter - insurance - argument, the result depends on the country as well as the type of shock (Ratha \& Shaw 2006; Chami et al. 2008; Grabel 2008; Plaza \& Ratha 2011). Natural or household shocks seem to have the most unambiguous countercyclical effect, as altruistically-motivated migrants remit more to alleviate the effects of a hurricane (Clarke \& Wallsten 2003), heavy rainfall (Yang \& Choi 2007) or exposure to violence (Lindley (2007). However, while a macro-economic shock can also stimulate an altruistic response, it can also stimulate an egoistic response, as migrants realize that the shock may be detrimental in time of slow growth (Lueth \& Ruiz-Arranz 2007).

\subsubsection{Rural household}

H-12: if a migrant's household lives in a rural area, then he or she is more likely to remit or to remit more.

Households from rural areas tend to adhere to more traditional cultural values, which reenforce family dynamics stipulated in Hypotheses 1 to 4 . Furthermore, rural areas in most countries tend to be less developed than urban areas, thus rely more on income from 
abroad. In the KR, migrants from rural areas may be culturally more obligated, and objectively see a greater need, to remit (Reeves 2012).

\subsubsection{Regional unemployment}

H-13: if a migrant's household is in an area with a high unemployment rate, then he or she is more likely to remit or to remit more.

Similarly to Hypothesis 12 , migrants from areas with a high unemployment rate may perceive a greater necessity to send money home. Since they may be the only working members in the household, they will be more willing - or expected - to remit, and they will remit more (Rodriguez 1996; Houle \& Schellenberg 2008).

\subsection{Dataset}

The KR remains severely "understudied" in remittances research (Brück et al 2012:2). Since its independence from the Soviet Union in 1989, only fourteen micro-level surveys were conducted. ${ }^{42}$ Of all the surveys carried out in the KR - and in Central Asia as a whole - the LIK survey is the only micro-level panel survey. ${ }^{43}$ It was conducted in three annual waves from 2010 to 2012 , at three levels of analysis. ${ }^{44}$ The current study is based on the first wave from 2010, which encompassed 13,739 individuals in 3,000 households from 120 communities. The dataset is appropriate for a study of remitting behaviour because the information is of unusually high reliability, the survey asks

\footnotetext{
42 This scarcity of research may be attributed to lack of data, which in turn may be attributed to lack of funding or expertise to conduct such surveys (Brück et al. 2012).

${ }^{43}$ The survey was conducted by the German Institute for Economic Research as part of the "Economic Transformation, Household Behaviour and Well-Being in Central Asia: The Case of Kyrgyzstan" research project, which was funded the Volkswagen Foundation. The goal of the survey was "to (1) to collect nationally representative panel survey data in Kyrgyzstan, (2) to investigate well-being and behaviour of individuals and households in this country, and (3) to improve research capacity within the Central Asian region." The final data includes information on "demographics, assets, expenditure, migration, employment, agricultural markets, shocks, social networks, and subjective well-being."

${ }^{44}$ The questionnaires are available at: http://www.diw.de/en/diw_01.c.412482.en/research_advicemacroeconomics_and_ financial_markets/development_and_security/questionnaires_and_manuals_kyrgyzstan.html. Accessed May 23, 2015.
} 
questions pertinent to remittances, and the data can be recoded for statistical analysis. ${ }^{45}$

\subsubsection{Remitters}

Household survey question H601 asks, "How many adult members of your household are currently staying abroad (for more than one month, excluding business trips, vacation and visiting)?", thus referring explicitly to labour migrants. In 2010, 363 (12.1\%) households reported at least one adult member to be abroad; most households (237) reported only one (see Table 4). In total, 531 migrants were reported. In subsequent questions H602-615, which request information on the reported members (e.g. age),, only 489 migrants were accounted for (see Appendix B.1. for migrants' characteristics).

\section{Table 4. Household members abroad.}

\begin{tabular}{|r|r|r|}
\hline \multicolumn{1}{|c|}{$\begin{array}{l}\text { \# of household } \\
\text { members }\end{array}$} & \# of households & Total migrants \\
\hline 2 & 237 & 237 \\
\hline $3+$ & 97 & 194 \\
\hline & 29 & 90 \\
\hline & $\mathbf{3 6 3}$ & $\mathbf{5 3 1}$ \\
\hline
\end{tabular}

Household question H616 asks if a household received "any money from abroad" specifically from members of the household. Only $300(10.0 \%)$ households reported to have received such remittances from at least one member; most households reported only one member. Consequently, only the 396 reported household members are considered as confirmed remitters. Once again, the incomplete list may is partly due to limited space in the questionnaire, in which the respondent could name only three migrants. Household

\footnotetext{
${ }^{45}$ The DIW is an independent, non-profit research institution. It has a long experience in research and publishing. Data obtained through its field projects may be deemed more reliable and impartial than many government-funded projects in Central Asia.
} 
members abroad who were not reported to send remittances are considered as confirmed non-remitters. Subsequent questions (H617-625) requested information on the amount, currency, frequency and transfer methods.

The merging of data from the household and community surveys was carried out by the author of this study for two reasons. First, to obtain a full set of variables about the remitters; for example, the household location was obtained from the community survey, whereas migrants' incidence of remitting came from the household survey. Second, to match the data on accounted for migrants abroad with the data on migrants' remitting behaviour. In the case of households with more than one migrant, all migrants were assumed to be confirmed remitters if the household received any remittances; conversely, all migrants were assumed to be confirmed non-remitters if the household did not receive any remittances. Individuals with incomplete data were removed from the dataset. The merging resulted in 374 migrants being retained, of which 295 (78.9\%) are confirmed remitters (see Appendix B.2. for confirmed remitters' characteristics). ${ }^{46}$

\subsubsection{Remitted Amounts}

299 households reported the amount of remittances they had received in the past year (H617), of which 209 reported only one remitter. In order to avoid measuring error in the amount of remittances per remitter (RPR), households with two or more remitters were removed from the sample. Since most households reported an annual amount, any monthly amounts were converted into a yearly amount by multiplying them by twelve.

\footnotetext{
${ }^{46}$ Isolating for only "single" remitters (only one remitter per household) resulted in 199 observations that could be used for statistical analysis. However, the estimations yielded unstable results - many variables were dropped automatically because they "predict success perfectly." Therefore, the initial selection of confirmed remitters (single or not) was retained for analysis.
} 
Furthermore, the amounts were reported in four currencies: Kyrgyz som (119), Russian ruble (72), US dollar (17) and Euro (1). In order to minimize errors inherent to currency conversion, the som was chosen as the base currency. ${ }^{47} \mathrm{~A}$ merging process was carried out to obtain a full set of variables for the remitters; 198 remitters were retained for empirical analysis.

\subsection{Empirical Analysis}

\subsubsection{Methodology}

Given that each hypothesis guiding this study is divided into two parts, the empirical analysis involves two separate econometric models. Both models are tested using the cross-sectional data from 2010, but each model employs a different estimation technique due to the format of its dependent variable. Both models employ the same 18 independent variables, which correspond to the concepts presented in the 13 Hypotheses, including two quadratic terms, two dummy variables for ethnicity, and three distinct types of shock. The variables can be classified according to three levels of analysis. Of the 13 individual-level variables, nine are binary (female gender, married status, household head, Kyrgyz ethnicity, "other" ethnicity, unskilled labour, information network, funding network, and contact). The three household-level variables and the two community-level variables are binary (natural shock, social shock, household shock, urban setting, and high unemployment) (see Appendix B.3. for the list of variables).

Model 1 tests the impact of explanatory variables on migrants' incidence of remitting:

\footnotetext{
47 Other currencies were converted to som using the 2010 annual average exchange rate. Annual (Jan. 31 to Dec. 31 , 2010) exchange rate, bid price: 1 Kyrgyz som $=0.02175$ US dollar, 0.65915 Russian ruble, 0.01641 Euro. Accessed May 27, 2015. (www.oanda.com)
} 


$$
\text { (1) } R^{*}={ }_{1} a+{ }_{1} b_{1}\left(x_{1}\right)+{ }_{l} b_{2}\left(x_{2}\right)+\ldots{ }_{1} b_{j}\left(x_{j}\right)+{ }_{l} e
$$

$$
\text { (1.1) } I=1 \text { if } I^{*}>0 \text { and } 0 \text { otherwise }
$$

Where $R^{*}$ is a latent variable measuring a migrant's propensity to remit, $R$ is the migrant's reported incidence of remitting $(R=1)$ or not $(R=0)$ in the 2010 survey, ${ }_{1} a$ is the constant term, $x_{j}$ are explanatory variables $(j=1, \ldots, 18),{ }_{1} b_{j}$ are the parameter coefficients to be estimated from equation 1 , and ${ }_{1} e$ is the error term having a normal distribution with mean 0 and standard deviation 1 . Given the binary format of the dependent variable, Model 1 is estimated using the probit technique; the marginal effects of the dprobit estimation are reported. The technique is applied to the full sample and three sub-samples: 1) women vs. men; 2) Kyrgyz vs. non-Kyrgyz; and 3) urban vs. rural. $^{48}$ In total, eight estimations are conducted using the standard robustness tests; only the robust results are reported. ${ }^{49}$

Model 2 verifies the impact of the variables on the magnitude of remittances:

$$
\text { (2) } S^{*}={ }_{2} a+{ }_{2} b_{1}\left(x_{1}\right)+{ }_{2} b_{2}\left(x_{2}\right)+\ldots{ }_{2} b_{j}\left(x_{j}\right)+{ }_{2} e
$$

Where $S^{*}$ is a latent variable measuring the magnitude of a migrant's remittances, $S$ indicates the monetary value of remittances reported in the 2010 survey, ${ }_{2} a$ is the constant, $x_{j}$ are explanatory variables $(j=1, \ldots, 18),{ }_{2} b_{j}$ are the parameter coefficients to be estimated, and ${ }_{2} e$ is the error term.

Given that the dependent variable is a monetary value, the model is tested using the ordinary-least-squares (OLS) technique. In order to minimize the disturbance effect of outliers, the dependent variable is in a logarithm form. As in Model 1, the estimation

\footnotetext{
${ }^{48}$ Results from additional estimations are available from the author upon request.

49 The estimations are conducted using the STATA (v14.0) statistical program. To obtain the marginal effects for the probit estimation, the "dprobit" statistical command is used. To obtain the robust results, "robust" command is used.
} 
technique is applied to the full sample of migrants and sub-samples. In total, four estimations are conducted; all include robust results.

Two econometric concerns require mention. First, endogeneity may exist, but in a limited scope (see discussion in section 2.4.1). Second, the missing variable problem may exist, since variables representing savings or investment were not included (see Menjivar et al. 1998, and Clark and Drinkwater 2007 for discussion of the problem in remittances equations). Although these variables would be valuable in the estimation, these data were not collected in the LIK, nor were there suitable instruments available from the survey.

\subsubsection{Results and Discussion}

\subsubsection{Incidence of Remitting}

The full-sample empirical results are listed in Table 5. A test for multicollinearity was carried out and indicated a low level of collinearity among variables other than quadratic terms and their base variables (age and education). ${ }^{50}$ Only the eight statistically significant variables are discussed below in detail. First, and as expected, the probability of remitting is $24 \%$ lower for women relative to men. The negative effect associated with the quadratic term of the age variable indicates a reversed U-shaped relationship between the probability of remitting and age, with the probability rising until the average migrant is just over the age of 25 , after which the probability declines.

Contrary to expectations, being married has a highly statistically significant and negative effect on the probability of remitting, reducing it by almost $20 \%$ for an average migrant. Hypothesis 3 indicates that marriage should have a positive effect, but this is

\footnotetext{
${ }^{50}$ To carry out the test for multicollinearity the variance inflation factors from an OLS version of the estimation were examined.
} 
Table 5. Model 1 full-sample estimation results (incidence of remitting)

\begin{tabular}{|c|c|c|c|}
\hline$\frac{\text { Variable }}{\text { (LEVEL) }}$ & $\frac{\text { Hypothesized }}{\text { Effect }}$ & $\frac{\text { Probit (marginal }}{\text { effects) }}$ & $\underline{Z \text { score }}$ \\
\hline \multicolumn{4}{|l|}{ INDIVIDUAL } \\
\hline Female & - & $-0.243 * * *$ & -4.54 \\
\hline Age & + & $0.053 * *$ & 2.53 \\
\hline Age (squared) & - & $-0.001 *$ & -1.65 \\
\hline Married & + & $-0.196 * * *$ & -3.79 \\
\hline Household head & + & 0.053 & 0.75 \\
\hline Ethnicity (Kyrgyz) & + & 0.071 & 1.27 \\
\hline Ethnicity (other) & - & 0.064 & 0.77 \\
\hline Education level & - & $-0.279 *$ & -1.69 \\
\hline Education (squared) & + & $0.026^{*}$ & 1.67 \\
\hline Unskilled job & - & -0.024 & -0.59 \\
\hline \multicolumn{4}{|l|}{ HOUSEHOLD } \\
\hline Network & + & 0.063 & 1.40 \\
\hline Loan & + & $-0.074 *$ & -1.75 \\
\hline Contact & + & 0.004 & 0.08 \\
\hline Shock - natural & + & -0.061 & -1.48 \\
\hline Shock - social & + & -0.001 & -0.01 \\
\hline Shock - household & + & -0.0001 & -0.01 \\
\hline \multicolumn{4}{|l|}{ COMMUNITY } \\
\hline Urban area & + & 0.012 & 0.26 \\
\hline High unemployment & + & $-0.135^{* * *}$ & -2.71 \\
\hline Observations & & 367 & \\
\hline Pseudo $\mathrm{R}^{2}$ & & 0.192 & \\
\hline Mean of dependent $v$. & & 0.79 & \\
\hline$*=<0.1, * *=<0.05, * * *=<0.01$ & & & \\
\hline
\end{tabular}

based on the assumption that a migrant's immediate family remains in the $\mathrm{KR}$, an assumption that cannot be tested explicitly due to the limitations of the survey; if this assumption is inaccurate it could explain this unexpected result. Also unexpected is the effect of education on the probability, since the positive quadratic term of education indicates a U-shaped relationship between higher levels of education and the probability, with the probability falling until a migrant reaches approximately education level 5 and rising thereafter. Most of the household level characteristics in the model also have little 
effect. The only variable that has a (weakly) statistically significant effect in the model is the presence of a loan to the migrant from the family. While it was expected that such a loan increase the probability of remitting, the results here indicate that the probability actually decreases by just over $7 \%$. This unexpected effect may be the result of a delay between receiving the loan and the financial capacity to repay it. For example a younger migrant may borrow money to get abroad, but not have the ability to repay quickly. Of the two community level variables in the model, only the indicator of high unemployment in the home community seems to affect the probability a migrant will remit money. Although the expectation was that high unemployment at home would increase pressure for remittances, the result here indicates a strong opposite effect in which the probability of remitting falls by over $13 \%$. High unemployment in the home community could discourage remittances from migrants hoping to invest in economic opportunities at home, but the effect needs further investigation with more detailed survey data.

The marginal effects of the probit estimation allow us to compare variables' relative strength. The only variables with a positive effect are age and education-squared. The variables with the largest negative effect are education, gender and married status. Moreover, it is necessary to interpret the real significance of each variable by referring to what it represents. ${ }^{51}$ In regards to the four binary variables with a negative effect, the probability of remitting is $24.3 \%$ lower for women, $19.6 \%$ lower for married people, $13.5 \%$ lower for communities with high unemployment, and $7.4 \%$ lower for migrants who had loans.

\footnotetext{
${ }^{51}$ Some of variables are binary, thus their marginal effect by itself represents the change in the probability of remitting. The real significance of age and education cannot be interpreted as such, given the significance of their quadratic terms.
} 
It is informative to note that most of the variables did not have a statistically significant effect. Given that neither the household head nor ethnicity variables had an effect, the implications for theory are that non-household heads (e.g. son, daughter) may be just as likely to remit, and that there are no differences in remitting among ethnic groups. Furthermore, the lack of an effect of an information network or regular contact indicates that a migrant may not feel obligated to repay for solely information (as opposed to for a loan) and that it does not matter whether the migrant maintains a frequent or infrequent contact. Although no type of shock had a statistically significant effect, the negative sign of the coefficients hints at the prevalence of self-interest, rather than altruistic, motivations. Finally, it appears that there may be no difference in remitting behaviour between migrants from urban and rural households.

To further investigate the propensities to remit, estimations are also conducted using sub-samples of the migrants in the survey. The full sample is split between women and men, between Kyrgyz and non-Kyrgyz, and between rural and urban households. In the sample of women only, the only three variables with statistically significant effects are married status, regional unemployment and the presence of a social shock at home. As in the full sample estimation, being married and coming from a region of high unemployment reduces the likelihood of remitting. The negative effect on remittances of a social shock is surprising at first, since theorized motivations such as altruism and the NELM theory would call for more remittances as an insurance effect. Instead, the presence of social unrest may be associated with concerns about the social or economic security of remittances, which might delay or inhibit remittances, especially those motivated more by self-interest. In the sample of men only, there are also only three 
variables with statistically significant marginal effects. The effect of married status is negative as in the sample of women, but the positive effect of age is unique to men; marginal effect of age-squared is negative, as expected, and reaches its peak at 44 years.

In the sample of the Kyrgyz only, six variables are significant, of which all have the same types of effects as in the full sample; the three strongest are education, female gender and married status. In the sample of other ethnicities, the only three statistically significant effects are associated with being female, being married, and the presence of a natural shock. Once again, the negative impact of a natural shock is surprising, and it may be explained by the dominance of self-interest; a possible alternative explanation may be a higher intention for family reunification abroad among non-Kyrgyz minorities.

In the sample of urban households, seven variables are significant, of which all have the same type of effect as in the full sample; the three variables with the strongest effect are education, female gender and household shock. The negative effect of a household shock may be due the inclusion of death (e.g. spouse, parents) into this category of shock, after which remittances may cease completely; given the higher mobility of urban migrants, family migration abroad may be more likely after death of a household member. In the rural sample, nine variables are significant, of which the strongest ones are education, female gender and married status. The variable that appears in this sub-sample but not in the full sample is a natural shock.

\subsubsection{Magnitude of Remittances}

Full-sample OLS results are listed in Table $6 .^{52}$ There are 195 observations

\footnotetext{
52 A tobit estimation was carried out on the entire sample, with the logarithm form of the remitted amounts as the dependent variable. The results were similar to the OLS estimation.
} 
included in the estimation, and the dependent variable is in a logarithmic form. The test for multicollinearity indicates a low level of collinearity among the explanatory variables other than quadratic terms and their base variables (see Appendix B.4. for the test results). ${ }^{53}$ Only the nine variables with statistically significant effects are discussed.

Contrary to expectations the amount of RPR initially decreases with age, but then increases at a rising rate beyond the age of 36.5; this statistically fairly weak effect (both coefficients are only marginally significant at the $10 \%$ level) is opposite of the effect found in the likelihood of remitting reported in the previous sub-section. As expected, household heads remit much more than others, since they are typically presumed to be the main breadwinners; unlike in Model 1, this variable is highly significant in Model 2. Household heads remit roughly 1.7 times the amount of non-household heads. ${ }^{54}$

Similarly, married migrants remit roughly 1.47 times less than their unmarried counterparts. Inadequate detail in the survey prevents us from attributing this effect to the location of the migrants own immediate family (spouse and children), which may well have joined the migrant abroad. Education also has a weak effect on remittance amounts, and as with age the effect is the opposite when compared with the effects it has on the propensity to remit. Specifically, remittances rise with education until it reaches a fairly high level (around category 5), suggesting that for most migrants remittances rise with education as we would expect if there was an associated income effect.

\footnotetext{
53 A full-sample estimation without the two quadratic terms has also been carried out. Impact on statistical results was major, including age variable no longer being significant at any level; the estimation accounted for only $15.2 \%$ of variance. Consequently, the quadratic terms were retained.

${ }^{54}$ The heckman regression technique was carried out in STATA using equations in Models 1 and 2. Most variables retained their statistical significance, including household head variable; this indicates the importance of the family status in the obligation to send large amounts.
} 
Table 6. Model 2 estimation results (remittances per remitter) (in KR som)

\begin{tabular}{|c|c|c|c|}
\hline$\frac{\text { Variable }}{\text { (LEVEL) }}$ & $\frac{\text { Hypothesized }}{\text { Effect }}$ & $\underline{\mathrm{OLS}}$ & $\underline{Z \text { score }}$ \\
\hline \multicolumn{4}{|l|}{ INDIVIDUAL } \\
\hline Female & - & 0.129 & 0.8 \\
\hline Age & + & $-0.073^{*}$ & -1.68 \\
\hline Age (squared) & - & $0.001 *$ & 1.85 \\
\hline HH head & + & $0.537 * * *$ & 2.83 \\
\hline Ethnicity (Kyrgyz) & + & 0.084 & 0.47 \\
\hline Ethnicity (other) & - & 0.192 & 0.85 \\
\hline Married & + & $-0.387 * *$ & -2.32 \\
\hline Education level & + & $0.694 *$ & 1.66 \\
\hline Education (squared) & + & $-0.072^{*}$ & -1.76 \\
\hline Unskilled job & - & -0.067 & -0.47 \\
\hline \multicolumn{4}{|l|}{ HOUSEHOLD } \\
\hline Network & + & -0.033 & -0.21 \\
\hline Loan & + & 0.154 & 1.15 \\
\hline Contact with $\mathrm{HH}$ & + & $0.354^{* *}$ & 2.18 \\
\hline Shock-natural & + & -0.103 & -0.77 \\
\hline Shock-social & + & $0.249 *$ & 1.81 \\
\hline Shock-household & + & -0.145 & -0.96 \\
\hline \multicolumn{4}{|l|}{ COMMUNITY } \\
\hline Urban area & + & $0.304^{* *}$ & 1.98 \\
\hline High unemployment & + & 0.004 & 0.02 \\
\hline Observations & & 195 & \\
\hline$R^{2}$ & & 0.177 & \\
\hline$*=<0.1, * *=<0.05, * * *=$ & & & \\
\hline
\end{tabular}

In terms of household-level effects, maintaining regular contact with the

household also increases the RPR by just over $40 \%$, providing strong support for the importance of family ties in determining remittance behavior. Similarly the insurance effect is apparent as the RPR increases by nearly $30 \%$ when the household experiences a social shock. Finally, in terms of community effects, migrants from urban households remit roughly $35 \%$ more than their rural counterparts. We hypothesized that the effect might be the reverse, due to a presumption that rural families would likely having stronger ties to one another. Urban migrants, however, might remit more to offset higher costs of living, because of better earnings opportunities abroad, or because of a higher 
intention to return to an urban setting with their family. As in many instances, the absence of sufficient detail in surveys prevents us from making stronger assertions.

Only a few of the variables in the full sample did not have a statistically significant effect. The positive yet insignificant effect of being female confirms the ambiguity - or rather the similarity - between remitting behaviour of genders that is reported in the literature. Once again, there appear to be no differences among ethnic groups. The lack of a significant effect of either information network or a loan indicates that the amount (unlike the incidence) of remittances is not influenced by help from the household. Similarly the presence of natural and household shocks does not have a statistically significant impact on remittance levels.

To extend the analysis of the amount of RPR, estimations are conducted on four sub-samples: men, non-household heads, remitters from rural areas and Kyrgyz remitters. ${ }^{55}$ In the sample of men only, five variables have a statistically significant effect (household head, married status, education and its quadratic, and urban setting), all of which have the same type of effect as in the full sample. In the rural sample, eight variables have a statistically significant effect, of which all have the same type of effect as in the full sample. In the sample of non-household heads, six variables are statistically significant (married status, education and its quadratic, contact, regular shock, urban setting), of which all have the same type of effect as in the full sample.

In the Kyrgyz sample, five variables are significant (household head, married status, education and its quadratic, and social shock), all of which have the same type of

\footnotetext{
55 In Model 2, four sub-samples were not suitable for OLS estimation due to insufficient number of observations $(<100)$ : women only $(\mathrm{N}=44)$, non-Kyrgyz only $(\mathrm{N}=54)$, urban only $(\mathrm{N}=59)$, household head only $(\mathrm{N}=35)$.
} 
effect as in the full sample. The positive response to shocks may be due to the insurance effect, especially since Kyrgyz migrants are more likely to return home after a period of migration than members of other ethnicities; those others may not wish to the Kyrgyzdominated country, especially after a period of civil unrest. The lack of significance of the urban variable reflects the fact that the Kyrgyz are spread across both rural and urban areas, whereas Uzbeks and Russians congregate in urban areas.

\subsection{Conclusion}

This chapter conducted an empirical analysis of household survey data in order to answer two questions: 1) which micro-level individual, household and community characteristics are correlated with remittances-sending; and 2) which of these characteristics are associated with the amounts of remittances received by the family? The analysis was used to examine a series of hypotheses that emerged primarily from the existing literature, or which were identified on the basis of common theories of remittance behaviour.

The resulting empirical evidence presented here support some of these hypotheses, but several hypotheses are either contradicted in the sense of having unexpected effects, or no effects at all. In Model 1, the analysis of the probability of remitting confirms the hypothesis that men are more likely to remit, but strongly contradicts the hypothesis that married migrants are also more likely to do so; this latter unexpected result may be due to the data's inability to distinguish between migrants who are accompanied by their spouse and children. Age and education have the hypothesized non-linear effects. The likelihood of remitting increases at a declining rate until the age of roughly 37, after which it declines. By contrast, remitting probabilities decline at a 
decreasing rate over the education categories until category 5 (i.e. primary technical), after which they increase. Also unexpected are the results that indicate that financial help from household members reduces the likelihood of remitting, as does high regional unemployment in the home community. Both of these results provide evidence against the hypothesis of risk-sharing behavior in the wider family context.

In Model 2, the analysis of the magnitude of remittances sent confirms the positive impact of household head status, regular contact, social shocks and urban setting on the amount of remittances per remitter. Also, it is clear that higher educated migrants remit higher amounts, but these remittances do not increase proportionally as education rises. The education variable is very likely a proxy for income, but as education rises either there are not commensurate increases in their income, or the income elasticity of remittances is less than one.

The only variable that has a statistically significant and consistent effect in both models and has the same sign is married status: its negative effect is unexpected. As noted previously this surprising result needs further study to determine if migrants typically bring their immediate family (spouse and children) with them, reducing their immediate financial commitment to the family members that remained at home.

In addition the age and education variables (linear and quadratic) have statistically significant coefficient estimates in both models, though the results vary in terms of sign. In terms of age, it appears that while older migrants are more likely to remit, they remit lower amounts. In terms of education, it appears that while more educated migrants are less likely to remit, they remit higher amounts (at a declining rate). Although a comparison of results for sub-samples of gender, ethnicity, household status and urban or 
rural location was not possible in Model 2 due to insufficient observations, the variables with significant coefficient estimates in the full-sample typically appear significant in the samples of men, Kyrgyz migrants, non-household heads and migrants from rural settings.

Based on the research findings, it is possible to identify some basic policy recommendations, though these need to be reviewed with some care to ensure that aspects of remittance behavior do not have other adverse effects that are not apparent in the data here. It is also necessary to make assumptions about policy objectives, though presumably these include trying to facilitate remittance receipts to assist in development.

In terms of education, not only should skill-development programs (e.g. engineering or nursing) be available to migrants even prior to departure in order to improve their earning potential, but also skill-matching programs should target already skilled workers in order to avoid under-employment of highly educated migrants. In addition, it may be useful to discourage very high skilled workers from emigrating, as very high educational attainment is associated with lower remittances, and their presence at home may improve domestic production capacity.

While it is standard to recommend that transactions costs for remitting (e.g. banking fees) should be reduced to encourage more remittances, the analysis here points to other important factors associated with remitting. For example, encouraging contact between migrants and their families and home communities could yield higher receipts from abroad. The policy recommendations should be considered in light of one particular survey questions. When asked whether "remittances improved the health and/or education of household members" in the past year (H638), the replies were evenly split between yes and no. Consequently, while remittances may help households to avoid 
falling into poverty or to cover the basic medical and educational expenses, they cannot compensate for a high unemployment rate or cuts in public services. The international development community as well as national governments must keep in mind that remittances should be a complement to, rather than a substitute for, sound macro-level policy. In a better policy environment, the pro-cyclical remittances may provide greater developmental potential than purely altruistic flows.

Future research should continue to explore the factors that appear linked to remittance behaviour, perhaps especially for regions such as Central Asia that are heavily remittance dependent. The survey data here provided several useful insights, and found evidence that was inconsistent with some common hypotheses. While there are some plausible explanations for these unexpected effects, it is necessary to collect more specific data to allow for more definitive conclusions. Several valuable extensions to this analysis could also be considered. More detailed data should be collected to account for non-cash remittances such as clothing or house merchandise, which could alter the value of RPR. Furthermore, analysis of the impact of the current recession in Russia on remitting patterns would allow to determine the role of host-country variables on remittances-spending: which variables (e.g. GDP growth) determine migrants' behavior. For example, do migrants adjust the amount sent when faced with economic uncertainty in their host community, or do they strive to send a regular (i.e. expected) amount regardless of the burden? How much do exchange rates influence the amount sent and method of transfer? Ultimately, future studies should elaborate on the subjective value of remittances to the sender (e.g. proof of adulthood) as well as to the receiver (e.g. security) to determine whether remittances are deemed to be symbolically and socially appropriate. 


\section{Chapter 4: Spending Decision-Makers and the Cost of "customs and traditions"}

\subsection{Introduction}

Although the international development community and national governments praise remittances as a key ingredient to economic growth and poverty reduction, there remains limited evidence - yet much controversy - regarding what remittances are actually spent on by recipients. Income spending patterns of remittances-receiving households (RRH's) remain a puzzle in the remittances literature, despite the fact that they are a crucial link in the migration-remittances-development discourse, including that of the Post-2015 Agenda. The current study addresses this research gap by investigating two issues: 1) the role of family dynamics in the allocation of remittances-based expenditures; and 2) the real cost - including gifts received - of spending on festivities regarded as "customs and traditions." (KR) not only because of its high remittances dependence, but also because of the availability of under-utilized nationally-representative household survey data.

The study poses two specific research questions: 1) why do the migrants themselves decide how their remittances are spent by the household in some cases but not others; and 2) do RRH's spend more on "customs and traditions" than households that do not receive remittances? With respect to who makes the spending decisions, it is expected that remitters that are younger and indebted are more likely to cede control of how the remittances are spent. In terms of spending on celebrations and festivities, it is hypothesized that remittance-receiving families will divert more income towards these

\footnotetext{
${ }^{56}$ The term "customs and traditions" is used in the LIK survey's household questionnaire, section 4.
} 
activities. ${ }^{57}$ On the face of it, such expenditures may be seen as a wasteful and frivilous diversion of remittance income away from more investment-oriented expenditures, and thus be less useful in supporting community and national development. However, such events can also have monetary and non-monetary benefits for families, including expanding and fostering community networks that can be exploited in the future. Investing in community social capital may be particularly important in a transition country with weak institutions. Therefore, it is expected that larger festivities that engage a wider part of the community may be particularly beneficial.

This study makes a contribution to the remittances literature in two ways. First, it employs high-quality survey data to carry out original statistical analysis that is directly related to understanding remittances-related phenomena. Second, it explores three topics that have not yet been quantitatively addressed in past studies: 1) who are the spending decision-makers in RRH's; 2) what are the different types of social festivities to which income might be diverted; and 3) what is the actual financial burden of such festivities taking into account the value of gifts received. The contribution is particularly salient to literature on Central Asia as a whole not only because spending on festivities has particularly high social importance (Reeves 2012), ${ }^{58}$ but also because despite the importance of remittances in the region, it remains seriously under-researched.

The research findings are policy-relevant because the manner in which

\footnotetext{
57 Other responses are, of course, quite possible. Standard theory and evidence suggest that transitory income is generally saved. However remittances in Kyrgyzstan are so common that it is more likely to be seen as semi-permanent income by recipient families, and factored into consumption decisions. In addition, building family and community ties will be seen as important for families with members engaged in (often circular) migration as part of the family's strategy for supplementing and diversifying income.

58 "'[W]hat emerges frequently [from research] is the capacity of lineage obligations to 'trump' other expenditures, including those that in other circumstances might be considered essential to household survival." Reeves (2012:127)
} 
remittances are spent fundamentally influences the impact - including developmental impact - of these funds at the family, community and national levels. It is a common assertion in the literature that remittances are often wasted on consumption, rather than invested into economic activities. ${ }^{59}$ However, from RRH's perspective, spending on festivities may be less risky and more beneficial than entrepreneurial activities; in other words, hosting events is a form of social investment that could provide better returns (e.g. favours, funds, prestige) than investment into production activities such as agriculture or small business. Only a better understanding of why and how RRH's allocate their income to different expenditures can allow policy-makers to develop policies to encourage larger inflows of remittances, and their more efficient use in the receiving countries.

The rest of this chapter unfolds accordingly: section II offers a review of theory and relevant studies; section III explains the research questions and hypotheses; section IV outlines the data; section V focuses on spending decision-makers, whereas section VI focuses on expenditures on "customs and traditions"; and section VII concludes.

\subsection{Literature Review}

\subsubsection{Theory}

A fundamental debate in the remittances literature is whether migrants remit for altruistic or egoistic reasons. ${ }^{60}$ On the one hand, remitters may be motivated by a concern for those left behind (e.g. income support for unemployed family members), and they do not expect any benefit in return. On the other hand, remitters may be motivated by selfinterest, and they receive or expect to receive a benefit (e.g. care for assets; support of

\footnotetext{
${ }^{59}$ See de Haas (2007:1274-1275) for review of studies concerning the "migration myth" which claims "that the money migrants remit to sending countries is mainly spent on conspicuous consumption and non-productive investments."

${ }^{60}$ Lucas \& Stark 1985; Taylor 1999; Clarke \& Wallsten 2003; Goldring 2004
} 
children; upholding the right to an inheritance). ${ }^{61}$

This emphasis on individualist decision-making has been called into question by the new economics of labour migration (NELM) theory, which situates the migrant in the context of a household. ${ }^{62}$ According to NELM, migration decisions are best understood not as individual choice made by a migrant in their own interest, but rather as collective decisions in the context of the family and for the benefit of the entire household. Such decision-making is more realistic, since a migrant's incentives, willingness and ability to go abroad are influenced by the actions of others, and especially of other family members. An advantage of this arrangement is that resources may be pooled to allow the migrant to leave their community (e.g. pay for travel). Two disadvantages are that household members not wishing to migrate may be pressured to migrate, and that migrants may be expected to remit a disproportionate amount of their income.

An assumption that underlies all three motivations is that a migrant does - or at least can - influence the spending of remittances. However, a migrant may be explicitly or implicitly excluded from the decision-making due to his or her status within the household as determined by gender, age, education level or other factors. Moreover, even if a migrant is allowed to make decisions, it is uncertain whether these wishes will be fulfilled during his or her absence. The theory of agency stipulates that an agent may have interests that differ from those of the principal when making decisions on the principal's behalf (Jensen \& Meckling 1976; Mitnick 2006). In the case of remittances,

\footnotetext{
${ }^{61}$ Das (2012) links household spending to the migrants' primary motivation to remit: 1) if the motivation is "pure altruism," then the remittances are spent on consumption; 2) if it is self-interest, then they are spent on investment; and 3 ) if it is "enlightened self-interest" or "tempered altruism", then they are spent on both.

${ }^{62}$ Stark 1978 \& 1991; Lucas \& Stark 1985; Schiff 1994; Taylor 1999
} 
household members may have other priorities when deciding how to spend the money, especially if the remitter's absence is prolonged or if he or she does not maintain regular contact with the household. For example, a remitter may expect remittances to be spent on house renovations, but members may divert a portion of the money to the purchase of consumer goods.

A model that is useful in explaining a household's spending priorities is Maslow's "hierarchy of needs" (Maslow 1943 \& 1954). Although the model stems from psychology research, it can be constructively applied to the study of RRH's behaviour. The model supposes that an individual can fulfill his or her five inherent needs only in a progressive manner: 1) physiological; 2) safety; 3) emotional; 4) esteem; and 5) selfactualization. Similarity, a household - as a collection of individuals - must first obtain basic necessities before it can strive to increase its status in a community, and finally to self-actualize.

Consequently, it should not be a surprise that the initial expenditures of a lowincome RRH are on the consumption of food, clothing, shelter and healthcare. Afterwards, the RRH may purchase better housing or education that may contribute to higher esteem - the emotional well-being of each member - as well as its standing within the community. Finally, after having fulfilled its basic needs and improved relations with other community members, the RRH can achieve its highest goals, whatever they may be (e.g. starting a business that may allow for greater wealth, security and independence).

In this context, spending on social festivities addresses needs at multiple levels. Such expenditures may increase a RRH's emotional well-being, since a family gathering may positively influence the feelings of the participants; for example, it may be a reward 
for the migrant for overcoming the difficulties abroad. If the festivity includes other households - or at least is noticed within the community - then the household's prestige may increase, thus improving its collective esteem or the esteem of its individual members. Ultimately, social festivities may be either the end goal of a RRH's aspirations, or a means to an end. In the first case, a RRH may consider large social events (e.g. luxurious wedding) as a form of self-actualization. The cultural context influences whether a household considers such spending as desirable or wasteful. In the second case, a RRH may consider the festivities as an opportunity to build up social capital with other households, who may help it achieve other goals (e.g. through loans). Thus the socioeconomic context influences whether a RRH can count more on personal favours than the official system for provision of loans or social services.

\subsubsection{Relevant Studies}

Micro-level remittances-spending is a small but growing subset of the remittances literature, which often focuses on the macro-level, especially in regards to remittances as a means to economic development. There exists a widespread assertion in the literature that remittances are wasted on consumption that has little developmental impact at either the micro- or macro-level.

In a report on sending practices of Haitian and Jamaican migrants in Canada, Simmons et al. (2005) confirm that according to the remitters, the main purposes of the money are food, rent or housing, healthcare, school fees and clothing. However, de Haas (2005) views this assertion as misleading. By bringing attention to spending on real estate in Morocco, the author argues that new housing is not just a status symbol, but rather one of the most secure forms of allocating money in a country with often unreliable financial 
system. In addition, better housing improves sanitation and privacy, which have a positive impact on the household's health and satisfaction; the improved well-being has long-term positive impacts on health and feelings of satisfaction that, in turn, may have long-term positive impacts on national health standards and on the economy. Finally, such spending still has some impact on growth, since it translates into the purchasing of building materials and hiring of local labour.

Zarate-Hoyos (2004) investigates the impact of remittances on spending patterns in Mexico. Using a household survey dataset, empirical results indicate that RRH's do not spend proportionally more on "conspicuous consumption" than non-RRH's, but rather save a larger portion of their income (Ibid 2004:556); in rural areas, remittances lead to increased expenditures on productive uses such as machinery and equipment. The author agrees that better housing improves not only hygiene and physical well-being at the micro-level, but also labour productivity at the macro-level. Adams (2005) shares the view that spending on housing is both a good investment for the RRH and a benefit for local economy. Using a household survey dataset from Guatemala, empirical results show that RRH's not only spend proportionally less on consumption, but also more on investment, including housing and human capital such as education and health care.

Tabuga (2007) conducts a study of the impact of remittances on spending on "vices" in the Philippines. Using a household survey dataset, empirical results indicate that even though RRH's spend more on consumption, there is no decisive impact of remittances on alcohol or tobacco. The study also finds that RRH's invest more in education, housing, health care and durable goods. Ukueva (2010) empirically analyzes the impact of remittances on the purchases of durable goods in the KR. Empirical results 
indicate a positive and statistically significant impact of remittances on the purchase of a durable good; however, the exact type of good is not specified in the analysis. Also, data from a national household survey reveal that more remittances are received by households in the poorer southern regions of the KR, as well as by households with an older or female household head.

Amuedo-Dorantes \& Pozo (2011) focus on the impact of remittances on healthcare expenditures as well as healthcare coverage. Using a household survey dataset from Mexico, empirical analysis concludes that remittances increase spending on healthcare, but the healthcare expenditures are more sensitive than spending on other purposes. However, the spending on health care by poorer RRH's appears less sensitive to remittances, potentially due to the households' reliance on social health care services.

In recent years, research on remittances has turned its attention to spending on social festivities, given that such expenditures are believed to consume a major portion of remittances and - from a development perspective - may be regarded as particularly frivolous. Lindley (2007:13) observes that while Somali households use most of their remittances for consumption, a large portion is indeed spent on "ways that reinforce social networks" (e.g. clan compensation and gifts), which are considered an investment during times of economic uncertainty. The fact that only a small portion of remittances is used for financial investment can be explained not only by lack of funds remaining after consumption and social spending, but also by the lack of a stable investment climate in a fragile country such as Somalia.

Bichsel et al. (2007) conduct a qualitative study of remittances-spending in rural communities in the KR, India and Mexico. In all three cases, remittances were first spent 
to satisfy daily needs such as food, clothing and medicine; since these needs consumed most of the remittances, spending on investment was uncommon. However, some differences were observed. First, while Indian and Mexican households did invest in housing as well as into communal projects, very few Kyrgyz households did either. Second, while Kyrgyz and Indian households spent remittances "to fulfill societal and traditional obligations" (e.g. wedding, funeral), none of the Mexican household did so (Bichsel et al. 2007:36). Therefore, while consumption-spending is universal, spending on investment and festivities appears to be influenced by other factors. Furthermore, before sending money home, migrants displayed a tendency to use remittances for the repayment of loans (e.g. funds borrowed for travel expenses) to family and friends residing abroad.

In the KR context, Rubinov (2010:10) interprets spending on social events - the "toi economy" - both as "the best return investment" for a household as well as a reward for a migrant. For a household, festivities are a form of investment into social capital: by inviting and entertaining other members of the community, the household can expect information about jobs abroad or possibly access to informal money lending. For a migrant, festivities may represent an affirmation of his or her success abroad as well as a reward for endured hardships. Isabaeva (2011) confirms that in addition to consumption, remittances are used by Kyrgyz households for social benefits such as paying for rituals, communal projects (e.g. contribution to building a school fence) and other prestigeenhancing spending. Migrants are willing to devote remittances to such expenditures not only to remain connected to their families, but also to maintain presence within the community. 
Reeves (2012:110) explains that the rise in spending on the "ritual economy" in the KR is due to rising costs of social festivities caused by extravagance and macro-level inflation. The growing costs of marriage - due to increases in the price of a bride particularly affect young men, who are culturally expected to fund the marriage ceremony; thus they choose to migrate in order to save money for the event. Furthermore, social festivities are becoming more elaborate to compensate for the more frequent and long-term absence of migrants. Remitters are willing to devote money to maintain their "social space" in the household and community (Ibid 2012:112).

\subsection{Research Questions and Hypotheses}

The study asks two research questions. First, why do the migrants decide how their remittances are spent by their household in some cases but not others? Second, do RRH's spend more on "customs and traditions" than non-RRH's? Based on three key theories - NELM, theory of agency, Maslow's hierarchy of needs - as well as on arguments and empirical findings in past research, the study offers a separate set of hypotheses for each of the two questions. Other theoretical approaches may suggest either similar or quite different hypotheses, and past empirical studies may or may not apply as well to the Kyrgyz case. Therefore these hypotheses should be treated as exploratory.

\subsubsection{Research Question 1}

Hypothesis 1: if the remitter is in a socially disadvantageous position relative to others, then he or she is less likely to be the main decision-maker (MDM) regarding remittances-spending.

Relevant variables include: 
H1-1. Gender: if a remitter is female, then she is less likely to be the MDM.

H1-2. Age: if a remitter is older, then he or she is more likely to be the MDM.

H1-3. Marital status: if a remitter is married, then he or she is more likely to be the MDM.

H1-4. Role: if a remitter is the household head, then he or she is more likely to be the MDM.

H1-5. Education: if a remitter is educated, then he or she is more likely to be the MDM.

H1-6. Family information: if a remitter had initially received information from household members about job opportunities abroad, then he or she is less likely to be the MDM.

H1-7. Family help: if a remitter had initially received financial help from household to go abroad, then he or she is less likely to be the MDM.

H1-8. Contact: if a remitter maintains regular contact with the household, then he or she is more likely to be the MDM.

H1-9. Urban setting: if a remitter comes from an urban household, then he or she is more likely to be the MDM.

H1-10. Household shocks: if a remitter's household experienced any type of shock, then he or she is less likely to be the MDM.

H1-11: Unemployment: if a remitter's household is located in an area with high unemployment, then he or she is less likely to be the MDM.

\subsubsection{Research Question 2}

Remittances provide a household with additional income to cover basic necessities. Any left-over funds may be spent on non-necessities such as higher education, better housing or social events. Social events may be considered as beneficial as - or more so - other types of spending depending on the economic environment in which a RRH is situated as well as on the RRH's culturally-influenced view of selfactualization. In addition, social events can be differentiated according to their theme 
(e.g. wedding, funeral), purpose (e.g. celebration, mourning) or size (e.g. household only, family only, community-wide). In order to maximize monetary (e.g. presents) as well as non-monetary (e.g. favours) benefits received from the events - and to reduce the burden of hosting such events - a household will spend more on events that involve many people.

Hypothesis 2: if a household receives remittances, then it will spend more on festivities regarded as "customs and traditions"; a RRH will spend proportionally more on social festivities from which it expect to receive more benefits.

Relevant characteristics of festivities include:

H2-1. Type: if an event is a festive celebration, then the household will spend more on it and can expect more benefits.

H2-2. Resonance: if an event has a wide acclaim and involvement in a family or community, then the household will spend more on it and can expect more benefits.

H2-3. Large in size: if an event involves a large number of people, then the household will spend more on it and can expect more benefits.

\subsection{Dataset}

The study resorts to quantitative analysis of the Life in Kyrgyzstan (LIK) survey, which survey is nationally-representative and covers three levels of analysis: community, household, individual. The survey was carried out annually in three waves (2010-2012). The current study employs data from the first and second waves. The LIK survey is appropriate for analysis of household spending because it is exceptionally detailed and includes unique information on decision-makers and social festivities. Furthermore, the dataset has not been used for research subject-matter identified in this study. In order to prepare the data for analysis, they were cleaned, recoded and then merged.

In regards to Hypothesis 1, 2010 data from surveys at all levels of analysis were 
combined to obtain relevant information on confirmed remitters. Only 295 migrants those who were reported by their households to had been abroad and to had sent remittances in previous 12 months - were retained (same individuals as in Chapter 3). Subsequently, the study referred to the 2011 individual-level survey question I513, which asks to indicate "Which member of the family has the main decision making authority for the following activities?" Of the 25 possible activities, this study focused on activity \#24, "how to use remittances" (see Appendix C.1. for the full list of categories). Finally, 2010 and 2011 data were merged to determine which of the confirmed remitters from 2010 took part in the 2011 survey and replied to I513. Only the 78 matched remitters were retained for analysis because their opinions are the most relevant.

In regards to Hypothesis 2, data from two sections of the 2011 household-level survey were required. First, Section 4C (Expenses on Customs and Traditions) includes questions regarding the purpose, frequency, size and costs of social festivities that a household has organized (see Appendix C.2. for the full list of questions). Data from multiple questions were combined to determine the purpose, expenditures and gifts received at the most expensive event. Second, question H501 from Section 5 (Income Sources) asks, "During the last 12 months, did you receive any income from [SOURCE]?" Of the 23 possible sources, this study focused on source type \#15, "Money transfers from persons living abroad." Merging of data from sections 4C and 5 allowed to determine details of spending on "customs and traditions" by self-declared RRH's.

\subsection{Spending Decision-Makers}

\subsubsection{Descriptive Analysis}

In $2011,8,038$ respondents replied to question I513. However, only 3,480 
respondents (43\%) indicated that activity \#24 was applicable to them; the others presumably were not part of a RRH (see Table 7, columns A \& B). The three most frequent categories of decision-makers were "I together with my spouse" (32\%), "all household members" (27\%), and "my parents or my parents-in-law" (16\%). Since categories 1 and 3 explicitly include the respondent, combining them results in a subgroup in which the respondent has direct input into the decision-making; this sub-group accounted for $44 \%$ of respondents. Other categories explicitly exclude the respondent, although the respondent may have indirect input; when combined, these categories accounted for $56 \%$ of respondents. Consequently, survey-wide responses demonstrate a slight prevalence of household decision-making, in accordance with the NELM theory.

Table 7. Responses to I513 (2011 data) (bolded categories are “independent” power)

\begin{tabular}{|c|c|c|c|c|}
\hline $\begin{array}{l}\text { "Which member of the family has the } \\
\text { main decision-making authority for the } \\
\text { following activity?" }\end{array}$ & A & B & C & D \\
\hline$\# 24$. How to use remittances & $\begin{array}{l}\text { Entire } \\
\text { sample }\end{array}$ & & $\begin{array}{l}\text { Confirmed } \\
\text { remitters }\end{array}$ & \\
\hline 1. myself & 426 & $12.24 \%$ & 8 & $10.25 \%$ \\
\hline 2. my spouse & 313 & $9.04 \%$ & 5 & $6.42 \%$ \\
\hline 3. I together with my spouse & 1116 & $32.08 \%$ & 18 & $23.08 \%$ \\
\hline 4. my parents or my parents-in-law & 567 & $16.32 \%$ & 24 & $30.77 \%$ \\
\hline 5. all male household members & 49 & $1.42 \%$ & 0 & $0 \%$ \\
\hline 6. all female household members & 63 & $1.83 \%$ & 0 & $0 \%$ \\
\hline 7. all household members together & 941 & $27.07 \%$ & 23 & $29.49 \%$ \\
\hline Sub-Total & $\underline{3480}$ & $100 \%$ & - & - \\
\hline 9. not applicable & 4558 & & - & - \\
\hline TOTAL & $\underline{8038}$ & & $\underline{78}$ & $\underline{100 \%}$ \\
\hline
\end{tabular}


In the sample of the 78 confirmed remitters retained after data merging, responses were quite different (see Table 7, columns C \& D). The three most frequent categories were "my parents or my parents-in-law" (31\%), "all household members" (29\%), and then "I together with my spouse" $(23 \%)$. The sub-group in which the remitter has direct input accounted for only $33 \%$, thus indicating a much stronger prevalence of household decision-making in RRH's.

\subsubsection{Methodology and Empirical Analysis}

In order to determine which variables are correlated with a change in a remitter's decision-making power, the study resorts to statistical analysis. In the estimation model, the dependent variable is independent decision-making over remittances, which represents a choice (binary) of either category $\# 1$ or \#3 in activity \#24 in question I513 in the 2011 survey; the two categories are combined because they both explicitly include the respondent. There estimation model is:

$$
\begin{gathered}
\text { (1) } P^{*}={ }_{1} a+{ }_{1} b_{1}\left(x_{1}\right)+{ }_{1} b_{2}\left(x_{2}\right)+\ldots{ }_{1} b_{j}\left(x_{j}\right)+{ }_{1} e \\
\text { (1.1) } P=1 \text { if } I^{*}>0 \text { and } 0 \text { otherwise }
\end{gathered}
$$

Where $\mathrm{P}^{*}$ is a latent variable measuring a remitter's independence, $\mathrm{P}$ is the confirmed remitter's reported choice of category \#1 or \#3 $(\mathrm{P}=1)$ or of other categories $(\mathrm{P}=0),{ }_{1} \mathrm{a}$ is the constant term, $x_{j}$ are explanatory variables $(j=1, \ldots, 14),{ }_{1} b_{j}$ are the parameter coefficients to be estimated, and ${ }_{1} \mathrm{e}$ is the error term having a normal distribution with mean 0 and standard deviation 1 . Given the binary format of the dependent variable, the model is estimated using the probit technique; the estimation indicates the marginal effects. The technique is applied to the full sample of confirmed remitters.

Fourteen independent variables were selected from 2011 survey to correspond to 
the concepts in the eleven sub-hypotheses of Hypothesis 1, including three separate shocks. ${ }^{63}$ The variables belong to three levels of analysis. Of the six variables at the individual-level, four are binary (gender, married status, household head, Kyrgyz ethnicity), one is ordinal (education), and one is interval-ratio (age). All six variables at the household-level (information from household, loan from household, frequent contact, three types of shock) as well as the two at the community-level (urban community, high unemployment) are binary (See Appendix C.3. for the list of variables).

Four variables are found to be statistically significant (see Table 8). First, unlike expected, the probability of decision-making independence increases in case of women; this may be due to women in category \#3, who make decisions jointly with their husbands. ${ }^{64}$ Second, as expected, independence increases with age, given that family status - thus influence - typically rises with age. Third, as expected, married status increases independence, since spouses typically seek more autonomy from the rest of the household in order to focus on their own family. Lastly, as expected, if a family helps a remitter with information, then his or her decision-making power decreases; this may be due to the remitter's repayment for the help in the form of remittances, and thus indicate his or her voluntary withdrawal from the decision-making.

\footnotetext{
63 Although ethnicity was not included in the Hypothesis 1, a dummy variable depicting the major ethnic group (i.e. Kyrgyz) was inserted into the analysis out of curiosity.

${ }^{64}$ Of the 78 matched remitters in the estimation, 17 (22\%) were women, who were almost evenly split between 9 married and 8 unmarried. Of the married women, 6 (66\%) displayed "independent decision-making", of whom all reported making decisions jointly with their husbands (category 3 ). Of the unmarried women, only 2 (25\%) displayed independence, of whom 1 reported own decisions (category 1) and 1 joint decisions (category 3 ). This not only reveals that married women make decisions with their husbands, but also confirms that unmarried women are less independent. As with all surveys, there may some reporting bias. Specifically, women and men may disagree about what constitutes influence over spending, and who might actually be exerting that influence. The fact that women migrants are more likely to report influence over spending decisions is an interesting and unexpected phenomenon that deserves additional investigation.
} 
Table 8. Estimation results (independent decision-making)

\begin{tabular}{|c|c|c|c|}
\hline $\begin{array}{l}\text { Variable } \\
\text { (LEVEL) } \\
\end{array}$ & Hypothesized Effect & $\begin{array}{l}\frac{\text { Probit (marginal }}{\text { effects) }} \\
\end{array}$ & $\underline{Z \text { score }}$ \\
\hline \multicolumn{4}{|l|}{ INDIVIDUAL } \\
\hline Female & - & $0.356 * *$ & 2.30 \\
\hline Age & + & $0.025 * * *$ & 3.09 \\
\hline Married & + & $0.397^{*}$ & 2.77 \\
\hline Household head & + & 0.044 & 0.22 \\
\hline Ethnicity (Kyrgyz) & ? & 0.149 & 0.89 \\
\hline Education level & + & 0.049 & 0.76 \\
\hline \multicolumn{4}{|l|}{ HOUSEHOLD } \\
\hline Information & - & $-0.362 *$ & -2.61 \\
\hline Loan & - & 0.043 & 0.30 \\
\hline Contact & + & -0.120 & -0.63 \\
\hline Shock - natural & - & 0.222 & 1.56 \\
\hline Shock - social & - & 0.171 & 1.17 \\
\hline Shock - household & - & -0.162 & -1.12 \\
\hline \multicolumn{4}{|l|}{ COMMUNITY } \\
\hline Urban area & - & -0.222 & -1.47 \\
\hline High unemployment & - & -0.115 & -0.41 \\
\hline Observations & & 78 & \\
\hline Pseudo $\mathrm{R}^{2}$ & & 0.414 & \\
\hline Mean of dependent $\mathrm{v}$. & & 0.403 & \\
\hline $\begin{array}{l}*=<0.1, * *=<0.05, * * *= \\
<0.01\end{array}$ & & & \\
\hline
\end{tabular}

The dprobit technique estimates the marginal effects of the variables, thus it allows to compare the relative strength of each variable. In descending order, the magnitudes of the four statistically significant independent variables are: married status, family information, female gender, and age. The real significance of the variables is straightforward, since three of them are binary, thus the marginal effect is the real effect. Consequently, being married increases the likelihood of independent decision-making by $39.7 \%$ and being female increases it by $35.6 \%$; however, receiving information from one's household decreases it by $36.2 \%$. The age variable indicates that each additional year increases one's independence by $2.5 \%$; thus a 40 -years-old remitter has a $50 \%$ higher likelihood of independent decision-making than a 20-years-old one. 


\subsection{Spending Patterns}

\subsubsection{General Patterns}

In 2011,832 out of the 2,863 interviewed households $(29 \%)$ reported to had hosted at least one festive event in the previous year. While 332 of the $832(40 \%)$ hosted only a single event, most organized more than one (see Table 9).

Table 9. Responses to Question H407 (2011 data)

\begin{tabular}{|l|l|}
\hline How many festive events did your household host? & \\
\hline \# of events & \# of replies \\
\hline 1 & 332 \\
\hline 2 & 195 \\
\hline 3 & 121 \\
\hline 4 or more & 184 \\
\hline & $\mathbf{8 3 2}$ \\
\hline
\end{tabular}

Survey question H408 asks, "Which festive event was the largest in terms of guests and expenditures?" Although a household might have hosted other events - with potentially a different purpose and also a high cost - comparing the single most expensive events provides an indication of the general trends in the surveyed sample (see Table 10). Values are given in Kyrgyz som and US dollars (in brackets in the text). ${ }^{65}$

The most frequently reported largest event is a Birthday (50\%), but the average total expenses associated with this event are the lowest: 8,325 som (US \$181); this total

\footnotetext{
${ }^{65} 1$ Kyrgyz som $=0.02175$ US dollar; conversely, US $\$ 1=46$ som. Annual (Jan. 31 to Dec. 31, 2010) exchange rate, bid price. Accessed June 23, 2015. (www.oanda.com)
} 
Table 10. Spending on "customs and traditions." Single largest event (2011. KR som)

\begin{tabular}{|c|c|c|c|c|c|c|c|c|c|}
\hline Event type & $\begin{array}{l}\text { \# of } \\
\text { events }\end{array}$ & $\begin{array}{l}\mathrm{H} 415: \\
\text { average } \\
\text { monetary } \\
\text { expenses }\end{array}$ & $\begin{array}{l}\text { H416: } \\
\text { average } \\
\text { non- } \\
\text { monetary } \\
\text { expenses }\end{array}$ & $\begin{array}{l}\text { Total } \\
\text { average } \\
\text { EXPENSES }\end{array}$ & $\begin{array}{l}\text { H418: } \\
\text { average } \\
\text { gifts } \\
\text { received } \\
\text { (cash) }\end{array}$ & $\begin{array}{l}\text { H418: } \\
\text { average } \\
\text { gifts } \\
\text { received } \\
\text { (presents) }\end{array}$ & $\begin{array}{l}\text { Total } \\
\text { average } \\
\text { GIFTS }\end{array}$ & $\begin{array}{l}\text { TOTAL } \\
\text { AVERAGE } \\
\text { COST } \\
\text { (expenses } \\
\text { - gifts) }\end{array}$ & $\begin{array}{l}\text { \% of total } \\
\text { cost } \\
\text { "saved" } \\
\text { (gifts / } \\
\text { expenses) }\end{array}$ \\
\hline $\begin{array}{l}\text { 1. son's wedding } \\
\text { /marriage }\end{array}$ & 93 & 66,636 & 21,564 & 88,200 & 36,281 & 11,422 & 47,703 & 40,497 & $54.1 \%$ \\
\hline $\begin{array}{l}\text { 2. daughter's } \\
\text { wedding/ } \\
\text { marriage }\end{array}$ & 39 & 53,175 & 16,538 & 69,713 & 30,051 & 13,589 & 43,640 & 26,073 & $62.6 \%$ \\
\hline 3. birth of baby & 66 & 12,841 & 6,559 & 19,400 & 8,272 & 3,696 & 11,968 & 7,432 & $61.7 \%$ \\
\hline $\begin{array}{l}\text { 4. jubilees } \\
\text { /anniversary }\end{array}$ & 34 & 27,688 & 7,475 & 35,163 & 31,750 & 5,511 & 37,261 & $-2,098$ & $105.9 \%$ \\
\hline 5. Birthday & 415 & 6,426 & 1,899 & 8,325 & 3,754 & 2,092 & 5,846 & 2,479 & $70.2 \%$ \\
\hline $\begin{array}{l}\text { 6. new housing } \\
\text { celebration }\end{array}$ & 13 & 13,815 & 10,615 & 24,430 & 10,084 & 6,350 & 16,434 & 7,996 & $67.3 \%$ \\
\hline 7. funeral & 64 & 30,314 & 18,557 & 48,871 & 15,936 & 1,967 & 17,903 & 30,968 & $36.6 \%$ \\
\hline $\begin{array}{l}\text { 8. remem- } \\
\text {-brance day }\end{array}$ & 68 & 12,802 & 7,367 & 20,169 & 5,610 & 1,667 & 7,277 & 12,892 & $36.1 \%$ \\
\hline other & 40 & 15,862 & 8,323 & 24,185 & 8,012 & 2,662 & 10,674 & 13,511 & $44.1 \%$ \\
\hline & 832 & & & & & & & & \\
\hline
\end{tabular}

includes 6,426 som in monetary expenses and 1,899 som in non-monetary expenses (i.e. "livestock slaughtered, food originated from own production"). The most expensive event is a wedding. Of the 93 households that reported a son's wedding to be the largest, the average total expenses were 88,200 som (US $\$ 1,918$ ); this is more than ten times the expenses on an average Birthday. Of the 39 households that reported a daughter's wedding to be largest, the average total expenses were 69,713 som (US \$1,516). 
Interestingly, given the debate in the literature regarding spending on housing, it is informative to know that 13 households reported a "new housing celebration" to be the largest event, with total average cost of 24,430 som (US \$513).

Previous studies in the literature end their analysis of costs of social events at this stage. However, thanks to information contained in the LIK survey, the current study goes a step further by accounting for the value of gifts received by the household, be they in a form of cash or presents. By subtracting the value of total gifts received from the total expenses, the study calculates the actual total cost of the events. In other words, it is possible to determine the true financial burden of hosting the events, which turns out to be much lower than the reported - and criticized - high costs reported in the literature. The highest values of gifts are received at weddings, averaging 47,703 som (US \$1,037) at a son's wedding and 43,640 som (US \$949) at a daughter's wedding. In the case of "jubilees/anniversary", the value of gifts actually exceeds the expenses, thus resulting in a net profit for the hosting households.

Going even another step further, it is possible to calculate the proportion of the total cost that was saved thanks to the gifts. It turns out that gifts offset the total cost by at least one third; the lowest amount was received during a "remembrance day", when gifts reduced the cost by $36 \%$. In case of a son's wedding, gifts reduced the cost by $54 \%$, and in the case of a daughter's wedding by $63 \%$. "Jubilees/anniversary" turn out to be the most beneficial, since gifts account for $106 \%$ of the costs! Consequently, given both the reduced actual cost of social events and other benefits that a household can expect, hosting events may have higher return on investment than other forms of spending. 


\subsubsection{Remittances-receiving Households}

Data merging determined that 156 of the 461 self-declared RRH's had hosted at least one festivity (see Table 11). This indicates that the remaining 305 RRH's (66\%) did not host any events. Therefore, the claims in the literature that remittances are systematically wasted on social events appear to be exaggerated.

Table 11. Reported festivities. Self-Declared RRH's only (2011 data)

\begin{tabular}{|r|r|}
\hline \# of events & \# of replies \\
\hline 1 & 60 \\
\hline 2 & 51 \\
\hline 3 & 16 \\
\hline 4 or more & 29 \\
\hline & 156 \\
\hline
\end{tabular}

Although RRH's spend on average more on some events, they do not do so on all. Furthermore, RRH's benefit less from the gifts received than non-RRH's (see Table 12). Similarly to the entire surveyed sample, the most frequently reported largest event by RRH's is a Birthday (49\%), which also has a low level of expenses; new housing celebrations and "other" expenditures have even lower levels. ${ }^{66}$ The most expensive event is also a wedding. Of the 34 households that reported a son's wedding to be the largest, the average total expenses were 107,290 som (US \$2,334). Of the eight households that reported a daughter's wedding to be largest, the average total expenses were even higher: 127,131 som (US $\$ 2,765$ ). The much higher expenses on weddings

\footnotetext{
${ }^{66}$ Since only one RRH reported its largest event to be "new housing celebration", this reported cost may not be representative.
} 
Table 12. Spending on “customs and traditions." Single largest event. Self-declared RRH's only (2011. KR som)

\begin{tabular}{|c|c|c|c|c|c|c|c|c|c|}
\hline Event type & $\begin{array}{l}\text { \# of } \\
\text { events }\end{array}$ & $\begin{array}{l}\text { H415: } \\
\text { average } \\
\text { monetary } \\
\text { expenses }\end{array}$ & $\begin{array}{l}\text { H416: } \\
\text { average } \\
\text { non- } \\
\text { monetar } \\
\text { y } \\
\text { expense } \\
\text { s }\end{array}$ & $\begin{array}{l}\text { Total } \\
\text { average } \\
\text { EXPENSES }\end{array}$ & $\begin{array}{l}\text { H418: } \\
\text { average } \\
\text { gifts } \\
\text { received } \\
\text { (cash) }\end{array}$ & $\begin{array}{l}\text { H418: } \\
\text { average } \\
\text { gifts } \\
\text { received } \\
\text { (presents) }\end{array}$ & $\begin{array}{l}\text { Total } \\
\text { average } \\
\text { GIFTS }\end{array}$ & $\begin{array}{l}\text { TOTAL } \\
\text { AVE. } \\
\text { COST } \\
\text { (expenses } \\
\text { - gifts) }\end{array}$ & $\begin{array}{l}\text { \% of total } \\
\text { cost } \\
\text { "saved" } \\
\text { thanks to } \\
\text { gifts (total } \\
\text { gifts / total } \\
\text { expenses) }\end{array}$ \\
\hline $\begin{array}{l}\text { 1. son's } \\
\text { wedding } \\
\text { /marriage }\end{array}$ & 34 & 81,173 & 26,117 & 107,290 & 37,020 & 15,185 & 52,205 & 55,085 & $49 \%$ \\
\hline $\begin{array}{l}\text { 2. daughter's } \\
\text { wedding/ } \\
\text { marriage }\end{array}$ & 8 & 103,614 & 23,517 & 127,131 & 42,857 & 31,856 & 74,713 & 52,418 & $59 \%$ \\
\hline 3. birth of baby & 12 & 10,039 & 5,591 & 15,630 & 2,791 & 3,300 & 6,091 & 9,539 & $39 \%$ \\
\hline $\begin{array}{l}\text { 4. jubilees/ } \\
\text { anniversary }\end{array}$ & 5 & 10,680 & 12,000 & 22,680 & 17,700 & 6,400 & 24,100 & $-1,420$ & $106 \%$ \\
\hline 5. Birthday & 77 & 6,315 & 3,145 & 9,460 & 1,900 & 1,937 & 3,837 & 5,623 & $41 \%$ \\
\hline $\begin{array}{l}\text { 6. new housing } \\
\text { celebration }\end{array}$ & 1 & 4,300 & 4,000 & 8,300 & 5,000 & 3,000 & 8,000 & 300 & $96 \%$ \\
\hline 7. funeral & 9 & 38,433 & 19,277 & 57,710 & 27,444 & 4,333 & 31,777 & 25,933 & $55 \%$ \\
\hline $\begin{array}{l}\text { 8. remem- } \\
\text {-brance day }\end{array}$ & 6 & 22,583 & 3,750 & 26,333 & 4,166 & 833 & 4,999 & 21,334 & $19 \%$ \\
\hline 9. other & 4 & 3,925 & 2,500 & 6,425 & 3,125 & 500 & 3,625 & 2,800 & $56 \%$ \\
\hline & 156 & & & & & & & & \\
\hline
\end{tabular}

are consistent with the observational findings in past studies that young men often go abroad to earn money specifically for their wedding, thus that typically have more funds to spend than non-migrants (Reeves 2012); the household may also contribute to the migrant's own funding. 
The highest values of gifts are received by RRH's at weddings, averaging 52,205 some (US \$1,135) at a son's wedding, and 74,713 som (US \$1,625) at a daughter's wedding; the higher value of gifts received at a daughter's wedding may be due to the price of bride paid by the groom. In case of "jubilees/anniversary", the value of gifts also exceeds the expenses, thus resulting in a net profit. In terms of the proportion of the total cost that is offset thanks to the gifts, the lowest average savings (19\%) are also in the case of a remembrance day. In case of a son's wedding, gifts reduced the total costs by $49 \%$, and in the case of a daughter's wedding by $59 \%$. Once again, "jubilees/anniversary" turn out to be the most beneficial, accounting for $106 \%$ of the costs.

In comparison with the whole sample, RRH dedicate on average more expenses to weddings, Birthdays, funerals and remembrance days, but less to birth of baby, jubilees/anniversary, new housing celebrations and "other" festivities. This generally supports the three sub-hypotheses of Hypothesis 2, which stipulate that a household will favour spending on events that are festive and large, and have wide resonance. In this sense, weddings and Birthdays may involve a greater amount of people and have wider resonance than the typically more private anniversaries or "other" events.

However, RRH's incur on average higher total costs and in more categories, including birth of baby and a remembrance day. The fact that gifts received represent a lower proportion of total expenses - thus lower savings - may be due both the higher expenses and due to guests' perception that since the household already receives money from abroad, then it does not need extra help in the form of gifts. Consequently, even though RRH's spend slightly more on some categories of social events, they incur a higher total burden of hosting almost all events. 
Last but not least, answers to survey question H419 actually refute the general perception in the literature that RRH's spend most of remittances on a single large event. In response to the question "How was this particular event funded?", only 82 out of the 156 households (53\%) indicated that the single largest event had been funded by "remittances sent from abroad only for this event." Given that multiple responses were allowed, most of the 82 households also indicated another source of funding, especially "financial savings" and "contributions from relatives \& friends in Kyrgyzstan." The remaining 74 RRH's (47\%) funded the largest event by other means, of which one could be remittances, but only in a small portion.

\subsection{Conclusion}

This chapter carried out descriptive as well as empirical analyses of the LIK survey dataset in order to answer two questions: 1) do remitters decide themselves how their remittances are spent; and 2) do remittances-receiving households spend more on "customs and traditions" than non-RRH's? Research results confirm the two initial sets of hypotheses. In regards to Hypothesis 1, survey data indicate the prevalence of household decision-making in RRH's, thus the remitter (or the remitter together with spouse) is usually not the primary decision-maker. Statistical estimations reveal, as expected, that independence in decision-making is increased by female gender (probably due to marriage), higher age, and married marital status; however, it is decreased by help from family members in getting information about going abroad.

In regards to Hypothesis 2, survey data indicate that less than half of RRH's host any events. In comparison with the whole sample, as expected, RRH's spend on average more on weddings, Birthdays, funerals, jubilees/anniversaries and remembrance days, but 
less on birth of baby, new housing celebrations, and other events. However, RRH's incur higher total costs, since gifts received represent a smaller portion of the expenses. In some cases, the value of gifts received actually exceeds the cost of hosting an event.

Given the high burden of hosting social events, it is policy-relevant to determine whether such events will continue to increase in cost. Two LIK survey questions shed light on what can be expected in the future. First, question H431 inquired, "In your opinion, what purpose do such festive events serve?", offering five choices (multiple answers allowed) (see Table 13).

Table 13. Responses to Questions H431 \#1-5 (2011 data)

\begin{tabular}{|l|r|}
\hline $\begin{array}{l}\text { “In your opinion, what purpose do such festive } \\
\text { events serve?” (multiple answers allowed) }\end{array}$ & \\
\hline To keep ties with close people & 560 \\
\hline To keep up with traditions & 652 \\
\hline To show that I am not worse off than others & 247 \\
\hline To demonstrate increased economic status & 113 \\
\hline Other & 7 \\
\hline
\end{tabular}

The most popular choice was to "to keep up with traditions", followed by "to keep ties with close friends." Explicitly prestige-enhancing choices were less frequent "to show that I am not worse off than others" and "to demonstrate increased economic status" (113) but perhaps many of the respondents simply refrained from admitting to such motives. Given that the main (admitted) reasons for hosting events are tradition and friendship, then it is unlikely that the number of events will decrease in the near future.

Second, question H432 asked respondents to indicate how much they agree with certain statements (see Table 14). 
Table 14. Responses to Questions H432 \#1-3 (2011 data)

\begin{tabular}{|l|l|l|l|l|l|}
\hline $\begin{array}{l}\text { “How much do you } \\
\text { agree with the } \\
\text { following statements } \\
\text { on a scale from 1 to 5?" }\end{array}$ & $\begin{array}{l}1=\text { strongly } \\
\text { agree }\end{array}$ & 2 & 3 & 4 & \\
\hline $\begin{array}{l}\text { 1. Festive expenses are } \\
\text { reasonable }\end{array}$ & $\begin{array}{l}230 \\
(28 \%)\end{array}$ & $\begin{array}{l}90 \\
(11 \%)\end{array}$ & $\begin{array}{l}109 \\
(13 \%)\end{array}$ & $\begin{array}{l}152 \\
(18 \%)\end{array}$ & $\begin{array}{l}251 \\
\text { disagree }\end{array}$ \\
\hline $\begin{array}{l}\text { 2. Festivities are } \\
\text { becoming simpler }\end{array}$ & $\begin{array}{l}73 \\
(9 \%)\end{array}$ & $\begin{array}{l}103 \\
(12 \%)\end{array}$ & $\begin{array}{l}137 \\
(17 \%)\end{array}$ & $\begin{array}{l}185 \\
(22 \%)\end{array}$ & $\begin{array}{l}334 \\
(40 \%)\end{array}$ \\
\hline $\begin{array}{l}\text { 3. It's good to have } \\
\text { regular festivities. }\end{array}$ & $\begin{array}{l}72 \\
(9 \%)\end{array}$ & $\begin{array}{l}108 \\
(13 \%)\end{array}$ & $\begin{array}{l}240 \\
(29 \%)\end{array}$ & $\begin{array}{l}155 \\
(19 \%)\end{array}$ & $\begin{array}{l}257 \\
(30 \%)\end{array}$ \\
\hline
\end{tabular}

Opinions on the statement "Festive expenses are reasonable" were evenly split; $28 \%$ of respondents strongly agreed and $30 \%$ strongly disagreed. However, most respondents disagreed with the statement that festivities are "becoming simpler"; $40 \%$ disagreed. Interestingly, an overwhelming majority of respondents were either ambivalent towards, or disagreed with, the statement "It's good to have regular festivities"; $30 \%$ strongly disagreed. Given the generally critical view of rising costs and frequency of social events, it seems that such events should be either curtailed or made more developmental.

Policy recommendations based on the research findings need to walk a fine line between promoting more economically responsible use of remittances and respecting local traditions. National governments need to provide not only a macro-level environment that is more appealing to financial investment (e.g. low inflation, stable banking system), but also higher financial literacy among the general population (e.g. remittances-focused investment courses). RRH's whose members have greater optimism 
towards, and knowledge about, entrepreneurial use of remittances will have a greater impact on national economic development. Since spending on social events can be expected to continue in the near future, policies that criticize or attempt to limit such spending are likely to be disregarded and circumvented by RRH's. Instead, pro-spending policies could, for example, promote the economic sector that caters to social events (e.g. loans to small businesses such as restaurants).

Many research questions remain unanswered regarding decision-makers and spending: how do attitudes of long-term or permanent migrants/remitters (those who become influenced by other cultures while abroad) change towards communal decisionmaking? For what other goods or services are remittances specifically used for? How does the spending behaviour differ among households from different income or ethnic (e.g. Kyrgyz/Uzbek/Russian) groups? How does a region's level of economic development impact spending practices? Future research may make further use of the LIK dataset or conduct new surveys. Interviews with remitters and their households may provide an opportunity for in-depth analysis to complement empirical work. 


\section{Chapter 5: Summary}

Why does this dissertation matter? Did it use any novel research methods, did it present any unique findings, and did it make a contribution to the literature? I believe that it matters because it captures the human face of migration by focusing on the impacts of individual characteristics (especially perceptions and attitudes) and by bringing attention to the cultural context (e.g. culture of migration, importance of hosting festivities). By doing so, this study does not approach migration, remittances and expenditures as impersonal, economics-driven phenomena, but rather as decisions - dependent on a multitude of factors, fundamentally subjective, often unplanned - that a person makes in the hope of a better future.

Despite being a quantitative study, this dissertation is not a large-n macro-level analysis of global migration flows (although it had started off as such in early 2013), but rather a micro-level analysis of a survey dataset in a remote country in Central Asia. By merging data from questionnaires at three levels of analysis and by estimating the marginal effects (and real significance) of a multitude of variables, this study goes beyond the standard methodology in the literature. By employing variables such gender, age and education, this study falls in line with concepts elaborated in past research. However, by highlighting the importance of subjective variables such perceptions of family well-being, worries about security and interest in politics, this study introduces new concepts.

Unique findings are discovered in each of the three chapters. Chapter 1 confirms the importance of travel experience, networks and unemployment for an intention to migrate, and ultimately of the intention on migrating behaviour. Two new findings are 
the tendency of non-intending individuals to actually migrate, and the large differences between genders as well as among ethnic groups in the significant variables.

Chapter 2 affirms the hypothesized negative effect of female gender and education, as well as the positive effect of age, on the likelihood of remitting. Furthermore, as expected, household heads, remitters who maintain regular contact with their households, and remitters from urban areas remit higher amounts. However, this chapter reveals numerous unexpected findings. First, incidence of remitting is decreased in the case of married remitters (probably due to family reunification), remitters who received financial help from household members (due to the need to repay the help first), and remitters from areas of high unemployment (due to self-interest / pro-cyclical effects). Second, the amount sent is decreased in the case of older or married remitters, and those with higher education. The only variable that has the same effect (unexpectedly negative) in both models is married status, whereas age and education have opposite effects.

Chapter 3 offers the most extensive contribution to the literature not only by investigating who the actual spending decision-makers are and which variables are responsible for a remitter's independence in spending choices, but also by calculating the financial burden of hosting social events. Findings indicate that in a majority of cases, confirmed remitters admit to not being the main decision-makers. Furthermore, older and married remitters are more independent; however, the remitters who had received help tend to let other family members decide. Perhaps the most unique finding is that spending on festivities is monetarily rewarding. Although households host social events for various reasons, be it self-actualization or expectations of future benefits from the invitees, 
households also receive immediate rewards in the form of gifts. In most cases, the value of gifts equals at least half of the cost of hosting the event, and in some cases, it actually exceeds the cost. Therefore, spending on festivities should not be regarded as unproductive, but rather as a long-term social investment as well as an immediate, lowcost reward.

Policy implications of the findings range from establishing specific initiatives that facilitate migration (e.g. skills training), remittances-sending (e.g. lower transfer fees) and remittances-spending (e.g. improved telecommunication services). Yet, unless concerns over unemployment, insecurity and corruption are addressed at the national level in migrant-sending countries, migration will continue inefficiently and illegally, despite any restrictions posed by migrant-receiving countries. Sending countries must not remain passive or in denial of citizens going abroad to work, whereas receiving countries must not treat incoming migrants as a threat.

Ultimately, the decisions to migrate, to send money home or to spend the money received are made by individuals - alone or with family members - irrespective (or in spite) of existing policies and barriers. People will intend to migrate as long as they believe that migration is the best alternative to an unsatisfactory life, and they will resort to various means - even if dangerous or undocumented - to realize this intention. Necessity is the mother of invention, and people in need of work and a better life will find a way. This dissertation demonstrates this. 


\section{Appendices}

\section{Appendix A.1. Data Overview : Community Characteristics (2010 data)}

\begin{tabular}{|l|r|r||||||}
\hline Question \# & & \\
\hline C103. "What proportion of hous eholds in this population point have migrants abroad?" \\
\hline
\end{tabular}

C112. "What part of the male working age population in this population point does not have a regular job at this time?"

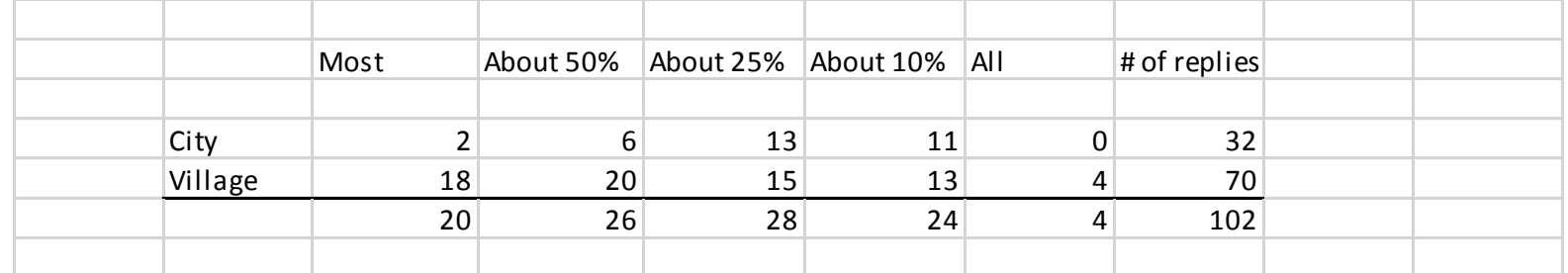

C114. "What is in your view the share of adult in this population point who work abroad during the course of the year?"

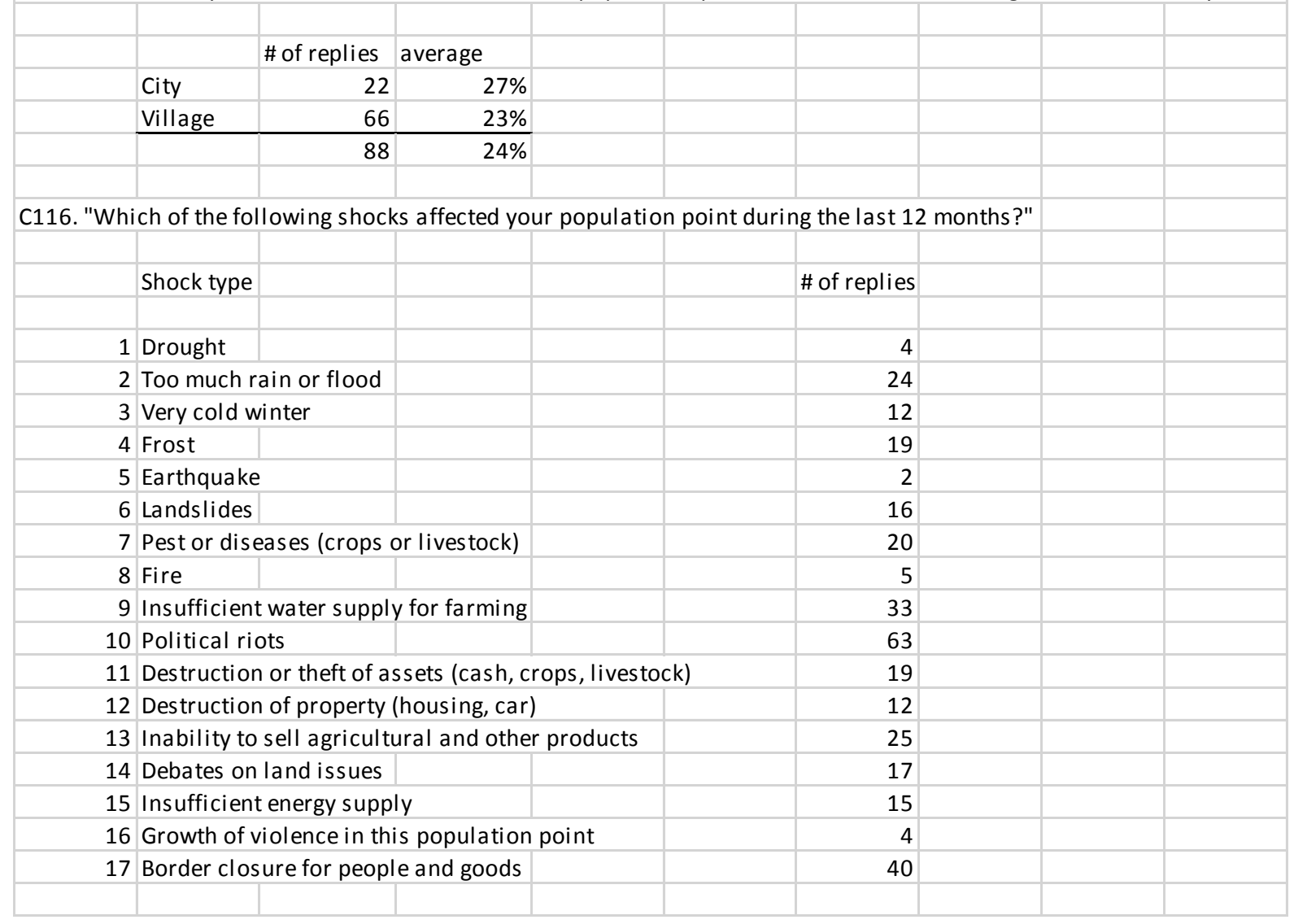


Appendix A.2. Data Overview: Intending Migrants' Characteristics (2010 data)

\begin{tabular}{|c|c|c|c|c|c|c|c|}
\hline \multirow[t]{4}{*}{ Gender } & Female & 143 & $39.9 \%$ & Children & total av. & 1 & \\
\hline & Male & 215 & $60.1 \%$ & & & & \\
\hline & & 358 & $100.0 \%$ & & 0 & 152 & $42.6 \%$ \\
\hline & & & & & 1 & 53 & $14.8 \%$ \\
\hline \multirow[t]{10}{*}{ Ethnicity } & Kyrgyz & 221 & $61.7 \%$ & & 2 & 70 & $19.6 \%$ \\
\hline & Uzbek & 48 & $13.4 \%$ & & 3 & 42 & $11.8 \%$ \\
\hline & Russian & 50 & $14.0 \%$ & & 4 & 24 & $6.7 \%$ \\
\hline & Dungan & 0 & $0.0 \%$ & & $5+$ & 16 & $4.5 \%$ \\
\hline & Uigur & 16 & $4.5 \%$ & & & 357 & $100.0 \%$ \\
\hline & Tajik & 5 & $1.4 \%$ & & & & \\
\hline & Kazakh & 4 & $1.1 \%$ & Siblings & total av. & 4 & \\
\hline & other & 14 & $3.9 \%$ & & & & \\
\hline & & 358 & $100.0 \%$ & & 0 & 16 & $4.5 \%$ \\
\hline & & & & & 1 & 31 & $8.7 \%$ \\
\hline \multirow[t]{9}{*}{ Age } & total av. & 32 & & & 2 & 54 & $15.1 \%$ \\
\hline & & & & & 3 & 55 & $15.4 \%$ \\
\hline & $18-29$ & 197 & $55.0 \%$ & & 4 & 78 & $21.8 \%$ \\
\hline & $30-39$ & 66 & $18.4 \%$ & & 5 & 55 & $15.4 \%$ \\
\hline & $40-49$ & 56 & $15.6 \%$ & & 6 & 23 & $6.4 \%$ \\
\hline & 50-59 & 23 & $6.4 \%$ & & 7 & 22 & $6.2 \%$ \\
\hline & $60+$ & 16 & $4.5 \%$ & & 8 & 11 & $3.1 \%$ \\
\hline & & 358 & $100.0 \%$ & & 9 & 7 & $2.0 \%$ \\
\hline & & & & & $10+$ & 5 & $1.4 \%$ \\
\hline \multicolumn{2}{|c|}{ Born in community } & & & & & 357 & $100.0 \%$ \\
\hline & yes & 289 & $80.7 \%$ & & & & \\
\hline & no & 69 & $19.3 \%$ & \multicolumn{2}{|c|}{ Relation to household head } & & \\
\hline & & 358 & $100.0 \%$ & & head & 83 & $23.2 \%$ \\
\hline & & & & & spouse/partner & 40 & $11.2 \%$ \\
\hline \multicolumn{2}{|c|}{ Marital status } & & & & son/daughter & 192 & $53.6 \%$ \\
\hline & married & 185 & $51.7 \%$ & & s/d-in-law & 26 & $7.3 \%$ \\
\hline & divorced & 23 & $6.4 \%$ & & s/d of spouse & 0 & $0.0 \%$ \\
\hline & liv. tog. & 0 & $0.0 \%$ & & father/mother & 1 & $0.3 \%$ \\
\hline & separated & 3 & $0.8 \%$ & & f/m-in-law & 0 & $0.0 \%$ \\
\hline & widowed & 14 & $3.9 \%$ & & sister/brother & 4 & $1.1 \%$ \\
\hline & single & 133 & $37.2 \%$ & & grandchild & 8 & $2.2 \%$ \\
\hline & & 358 & $100.0 \%$ & & grandparent & 0 & $0.0 \%$ \\
\hline & & & & & nephew/niece & 1 & $0.3 \%$ \\
\hline \multirow[t]{10}{*}{ Education } & & & & & other relative & 2 & $0.6 \%$ \\
\hline & Illiterate & 0 & $0.0 \%$ & & servant & 0 & $0.0 \%$ \\
\hline & Primary & 5 & $1.4 \%$ & & other & 1 & $0.3 \%$ \\
\hline & Basic & 43 & $12.0 \%$ & & & 358 & $100.0 \%$ \\
\hline & Secondary general & 211 & $58.9 \%$ & & & & \\
\hline & Primary Technical & 17 & $4.7 \%$ & & & & \\
\hline & Secondary technic: & 33 & $9.2 \%$ & & & & \\
\hline & University (BA, MA & 49 & $13.7 \%$ & & & & \\
\hline & University (PhD) & 0 & $0.0 \%$ & & & & \\
\hline & & 358 & $100.0 \%$ & & & & \\
\hline
\end{tabular}




\begin{tabular}{|c|c|c|c|c|c|}
\hline Every been abroad & \multirow[b]{2}{*}{109} & \multirow[b]{2}{*}{$30.4 \%$} & Satisfaction with health & \multirow[b]{2}{*}{25} & \multirow[b]{2}{*}{$7.0 \%$} \\
\hline yes & & & $0-3$ & & \\
\hline no & 249 & $69.6 \%$ & 4 to6 & 62 & $17.3 \%$ \\
\hline & 358 & $100.0 \%$ & 7to10 & 271 & $75.7 \%$ \\
\hline & & & & 358 & $100.0 \%$ \\
\hline \multicolumn{6}{|l|}{ Been abroad in past 12 months } \\
\hline yes & 33 & & Satisfaction with current job & & \\
\hline no & 76 & & $0-3$ & 49 & $25.7 \%$ \\
\hline & 109 & & 4to6 & 59 & $30.9 \%$ \\
\hline & & & 7to10 & 83 & $43.5 \%$ \\
\hline Where abroad, during last stay & & & & 191 & $100.0 \%$ \\
\hline Russia & 89 & $24.9 \%$ & & & \\
\hline Kazakhstan & 14 & $3.9 \%$ & \multicolumn{2}{|l|}{ Satisfaction with household income } & \\
\hline Tajikistan & 0 & $0.0 \%$ & $0-3$ & 81 & $22.6 \%$ \\
\hline Uzbekistan & 0 & $0.0 \%$ & 4to6 & 180 & $50.3 \%$ \\
\hline USA & 2 & $0.6 \%$ & 7to10 & 97 & $27.1 \%$ \\
\hline Turkey & 4 & $1.1 \%$ & & 358 & $100.0 \%$ \\
\hline Japan & 0 & $0.0 \%$ & & & \\
\hline China & 0 & $0.0 \%$ & Satisfaction with own income & & \\
\hline Europe & 0 & $0.0 \%$ & $0-3$ & 66 & $34.6 \%$ \\
\hline other CIS countries & 0 & $0.0 \%$ & 4to6 & 80 & $41.9 \%$ \\
\hline other Asian countr & 0 & $0.0 \%$ & 7to10 & 45 & $23.6 \%$ \\
\hline & 109 & $30.4 \%$ & & 191 & $100.0 \%$ \\
\hline Where intending to go? & & & \multicolumn{3}{|c|}{ Satisfaction with household standard of living } \\
\hline Russia & 305 & $85.2 \%$ & $0-3$ & 49 & $13.7 \%$ \\
\hline Kazakhstan & 33 & $9.2 \%$ & 4 to 6 & 192 & $53.6 \%$ \\
\hline Tajikistan & 0 & $0.0 \%$ & 7to10 & 117 & $32.7 \%$ \\
\hline Uzbekistan & 0 & $0.0 \%$ & & 358 & $100.0 \%$ \\
\hline USA & 5 & $1.4 \%$ & & & \\
\hline Turkey & 4 & $1.1 \%$ & Risk-taker (ascending) & & \\
\hline Japan & 1 & $0.3 \%$ & $0-3$ & 115 & $32.1 \%$ \\
\hline China & 0 & $0.0 \%$ & 4to6 & 108 & $30.2 \%$ \\
\hline Europe & 5 & $1.4 \%$ & 7to10 & 135 & $37.7 \%$ \\
\hline other CIS countries & 3 & $0.8 \%$ & & 358 & $100.0 \%$ \\
\hline other Asian countr & 2 & $0.6 \%$ & & & \\
\hline & 358 & $100.0 \%$ & \multicolumn{2}{|l|}{ Worried about economy (ascending) } & \\
\hline Where wishing to go? & & & $0-3$ & 22 & $6.2 \%$ \\
\hline Russia & 263 & $73.5 \%$ & 4to6 & 93 & $26.1 \%$ \\
\hline Kazakhstan & 32 & $8.9 \%$ & 7to10 & 241 & $67.7 \%$ \\
\hline Tajikistan & 0 & $0.0 \%$ & & 356 & \\
\hline Uzbekistan & 0 & $0.0 \%$ & & & \\
\hline USA & 11 & $3.1 \%$ & \multicolumn{2}{|l|}{ Worried about personal security } & \\
\hline Turkey & 12 & $3.4 \%$ & $0-3$ & 100 & $28.1 \%$ \\
\hline Japan & 5 & $1.4 \%$ & 4to6 & 77 & $21.6 \%$ \\
\hline China & 2 & $0.6 \%$ & 7to10 & 179 & $50.3 \%$ \\
\hline Europe & 23 & $6.4 \%$ & & 356 & $100.0 \%$ \\
\hline other CIS countries & 8 & $2.2 \%$ & & & \\
\hline other Asian countr & 2 & $0.6 \%$ & Interest in politics & & \\
\hline & 358 & $100.0 \%$ & Very interested & 47 & $13.2 \%$ \\
\hline & & & Fairly interested & 144 & $40.3 \%$ \\
\hline & & & Not very interested & 136 & $38.1 \%$ \\
\hline & & & Not interested at all & 30 & $8.4 \%$ \\
\hline & & & & 357 & $100.0 \%$ \\
\hline
\end{tabular}




\section{Appendix A.3. List of Variables}

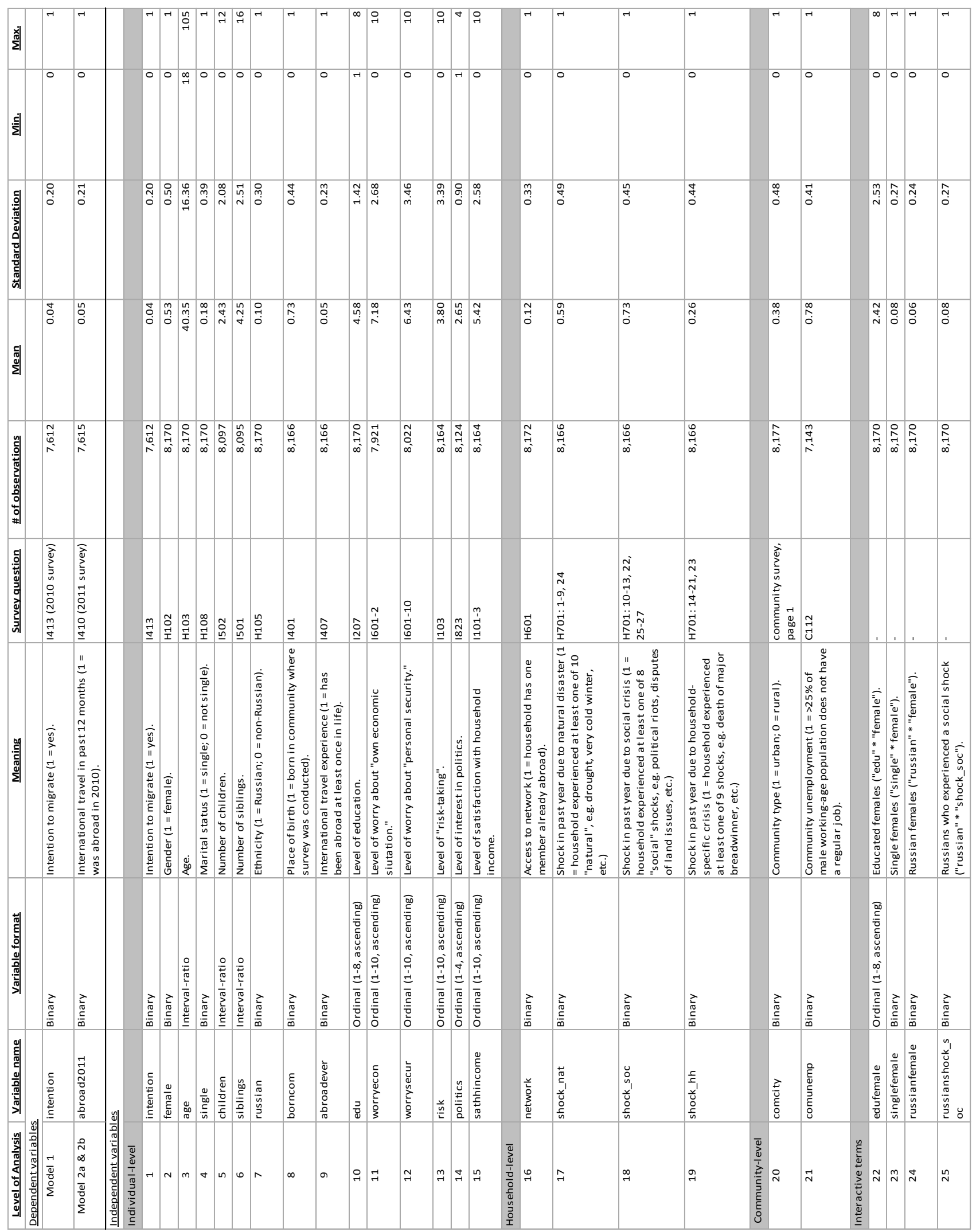




\section{Appendix B.1. Data Overview: Migrants' Characteristics (2011 data)}

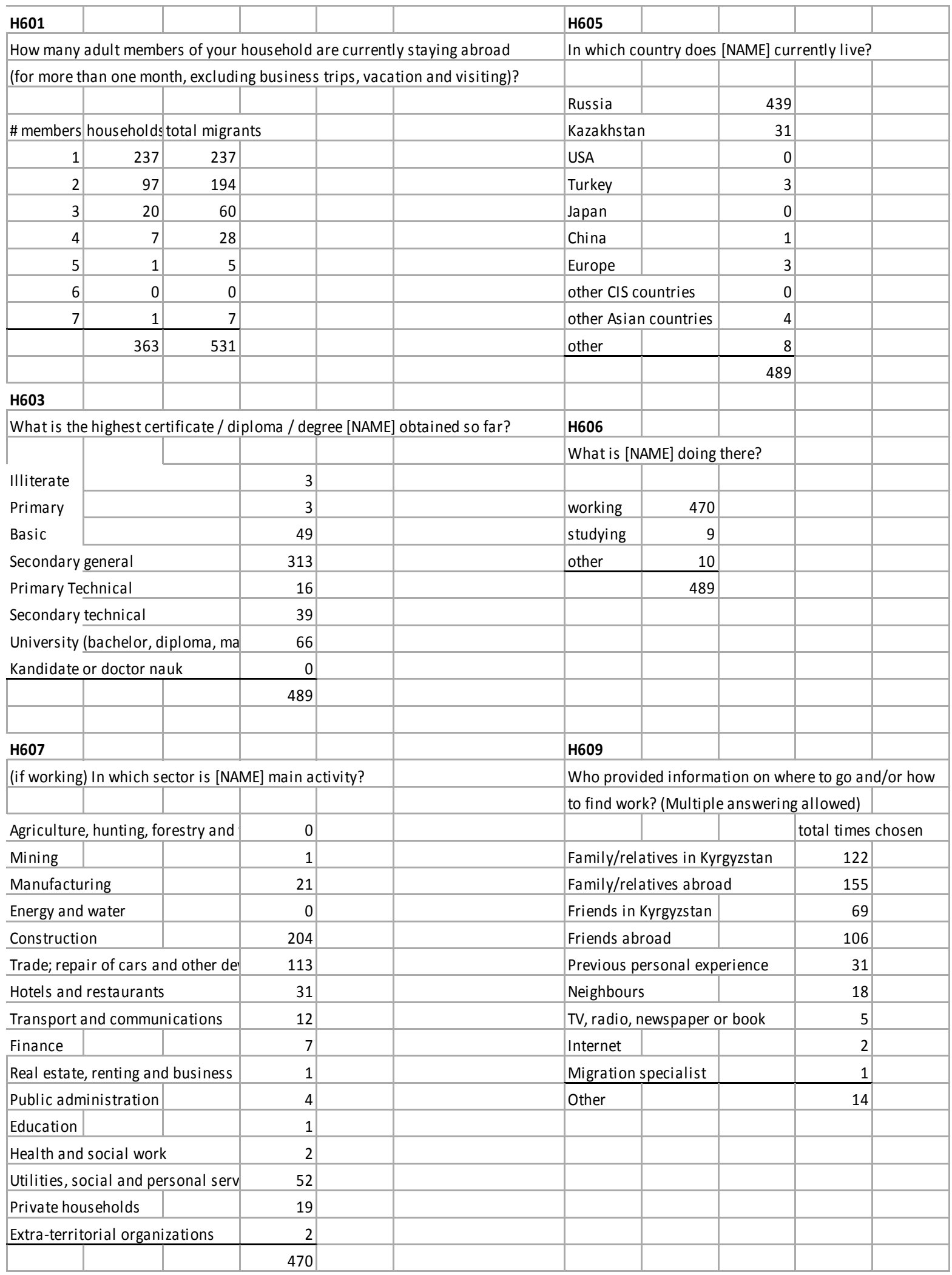




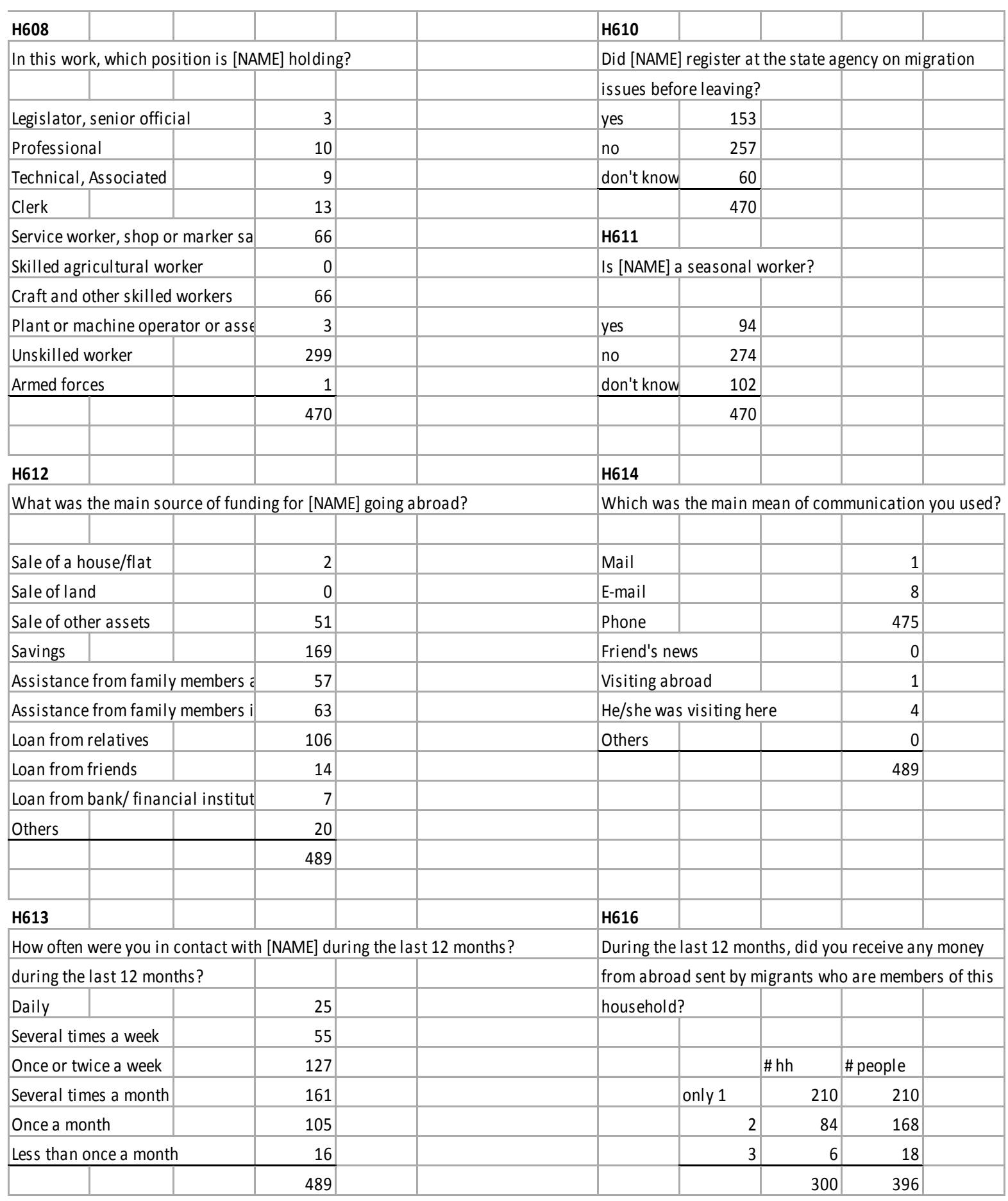




\section{Appendix B.2. Data Overview: Confirmed Remitters' Characteristics (2011 data)}

\begin{tabular}{|c|c|c|c|c|c|c|c|c|}
\hline \multirow[t]{2}{*}{ Gender } & \multirow[b]{2}{*}{ female } & \multirow[b]{2}{*}{64} & \multirow[b]{2}{*}{$21.7 \%$} & \multicolumn{2}{|c|}{ Marital status } & \multirow[b]{2}{*}{140} & \multirow[b]{2}{*}{$47.5 \%$} & \\
\hline & & & & & married & & & \\
\hline & male & 231 & $78.3 \%$ & & not marriec & 155 & $52.5 \%$ & \\
\hline & & 295 & $100.0 \%$ & & & 295 & $100.0 \%$ & \\
\hline \multirow[t]{10}{*}{ Age } & & & & \multicolumn{2}{|c|}{ Household head } & & & \\
\hline & total av. & 30.3 & & & head & 37 & $12.5 \%$ & \\
\hline & & & & & not head & 258 & $87.5 \%$ & \\
\hline & $<30$ & 164 & $55.6 \%$ & & & 295 & $100.0 \%$ & \\
\hline & $30-39$ & 75 & $25.4 \%$ & & & & & \\
\hline & $40-49$ & 47 & $15.9 \%$ & Ethnicity & & & & \\
\hline & $50-59$ & 8 & $2.7 \%$ & & Kyrgyz & 212 & $71.9 \%$ & \\
\hline & $50<$ & 1 & $0.3 \%$ & & Uzbek & 63 & $21.4 \%$ & \\
\hline & & 295 & $100.0 \%$ & & other & 20 & $6.8 \%$ & \\
\hline & & & & & & 295 & $100.0 \%$ & \\
\hline \multicolumn{9}{|c|}{ Education } \\
\hline & Illiterate & 1 & $0.3 \%$ & \multicolumn{3}{|c|}{ Skill level of work abroad } & & \\
\hline & Primary & 1 & $0.3 \%$ & & \multicolumn{2}{|c|}{ semi-skilled, skilled } & 107 & $36.3 \%$ \\
\hline & Basic & 33 & $11.2 \%$ & & unskilled & & 188 & $63.7 \%$ \\
\hline & Secondary general & 193 & $65.4 \%$ & & & & 295 & $100.0 \%$ \\
\hline & Primary Technical & 9 & $3.1 \%$ & & & & & \\
\hline & Secondary technical & 22 & $7.5 \%$ & \multicolumn{3}{|c|}{ Frequency of contact with household } & & \\
\hline & University (BA, MA) & 36 & $12.2 \%$ & & \multicolumn{2}{|c|}{ daily to several times a month } & 228 & $77.3 \%$ \\
\hline & University (PhD) & 0 & $0.0 \%$ & & \multicolumn{2}{|c|}{ once a month or less } & 67 & $22.7 \%$ \\
\hline & & 295 & $100.0 \%$ & & & & 295 & $100.0 \%$ \\
\hline \multicolumn{4}{|c|}{ Information about going abroad (multiple choices allowed) } & \multicolumn{4}{|c|}{ Funding for going abroad (multiple choices allowed) } & \\
\hline & from family & 71 & $24.1 \%$ & & \multicolumn{2}{|l|}{ from family } & 107 & $36.3 \%$ \\
\hline & non-family sources & 224 & $75.9 \%$ & & \multicolumn{2}{|c|}{ non-family sources } & 188 & $63.7 \%$ \\
\hline & & 295 & $100.0 \%$ & & & & 295 & $100.0 \%$ \\
\hline \multicolumn{2}{|c|}{ Household setting } & & & \multicolumn{4}{|c|}{ Household in region with high unemployment } & \\
\hline & urban & 89 & $30.2 \%$ & \multicolumn{5}{|c|}{ ( $>25 \%$ of male working-age population does not have a regular job) } \\
\hline & rural & 206 & $69.8 \%$ & & yes & 232 & $78.6 \%$ & \\
\hline & & 295 & $100.0 \%$ & & no & 63 & $21.4 \%$ & \\
\hline & & & & & & 295 & $100.0 \%$ & \\
\hline \multicolumn{9}{|c|}{ Household experienced a "natural shock" in past year } \\
\hline & yes & 177 & $60.0 \%$ & & & & & \\
\hline & no & 118 & $40.0 \%$ & & & & & \\
\hline & & 295 & $100.0 \%$ & & & & & \\
\hline \multicolumn{4}{|c|}{ Household experienced a "social shock" in past year } & Household & experienced & hock" & past year & \\
\hline & yes & 195 & $66.1 \%$ & & yes & 82 & $27.8 \%$ & \\
\hline & no & 100 & $33.9 \%$ & & no & 213 & $72.2 \%$ & \\
\hline & & 295 & $100.0 \%$ & & & 295 & $100.0 \%$ & \\
\hline
\end{tabular}




\section{Appendix B.3. List of Variables}

\begin{tabular}{|c|c|c|c|c|c|}
\hline$\underline{\text { Level of Analysis }}$ & Variable name & Variable format & Meaning & Survey question & \# of observations \\
\hline \multicolumn{6}{|l|}{ Individual-level } \\
\hline 1 & remitted & Binary & $\begin{array}{l}\text { Incidence of remitting ( } 1=\text { remitted in past } \\
12 \text { months). }\end{array}$ & H616 & 374 \\
\hline 2 & amount & Interval-ratio & Amount remitted. & H617 & \\
\hline 3 & female & Binary & Gender (1 = female). & H102 & 374 \\
\hline 4 & age & Interval-ratio & Age. & $\mathrm{H} 103$ & 374 \\
\hline 5 & agesq & Interval-ratio & Quadratic of "age". & - & 374 \\
\hline 6 & married & Binary & Marital status ( 1 = married). & $\mathrm{H} 108$ & 374 \\
\hline 7 & head & Binary & Role in household (1 = head). & $\mathrm{H} 104$ & 374 \\
\hline 8 & ethkyrgyz & Dummy & Ethnicity (1 = Kyrgyz). & $\mathrm{H} 105$ & 374 \\
\hline 9 & ethother & Dummy & Ethnicity (1 = other, mostly Russian). & $\mathrm{H} 105$ & 374 \\
\hline 10 & edu & $\begin{array}{l}\text { Ordinal (1-8, } \\
\text { ascending) }\end{array}$ & Level of education. & $\mathrm{H} 603$ & 374 \\
\hline 11 & edusq & $\begin{array}{l}\text { Ordinal (1-64, } \\
\text { ascending) }\end{array}$ & Quadratic of "edu". & - & 374 \\
\hline 12 & unskilled & Binary & Level of work abroad (1 = unskilled). & $\mathrm{H} 608$ & 374 \\
\hline 13 & familyinfo & Binary & $\begin{array}{l}\text { Information network ( } 1 \text { = family provided } \\
\text { information about going abroad). }\end{array}$ & H609 & 374 \\
\hline 14 & familyhelp & Binary & $\begin{array}{l}\text { Funding network ( } 1 \text { = family provided } \\
\text { funding for going abroad). }\end{array}$ & H612 & 374 \\
\hline 15 & contact & Binary & $\begin{array}{l}\text { Frequency of contact ( } 1 \text { = maintains contact } \\
\text { with household at least several times a }\end{array}$ & H613 & 374 \\
\hline \multicolumn{6}{|l|}{ Household-level } \\
\hline 16 & shocknat & Binary & $\begin{array}{l}\text { Shock in past year due to natural disaster (1 } \\
=\text { household experienced at least one of } 10 \\
\text { "natural", e.g. drought, very cold winter, } \\
\text { etc.) }\end{array}$ & H701: 1-9, 24 & 374 \\
\hline 17 & shocksoc & Binary & $\begin{array}{l}\text { Shock in past year due to social crisis ( } 1= \\
\text { household experienced at least one of } 8 \\
\text { "social" shocks, e.g. political riots, disputes } \\
\text { of land issues, etc.) }\end{array}$ & $\begin{array}{l}\text { H701: 10-13, 22, } \\
25-27\end{array}$ & 374 \\
\hline 18 & shockhh & Binary & $\begin{array}{l}\text { Shock in past year due to hous ehold- } \\
\text { specific crisis ( } 1 \text { = household experienced } \\
\text { at least one of } 9 \text { shocks, e.g. death of major } \\
\text { breadwinner, etc.) }\end{array}$ & H701: 14-21, 23 & 374 \\
\hline \multicolumn{6}{|l|}{ Community-level } \\
\hline 19 & urban & Binary & Community type (1 = urban; 0 = rural). & $\begin{array}{l}\text { community survey, } \\
\text { page } 1\end{array}$ & 374 \\
\hline 20 & unemploy & Binary & $\begin{array}{l}\text { Community unemployment }(1=>25 \% \text { of } \\
\text { male working-age population does not have } \\
\text { a regular job). }\end{array}$ & C112 & 367 \\
\hline
\end{tabular}


Appendix B.4. Test for Multicollinearity

\begin{tabular}{r|rr} 
estat vif & & \\
Variable & VIF & $1 /$ VIF \\
\hline edu & 56.80 & 0.017607 \\
age & 56.19 & 0.017795 \\
edusq & 55.82 & 0.017915 \\
agesq & 52.92 & 0.018897 \\
married & 1.89 & 0.527743 \\
ethkyrgyz & 1.66 & 0.600924 \\
head & 1.63 & 0.614734 \\
ethother & 1.48 & 0.676318 \\
female & 1.27 & 0.790214 \\
unemploy & 1.25 & 0.802058 \\
urban & 1.24 & 0.804599 \\
shocksoc & 1.17 & 0.855844 \\
familyinfo & 1.15 & 0.870556 \\
shocknat & 1.14 & 0.879147 \\
unskilled & 1.12 & 0.895165 \\
contact & 1.10 & 0.906191 \\
familyhelp & 1.10 & 0.909432 \\
shockhh & 1.06 & 0.944885 \\
\hline Mean VIF & 13.33 &
\end{tabular}




\section{Appendix C.1. LIK 2011 Survey Questionnaire (I513) (highlights not in original)}

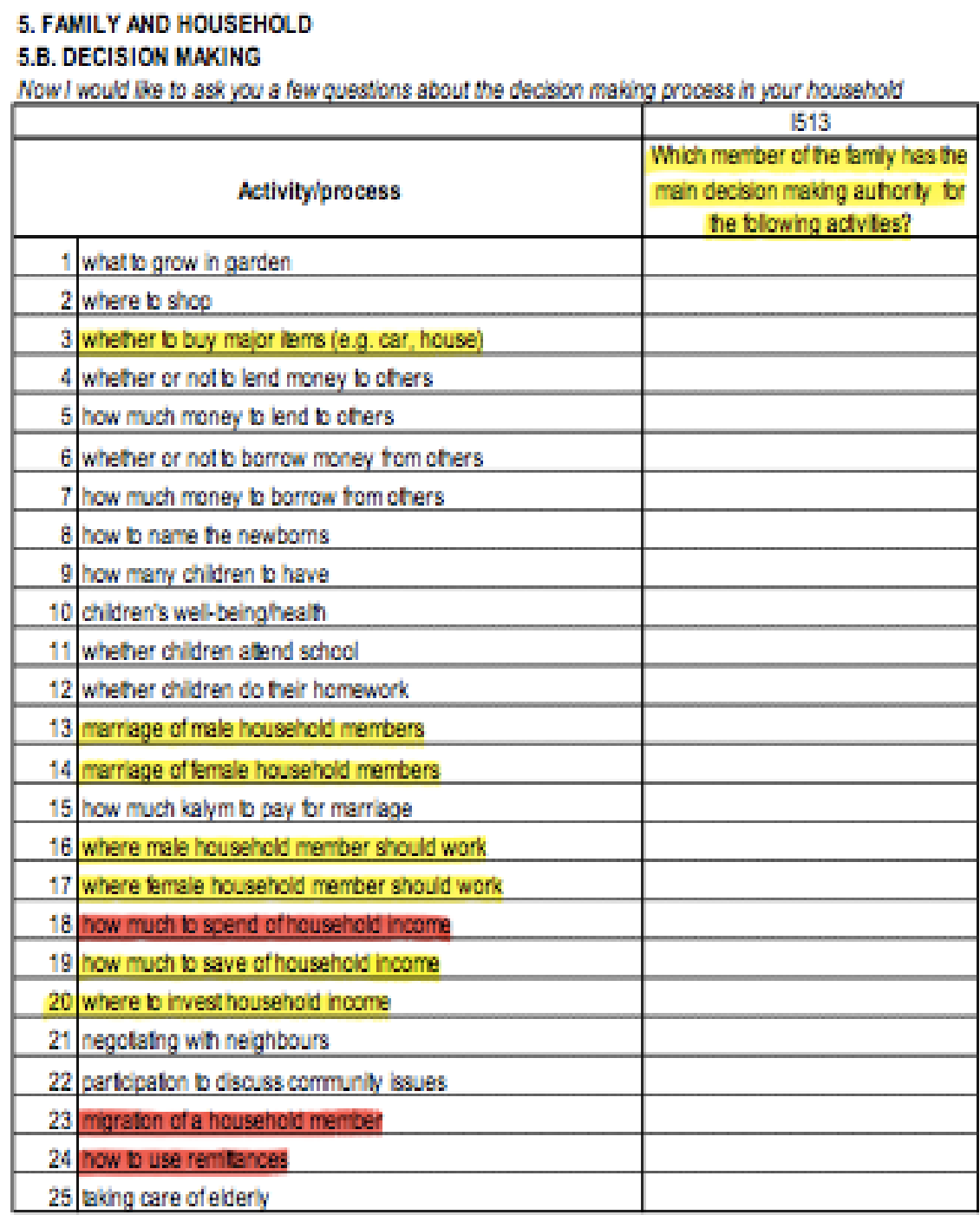

\begin{tabular}{|lr|}
\hline Codings for 1513 \\
\hline Myseif & 1 \\
\hline My spouse & 2 \\
\hline I boether whin my spcuse & 3 \\
\hline My parents or my parents-in-law & 4 \\
\hline All male househoid members & 5 \\
\hline All temale household members & 6 \\
\hline All househoid members bgefner & 7 \\
\hline Children (under 18) & 8 \\
\hline Not applicable & 90 \\
\hline
\end{tabular}




\section{Appendix C.2. LIK 2011 Survey Question (Section 4C) (highlights not in original)}

4. CONSUNPTION AYO EXPENDITURE

4,C. EXPENSES ON CUSTOMS AND TRADITIONS

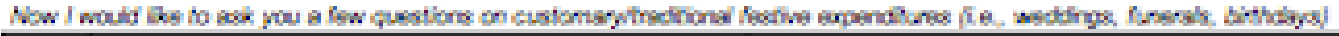

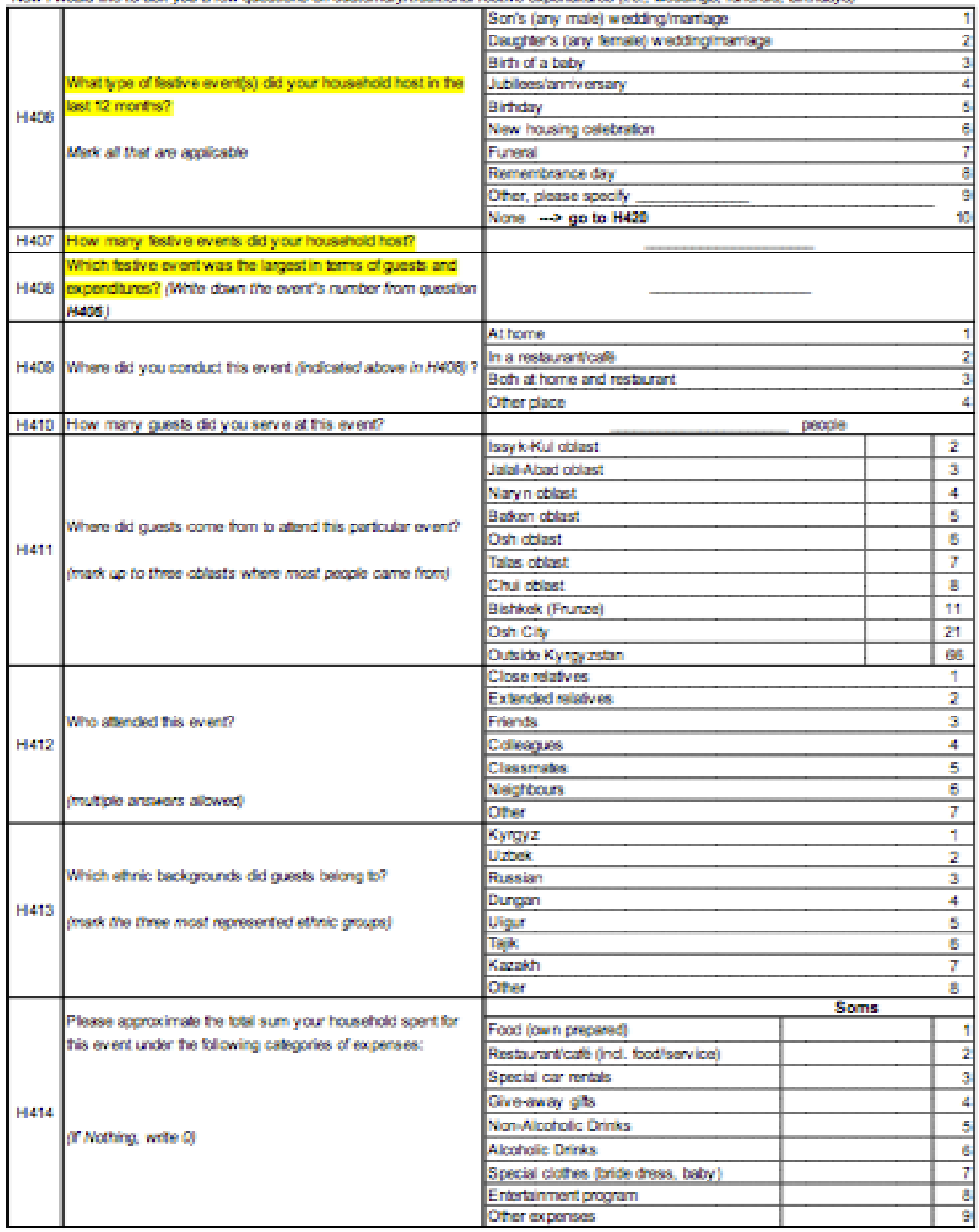




\section{Appendix C.3. List of Variables}

\begin{tabular}{|c|c|c|c|c|c|}
\hline$\underline{\text { Level of Analysis }}$ & $\underline{\text { Variable name }}$ & Variable format & Meaning & Survey question & \# of observations \\
\hline \multicolumn{6}{|l|}{ Individual-level } \\
\hline 1 & indeprem & Binary & $\begin{array}{l}\text { independent decision-making over one's } \\
\text { remittances ( } 1 \text { = choice of category } 1 \text { or } 3 \text { in } \\
\text { activity } 24 \text {, "How to use remittances"). }\end{array}$ & 1513 & 78 \\
\hline 2 & female & Binary & Gender (1 = female). & $\mathrm{H} 102$ & 78 \\
\hline 3 & age & Interval-ratio & Age. & H103 & 78 \\
\hline 4 & married & Binary & Marital status ( 1 = married). & H108 & 78 \\
\hline 5 & head & Binary & Role in household (1 = head). & H104 & 78 \\
\hline 6 & ethkyrgyz & Dummy & Ethnicity (1 = Kyrgyz). & H105 & 78 \\
\hline 7 & edu & $\begin{array}{l}\text { Ordinal (1-8, } \\
\text { ascending) }\end{array}$ & Level of education. & H603 & 78 \\
\hline 8 & familyinfo & Binary & $\begin{array}{l}\text { Information network ( } 1 \text { = family provided } \\
\text { information about going abroad). }\end{array}$ & H609 & 78 \\
\hline 9 & familyhelp & Binary & $\begin{array}{l}\text { Funding network ( } 1 \text { = family provided } \\
\text { funding for going abroad). }\end{array}$ & H612 & 78 \\
\hline 10 & contact & Binary & $\begin{array}{l}\text { Frequency of contact ( } 1 \text { = maintains contact } \\
\text { with hous ehold at least several times a }\end{array}$ & H613 & 78 \\
\hline \multicolumn{6}{|l|}{ Household-level } \\
\hline 11 & shocknat & Binary & $\begin{array}{l}\text { Shock in past year due to natural disaster (1 } \\
=\text { household experienced at least one of } 10 \\
\text { "natural", e.g. drought, very cold winter, }\end{array}$ & H701: 1-9, 24 & 78 \\
\hline 12 & shocksoc & Binary & $\begin{array}{l}\text { Shock in past year due to social crisis (1 = } \\
\text { household experienced at least one of } 8 \\
\text { "social" shocks, e.g. political riots, disputes } \\
\text { of land issues. etc.) }\end{array}$ & $\begin{array}{l}\text { H701: 10-13, 22, } \\
25-27\end{array}$ & 78 \\
\hline 13 & shockhh & Binary & $\begin{array}{l}\text { Shock in past year due to household- } \\
\text { specific crisis ( } 1 \text { = hous ehold experienced } \\
\text { at least one of } 9 \text { shocks, e.g. death of major } \\
\text { breadwinner, etc.) }\end{array}$ & H701: 14-21, 23 & 78 \\
\hline \multicolumn{6}{|l|}{ Communty-level } \\
\hline 14 & urban & Binary & Community type ( 1 = urban; 0 = rural). & $\begin{array}{l}\text { community survey, } \\
\text { page } 1\end{array}$ & 78 \\
\hline 15 & unemploy & Binary & $\begin{array}{l}\text { Community unemployment }(1=>25 \% \text { of } \\
\text { male working-age population does not have } \\
\text { a regular job). }\end{array}$ & C112 & 77 \\
\hline
\end{tabular}




\section{Bibliography}

Abazov, Rafis. 1999. "Economic Migration in Post-Soviet Central Asia: The Case of Kyrgyzstan.” Post-Communist Economies. 11:2. 237-252.

Abdih, Y. et al. 2008. "Remittances and institutions: Are remittances a curse?" IMF working paper. 08:29.

Adams, Richard H. Jr. 2003. "International Migration, Remittances, and the Brain Drain.” World Bank working paper. 3069.

Adams, Richard H. Jr. and John Page. 2003. "International Migration, Remittances and Poverty in Developing Countries." World Bank. MSNMC4-415.

Adams Jr., Richard H. 2005. "Remittances, household expenditure and investment in Guatemala.” World Bank Policy Research working paper. 3532.

Adelman, Carol. 2003. "The Privatization of Foreign Aid: Reassessing National Largess.” Foreign Affairs. 82:6. 9-14.

Agadjanian, Victor, Lesia Nedoluzhko and Gennady Kumskov. 2008. "Eager to Leave? Intentions to Migrate Abroad among Young People in Kyrgyzstan.” International Migration Review. 42:3. 620-651.

Ai, C. and Norton, E. C. 2003. "Interaction Term in Logit and Probit Models.” Economic Letters. 80:1. 123-129.

Ajzen, Icek. 1985. "From intentions to actions: A theory of planned behavior." In J. Kuhl and J. Beckmann (eds.) Action control: From cognition to behavior. 2012.

Ajzen, Icek. 1991. "The theory of planned behavior." Organizational Behavior and Human Decision Processes. 50:2. 179-211.

Alfieri, Alessandra and Ivo Havinga. 2006. "Issue Paper: Definition of Remittances." 
United Nations Department of Economic and Social Affairs. Meeting of the United Nations Technical Subgroup on Movement of Persons.. New York, Feb. 2006. Amuedo-Dorantes, Catalina and Susan Pozo. 2011. "New evidence on the role of remittances on healthcare expenditures by Mexican households." Rev Econ Household. 9:1. 69-98.

Andreopoulos, George et al. 2005. "The Effects Of South-South Migration On Economic Development And Its Security Implications." International Business \& Economics Research Journal. 4:7. 17-22.

Atamanov, A. and M. van den Berg. 2012. "International Labour Migration and Rural Activities in the Kyrgyz Republic: Determinants and Trade-Offs." Central Asian Survey. 31:2. 119-136.

Bakewell, Oliver. 2009. "South-South Migration and Human Development. Reflections on African Experiences.” MPRA Paper. 19185.

Becerra, David et. al. 2010. "Poverty and Other Factors Affecting Migration Intentions among Adolescents in Mexico." Journal of Poverty. 14:1. 1-16.

Bhagwati, Jagdish. 2003. "Borders Beyond Control.” Foreign Affairs. 82:1. 98-104.

Bichsel, C., S. Hostettler, and B. Strasser. 2007. “'Should I Buy a Cow or a TV?’ Reflections on the Conceptual Framework of the NCCR North-South, Based on a Comparative Study of International Labour Migration in Mexico, India and Kyrgyzstan.” NCCR North-South Dialogue working paper. 7.

Bilsborrow, R. E. 2007. "Surveys of International Migration: Issues and Tips.” Paper presented at the Sixth Coordination Meeting on International Migration. United Nations, New York. 
Bitran, Maurice and Serene Tan. 2013. "Diaspora Nation: An inquiry into the economic potential of diaspora networks in Canada."

Blouin, Chantal and Priyanka Debnath. 2011. "CARICOM return migration and brain circulation: case study of Caribbean-born nurses." Canadian Foreign Policy Journal. 17:2. 101-114.

Boone, Peter. 1996. "Politics and the effectiveness of foreign aid." European Economic Review. 40. 289-329.

Borjas, George. 1999. "The Economic Analysis of Immigration.” Handbook of Labor Economics. Chapter 28. 1697-1760.

Brinkerhoff, Jennifer. 2009. “Creating an Enabling Environment for Diasporas’ Participation in Homeland Development.” International Migration. 50:1. 75-95.

Brown, Richard. 2010. “Assessing the Impacts of Remittances on Poverty using Household Survey Data: Some Lessons from Asia and South Pacific.” Prepared for IOM Interagency Seminar Series, Geneva, June 2010.

Brzozowski, Jan. 2007. "Brain Waste, Educational Investments and Growth in Transitional Countries.” Novosak, J. (ed.) On Some Migration and Development Issues. University of Ostrava. 2008.

Brück, Tilman et al. 2012. "Household Survey Data for Research on Well-Being and Behavior in Central Asia.” DIW Berlin. Discussion paper. 1257.

Brückner, Markus. 2013. "On the Simultaneity Problem in the Aid and Growth Debate." Journal of Applied Econometrics. 28:1. 126-150.

Buckley, C. , B. Ruble and E. Hofman (eds.). 2008. Migration, Homeland and Belonging in Eurasia. Washington, DC: Woodrow Wilson Center. 
Burgess, Robert and Vikram Haksar. 2005. "Migration and Foreign Remittances in the Philippines.” IMF working paper. 05:111.

Campillo-Carrete, Beatriz. 2013. "South-South Migration: A review of the literature." International Institute for Social Studies working paper. 570.

Carling, Jørgen. 2008. “The determinants of migrant remittances.” Oxford Review of Economic Policy. 24:3. 581-598.

Chami, R. et al. 2008. Macroeconomic Consequences of Remittances. IMF occasional paper. 259.

Clark, Ken, and Stephan Drinkwater. 2007. "An investigation of Household Remittances Behaviour: Evidence from the United Kingdom." The Manchester School. 75:6. 717-741.

Clarke, George R.G. and Scott J. Wallsten. 2003. “Do Remittances Act Like Insurance? Evidence From a Natural Disaster in Jamaica.” World Bank. Development Research Group. January.

Clemens, Michael A. and David McKenzie. 2014. "Why Don’t Remittances Appear to Affect Growth?” Center for Global Development working paper. 366.

Combes, J-L., and Christian Ebeke. 2010. "Remittances and household consumption instability in developing countries.” CERDI. Etudes et Documents, E 2010.15. Combes, J-L et al. 2012. “Are Foreign Aid and Remittance Inflows a Hedge against Food Price Shocks?" IMF working paper. WP 12:67.

Cooray, Arusha. 2014. "Who Remits? An Examination of Emigration by Education Level and Gender." The World Economy. 37:11. 1441-1453.

Coulter, R., van Ham, M. and Feijten, P. 2011. "A longitudinal analysis of moving 
desires, expectations and actual moving behavior." Environment and Planning. 43:11. $2742-2760$.

Das, Anupam and John Serieux. 2010. "Remittances and Reverse Flows in Developing Countries.” IDEAs Working Paper Series. 2.

Das, Anupam and Murshed Chowdhury. 2011. "Remittances and GDP Dynamics in 11 Developing Countries: Evidence from Panel Cointegration and PMG Techniques.” Romanian Journal of Economics. 24:42. 3-23.

Das, Anupam. 2012. “Macroeconomic Effects of Remittances in Four Developing Countries." International Journal in Applied Behavioral Economics. 1:1. 41-59. de Haan and Shahin Yaqub. 2008. "Migration and Poverty: Linkages, Knowledge Gaps and Policy Implications.” Revised Paper UNRISD/IOM/IFS workshop "Social Policy and Migration in Developing Countries." Stockholm, 22-23 Nov. 2007. de Haas, Hein. 2005. "International migration and regional development in Morocco: a review." WOTRO/NWO research project. MDR Working Paper. 4. de Haas, Hein. 2007. "International migration, remittances and development: myths and facts." Third World Quarterly. 26:8, 1269-1284.

de Jong, Gordon F. and Fawcett J.T. (eds.) 1981. "Multidisciplinary Frameworks and Models of Migration Decision Making.” In Migration decision making: multidisciplinary approaches to microlevel studies in developed and developing countries. New York: Pergamon. Part 2. 13-58.

de Jong, Gordon F., K. Richter and P. Isarabhakdi. 1996. “Gender, Values, and Intentions to Move in Rural Thailand." International Migration Review. 30:3. 748-770. de Jong, Gordon F. 1999. "Choice Processes in Migration Behaviour.” In Migration and 
Restructuring in the United States: A Geographic Perspective. Chapter 13.

de Jong, Gordon F. 2000. "Expectations, gender, and norms in migration decisionmaking.” Population Studies: A Journal of Demography. 54:3. 307-319.

Dhungana, B. 2012. “Remittance and Nepalese Economy.” Journal of SMC. Issue 12.

Docquier, F. et al. 2014. "The cross-country determinants of potential and actual migration." International Migration Review 48:1. 37-99.

Dumont, J.C. et al. 2010. “International Migrants in Developed, Emerging and Developing Countries: An Extended Profile.” OECD working paper.114.

Dustmann, Christian and Josep Mestres. 2010. "Remittances and temporary migration." Journal of Development Economics. 92:1. 62-70.

Easterly, William. 2003. “Can Foreign Aid Buy Growth?” Journal of Economic Perspectives. 17:3. 23-48.

Economist. 2013. "Remittance man." Sep. 7. Print edition.

Economist. 2015. "Refugees in the Mediterranean: The Worst yet?" Apr. 19. Accessed April 21, 2015.

$<$ http://www.economist.com/news/europe/21648896-another-boat-capsizesbetween-libya-and-italy-europe-debates-migration-policy-worst-drowning-yet>

Economist. 2016. "How to manage the migrant crisis." Feb. 6. Accessed Feb. 6, 2016. $<$ http://www.economist.com/news/leaders/21690028-european-problem-demandscommon-coherent-eu-policy-let-refugees-regulate> 
Fagen, P. W. 2006. "Remittances in Conflict and Crises: How Remittances Sustain Livelihoods in War, Crises and Transitions to Peace.” International Peace Academy. Policy Paper.

Fishbein, Martin and Icek Ajzen. 1975. Belief, attitude, intention, and behaviour: An introduction to theory and research. Addison-Wesley.

German Development Institute. 2013. Post 2015: Making Migration Work for Sustainable Development.

Gindling, T. H. 2008. "South-south migration: the impact of Nicaraguan immigrants on earnings, inequality and poverty in Costa Rica.” IZA discussion paper. 3279.

Goldring, L. 2004. "Family and collective remittances to Mexico: a multi-dimensional typology." Development and Change. 35:4. 799-840.

Grabel, Ilene. 2008. "The Political Economy of Remittances: What Do We Know? What Do We Need to Know?" Political Economy Research Institute working paper. 184. Gubhaju, Bina and Gordon F. de Jong. 2009. "Individual versus Household Migration Decision Rules: Gender and Marital Status Differences in Intentions to Migrate in South Africa." International Migration Volume. 47:1. 31-61.

Hadler, Markus. 2006. "Intentions to migrate within the European Union: a challenge for simple economic macro-level explanations.” European Societies. 8:1. 111-140.

Hale, Jerold I., Brian J. Householder and Kathryn L. Greene. 2002. “The theory of reasoned action.” In J.P. Dillard \& M. Pfau (eds.), The persuasion handbook: Developments in theory and practice. Thousand Oaks, CA: Sage. Chapter 14.

Harris, J. R., and Michael P. Todaro. 1970. "Migration, unemployment and development: A two-sector analysis." American Economic Review. 60:1. 126-142. 
Heering, Liesbeth, Rob van der Erf and Leo van Wissen. 2004. "The role of family networks and migration culture in the continuation of Moroccan emigration: a gender perspective." Journal of Ethnic and Migration Studies. 30:2. 323-337.

Horst, Cindy et al. 2014. "Private money, public scrutiny? Contrasting perspectives on remittances." Global Networks. 14:4. 514-532.

Houle, René and Grant Schellenberg. 2008. "Remittance Behaviours Among Recent Immigrants in Canada.” Statistics Canada. Analytical Studies Branch Research Paper Series.

Hujo, K. and N. Piper 2007. "South-South migration: Challenges for development and social policy." Development. 50:4. 19-25.

Hume, Yanique. 2011. "Diaspora tourism in the Dominican Republic: Capitalizing on circular migration.” Canadian Foreign Policy Journal. 17:2. 155-170.

Hundson Institute. 2012. Index of Global Philanthropy and Remittances 2012.

International Labour Organization. 2013. Integrating Labour Migration into the 2013 UN High-level Dialogue on International Migration and Development, and the Post2015 UN Development Agenda. ILO position paper.

International Monetary Fund. 2011. “Appendix 5: Remittances.” Balance of Payments Manual. 6th Edition.

International Organization for Migration. 2006. International Migration and Development: Perspectives and Experiences of the International Organization for Migration.

International Organization for Migration. 2016. Key Migration Terms. Accessed March 14, 2016. < https://www.iom.int/key-migration-terms\#Labour-migration > 
International Organization for Migration. 2012. Extended Migration Profile of the Kyrgyz Republic.

International Organization for Migration. 2013a. Gender, Migration and Remittances. International Organization for Migration. 2013b. World Migration Report 2013. Isabaeva, E. 2011. "Leaving to Enable Others to Remain: Remittances and New Moral Economies of Migration in Southern Kyrgyzstan." Central Asian Survey. 30:3-4. $541-554$.

Ismailbekova, Aksana. 2013. "Coping Strategies: Public Avoidance, Migration, and Marriage in the Aftermath of the Osh Conflict, Fergana Valley." Nationalities Papers. 41:1.109-127.

Ivlevs, Artjoms. 2015. "Happy moves? Assessing the link between life satisfaction and emigration intentions." Institute for the Study of Labour discussion paper. 9017. Jackson, Jason. 2011. "Promoting Caribbean science and technology-intensive development through brain circulation: The case of biotechnology in Jamaica." Canadian Foreign Policy Journal. 17:2. 115-128.

Jensen, Michael C. and William H. Meckling. 1976. "Theory of the firm: Managerial behavior, agency costs and ownership structure." Journal of Financial Economics. 3:4. 305-360.

Javid, M., Arif, U. and Qayyum, A. 2012. "Impact of Remittances on Economic Growth and Poverty." Academic Research International. 2:1. 433-447.

Kalyuzhnova, Yelena and Uma Kambhampati. 2008. "The Determinants of Individual Happiness in Kazakhstan.” Economic Systems. 32:3. 285-299. 
Kapur, D. 2004. "Remittances: The New Development Mantra?" G-24 Discussion Paper Series. United Nations Conference on Trade and Development. New York.

Kleist, Nauja and Ida Vammen. 2012. "Diaspora Groups and Development in Fragile Situations: Lessons Learnt.” Danish Institute for International Studies. Report 2012:09.

Kuznetsova, Irina and John Round. 2014. "Communities and social care in Russia: The role of Muslim welfare provision in everyday life in Russia's Tatarstan region.” International Social Work. 57:5. 486-496.

Laczko, Frank and Tara Brian. 2013. "North-South migration: A different look at the migration and development debate." Migration Policy Practice. 3:3.

Laruelle, Marlène. 2007. “Central Asian Labor Migrants in Russia: The 'Diasporization' of the Central Asian States?" China and Eurasia Forum Quarterly. 5:3. 101-119.

Laruelle, Marlène. ed. 2013. Migration and Social Upheaval as the Face of Globalization in Central Asia. Boston: Brill.

Lindley, Anna. 2007. "Remittances in Fragile Settings: a Somali Case Study." Households in Conflict Network working paper. 27.

Lindley, Anna. 2009. "Remittances and Conflict: Some Conceptual Considerations." Jahrbücher für Nationalökonomie und Statistik. Stuttgart, Germany. 229:6.

Lindley, Anna. 2013. "Diaspora and Transnational Perspectives on Remittances." Companion to Diaspora and Transnationalism. Chapter 18. 
Lu, Max. 1999. "Do People Move When They Say They Will? Inconsistencies in Individual Migration Behavior.” Population and Environment. 20:5. 467-488.

Lucas, Robert E. B. and Oded Stark. 1985. "Motivations to remit: evidence from Botswana." Journal of Political Economy. 93:5. 901-918.

Lueth, Eric and Marta Ruiz-Arranz. 2007. “Are Workers' Remittances a Hedge Against Macroeconomic Shocks? The Case of Sri Lanka.” IMF working paper. 07:22.

Lum, Brandon et al. 2013. "Diasporas, Remittances and State Fragility: Assessing the Linkages." Ethnopolitics: Formerly Global Review of Ethnopolitics. 12:2. 201-219.

Mascarenhas, Raechelle and Todd Sandler. 2013. "Remittances and terrorism: A global analysis." Defence and Peace Economics. 25:4. 331-347.

Maslow, A.H. 1943. "A theory of human motivation." Psychological Review. 50:4. 370396.

Maslow, A.H. 1954. Motivation and personality. New York, NY: Harper.

Massey, Douglas S. 1990. "Social Structure, Household Strategies and the Cumulative Causation of Migration." Population Index. 3-26.

McGillivray, Mark and Simon Feeny. 2008. "Aid and growth in fragile states.” United Nations University research paper. 2008:03.

Menjivar, C., DaVanzo, J., Greenwell, L., and Valdez, R. B. 1998. "Remittance behavior among Salvadoran and Filipino immigrants in Los Angeles." International Migration Review. 32:1.97-126. 
Minto-Coy, Indianna D. 2011. “'Beyond Remittancing': An investigation of the role of ICTs in facilitating and extending the diaspora's contribution to the Caribbean." Canadian Foreign Policy Journal. 17:2. 129-141.

Mitnick, Barry M. 2006. “Origins of the Theory of Agency.” University of Pittsburgh: Katz Graduate School of Business.

Mortley, Natasha. 2011. "Strategic opportunities from diaspora tourism: The Jamaican perspective." Canadian Foreign Policy Journal. 17:2. 171-185.

Naiditch, Claire and Radu Vranceanu. 2011. "Remittances as a social status signaling device." Research in Economics. 65:4. 305-318.

Namazie, Ceema and Peter Sanfey. 2001. "Happiness in Transition: The Case of Kyrgyzstan.” Review of Development Economics. 5:3. 392- 405.

National Council for Sustainable Development of the Kyrgyz Republic. 2012. National Strategy of Sustainable Development for the Kyrgyz Republic for the period 20132017. Accessed Feb. 6, 2016.<https://eiti.org/files/Kyrgyz_NSSD-final-versioneng-Feb4.pdf $>$

National Statistical Committee of the Kyrgyz Republic. 2014. "Ethnic composition of the population in Kyrgyzstan 1999-2014.” (in Russian). Accessed April 22, 2015. $<$ http://web.archive.org/web/20140706220049/http://www.stat.kg/stat.files/din.files/census 15010003.pdf $>$

Nedoluzhko, L. and V. Agadjanian. 2010. "Marriage, childbearing, and migration in Kyrgyzstan: Exploring interdependences.” Demographic Research. 22. 159-188

Newland, Kathleen and Erin Patrick. 2004. "Beyond Remittances: The Role of Diaspora in Poverty Reduction in their Countries of Origin.” Migration Policy Institute. July. 
Nielsen, Richard A. et al. 2011. "Foreign Aid Shocks as a Cause of Violent Armed Conflict." American Journal of Political Science. 55:2. 219-232.

Nurse, Keith. 2011. "Diasporic tourism and investment in Suriname." Canadian Foreign Policy Journal. 17:2. 142-154.

OECD. 2006. "International Migrant Remittances and their Role in Development." International Migration Outlook. Part III. 139-161.

Otrachshenko, Vladimir and Olga Popova. 2014. "Life (dis)satisfaction and the intention to migrate: Evidence from Central and Eastern Europe." Journal of SocioEconomics. 48. 40-49.

Özden, Çaglar and Maurice Schiff. (eds.) 2006. International Migration, Remittances and the Brain Drain. World Bank.

Pieke, Frank N., Nicholas Van Hear, and Anna Lindely. 2007. "Beyond control? The mechanics and dynamics of 'informal' remittances between Europe and Africa." Global Networks. 7:3. 348-366.

Plaza, Sonia, Mario Navarrete and Dilip Ratha. 2011. Migration and Remittances Household Surveys in Sub-Saharan Africa: Methodological Aspects and Main Findings. March 31.

Ratha, Dilip. 2005. “Workers' Remittances: An Important and Stable Source of External Development Finance.” St. Cloud State University. Economics Seminar Series. Paper 9.

Ratha, Dilip and William Shaw. 2006. "South-South Migration and Remittances." World Bank working paper. 102. 
Ratha, Dilip and Sanket Mohapatra. 2007. "Increasing the Macroeconomic Impact of Remittances on Development.” World Bank. Development Prospects Group. Reeves, Madeleine. 2012. “Black Work, Green Money: Remittances, Ritual, and Domestic Economies in Southern Kyrgyzstan.” Slavic Review. 71:1. 108-134. Rodriguez, Edgard R. 1996. "International Migrants' Remittances in the Philippines." The Canadian Journal of Economics. 29:2. 427-432.

Rodriguez, Edgard R. and Erwin R. Tiongson. 2001. “Temporary Migration Overseas and Household Labor Supply: Evidence from Urban Philippines." International Migration Review. 35:3. 709-725.

Rosenzweig, Marl. 2005. "Consequences of Migration for Developing Countries." UN Expert Group Meeting on International Migration and Development. New York. July 6-8, 2005.

Rowlands, Dane 2004. “The Effects of Poverty, Environmental Degradation, and Gender Conditions on South-to-North Migration." Canadian Journal of Development Studies. 25:4. 555-572.

Rubinov, Igor. 2010. “Migration, Development, and the ‘Toi Economy': cultural integration of remittances in Northern Kyrgyzstan.” International Development, Community and Environment Program. Clark University, USA.

Salahuddin, Mohammad. 2013. "Empirical Link between Growth and Remittance: Evidence from panel data." Journal of Applied Business and Economics. 14:5. Schiff, Maurice. 1994. "How Trade, Aid, and Remittances Affect International Migration.” World Bank policy research paper. 1376. 
Simmons, A., D. Plaza, and V. Piche. 2005. "The Remittance Sending Practices of Haitians and Jamaicans in Canada." Centre for Research on Latin and the Caribbean. York University, Toronto.

Singh, Anita. 2012. "The diaspora networks of ethnic lobbying in Canada." Canadian Foreign Policy Journal. 18:3. 340-357.

Stark, Oded. 1978. Economic-Demographic Interactions in Agricultural Development: The Case of Rural-to-Urban Migration. UN Food and Agricultural Organization.

Stark, Oded. 1991. The Migration of Labour. Harvard University Press.

Tabuga, Aubrey D. 2007. "International Remittances and Household Expenditures: The Philippine Case.” Philippine Institute for Development Studies. Discussion Paper Series No. 2007-18.

Tamas, Kristof. 2004. Mapping Study on International Migration. Institute for Future Studies.

Taylor, J. Edward et al. 1996a. "International Migration and National Development." Population Index. 62:2. 181-210.

Taylor, J. Edward et al. 1996b. "International Migration and Community Development." Population Index. 62:3. 181-210.

Taylor, J. Edward. 1999. "The New Economics of Labor Migration and the role of Remittances in the Migration Process." International Migration. 37:1. 63-88.

Thieme, S. 2008. "Sustaining Livelihoods in Multi-Local Settings: Possible Theoretical Linkages Between Transnational Migration and Livelihood Studies." Mobilities. 3:1. 51-71. 
Tishkov, Valery et al. 2005. "Migration in the countries of the former Soviet Union." Global Commission on International Migration. Prepared for the Policy Analysis and Research Program of the Global Commission on International Migration.

Ukueva, Nurgul. 2010. “Private Transfers and International Remittances in Kyrgyzstan's Post Transition Environment: Results from a New Household Panel Dataset (with C. Becker).” PhD dissertation. Chapter 3. Duke University.

Unheim, Per and Dane Rowlands. 2012. "Micro-Level Determinants of Remittances from Recent Migrants to Canada.” International Migration. 50:4. 124-139.

United Nations. 2013. "Making migration work: an eight-point agenda for action.” HighLevel Dialogue on International Migration and Development. New York, USA. $<$ http://www.un.org/en/ga/68/meetings/migration/pdf/migration_8points_en.pdf $>$

United Nations. 2014. “International Migration.” United Nations Population Division. $<$ http://www.un.org/en/development/desa/population/theme/internationalmigration/index.shtml>

USAID. 2009. Diaspora Direct Investment (DDI): the Untapped Resource for Development.

van Dalen, Hendrik P. and Kene Henkens. 2008. "Emigration Intentions: Mere Words or True Plans? Explaining International Migration Intentions and Behavior.” Center for Economic Research discussion paper. 2008:60.

van Dalen, Hendrik P. and Kene Henkens, K. 2013. "Explaining emigration intentions and behavior in the Netherlands, 2005-10.” Population Studies. 67:2. 225-241. Winters, Alan. 2007. “Quantifying International Migration: A Database of Bilateral Migrant Stocks.” World Bank working paper. 4165. 
Wood, Charles H., Chris L. Gibson, Ludmila Ribeiro and Paula Hamsho-Diaz. 2010. "Crime Victimization in Latin America and Intentions to Migrate to the United States." International Migration Review. 44:1. 3-24.

World Bank. 2014. Migration and Remittances Brief 22. April 11.

World Bank. 2015. Migration and Remittances Brief 24. April 13.

Wouterse, F.S. 2008. "Migration, Poverty, and Inequality: Evidence from Burkina Faso." International Service for National Agricultural Research Division. IFPRI Paper. 00786.

Yang, Dean and HwaJung Choi. 2007. “Are Remittances Insurance? Evidence from Rainfall Shocks in the Philippines." World Bank Economic Review. 21:2. 219-248.

Yang, Xiushi. 1999. "Determinants of migration intentions in Hubei province, China: individual versus family migration." Environment and Planning. 32:5. 769-787.

Zarate-Hoyos, German. 2004. "Consumption and Remittances in Migrant Households: Toward a Productive Use of Remittances." Contemporary Economic Policy. 22:4. $555-565$. 